\title{
Suspenseful Design: \\ Engaging Emotionally with Complex Applications through Compelling Narratives
}

\author{
by \\ Kimberly Rebecca Langer \\ A thesis \\ presented to the University of Waterloo \\ in fulfillment of the \\ thesis requirement for the degree of \\ Master of Mathematics \\ in \\ Computer Science
}

Waterloo, Ontario, Canada, 2014

(C) Kimberly Rebecca Langer 2014 


\section{AUTHOR'S DECLARATION}

I hereby declare that I am the sole author of this thesis. This is a true copy of the thesis, including any required final revisions, as accepted by my examiners.

I understand that my thesis may be made electronically available to the public. 


\begin{abstract}
Stories are fundamental to how we learn about and experience the world, but few software interfaces incorporate stories or use story-telling techniques. This thesis explores the possibility of applying principles of suspenseful storytelling to interaction design to create more engaging and emotionally compelling applications. Specifically, this work introduces a theoretical framework for designing suspenseful software-applications; describes the process of constructing a suspenseful, story-based tutorial; and documents a controlled experiment in which this suspenseful tutorial was pitted against two more traditional tutorial designs. Participants who used the narrative-based tutorial reported greater feelings of hopeful suspense than those who worked through an unsuspenseful tutorial.
\end{abstract}




\section{Acknowledgements}

I am profoundly grateful to my supervisor, Mark Hancock, for his thoughtful and knowledgeable advice, his steadfast support, and his generous encouragement. Thank you, Mark, for taking a chance on me and thank you for pushing me to think more deeply and write more clearly. I am proud to have been a part of your lab.

I would also like to thank my readers, Stacey for her sharp insight and invaluable assistance in helping me to understand and shape my research, Chrysanne for her careful feedback and for introducing me to fascinating new research. I would like to thank my fellow grad students in the surface research group as well, for challenging me, exposing me to new perspectives, and for just generally being phenomenal, fun, and interesting people. I look forward to seeing where the future takes you.

Above all, thanks to my family for their patience and support, and thanks to my partner Eli for joining me on this crazy adventure, for being my rock in hard times, and for bringing me joy always. 


\section{Dedication}

To my mother and father

CARROLL CHUBB \& THOMAS LANGER 


\section{Table of Contents}

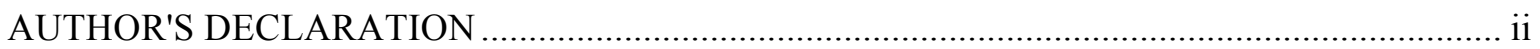

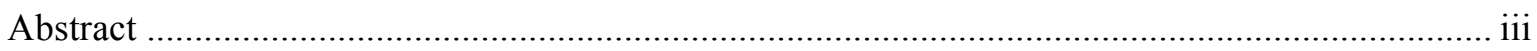

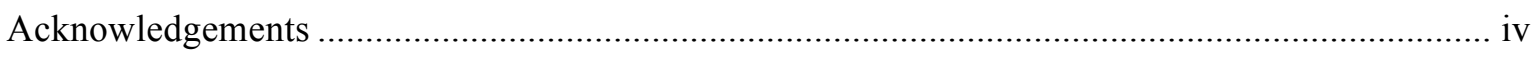

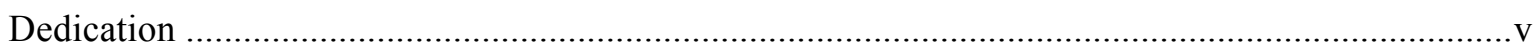

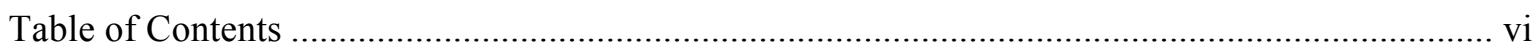

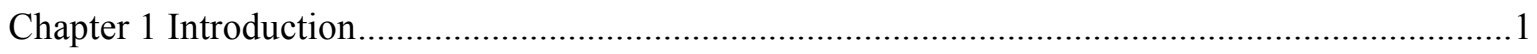

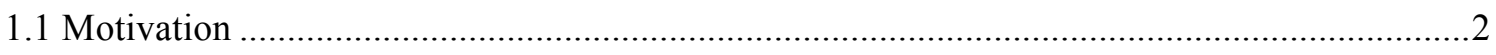

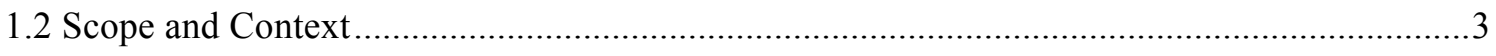

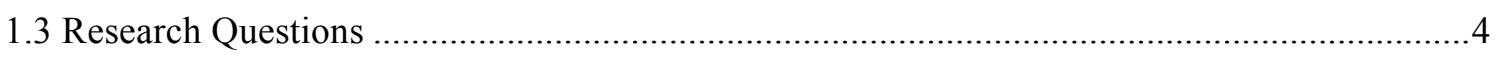

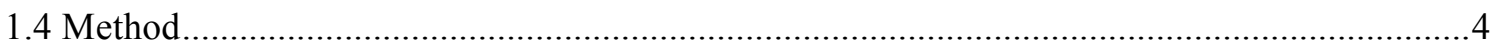

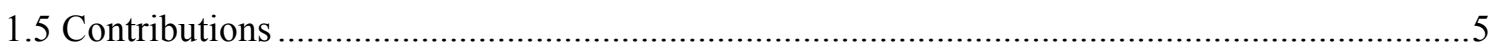

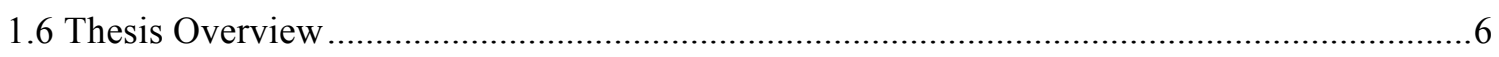

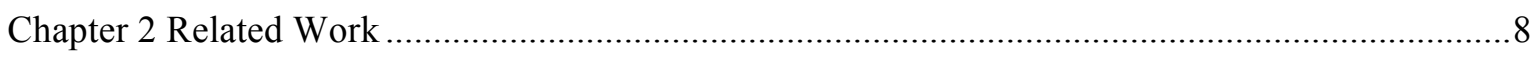

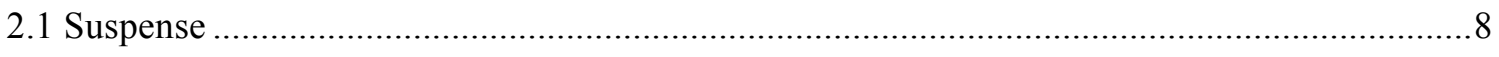

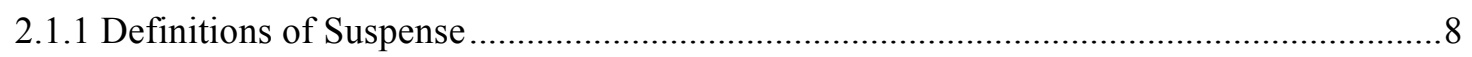

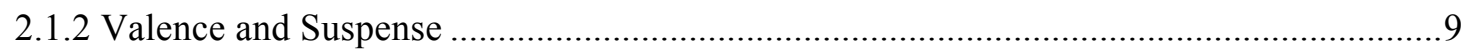

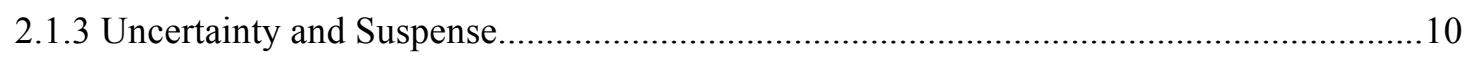

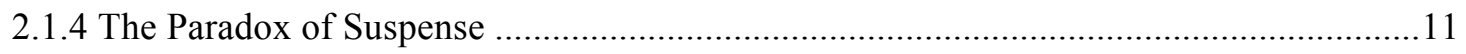

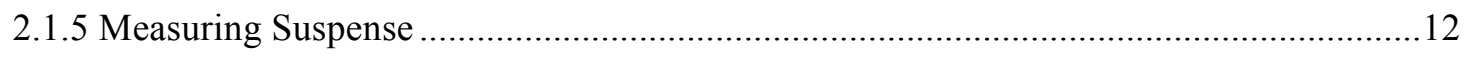

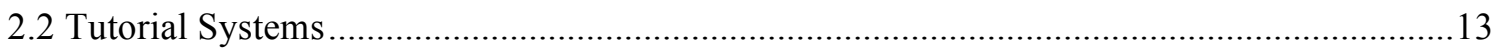

2.2.1 Generating Tutorial Content ............................................................................ 14

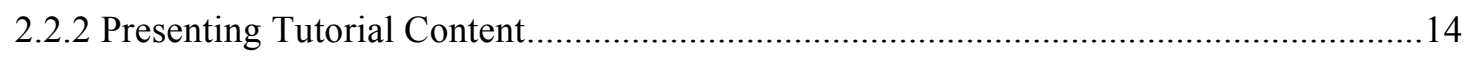




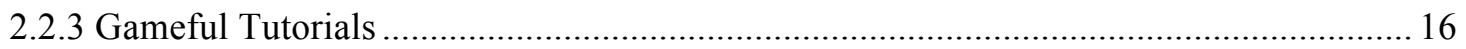

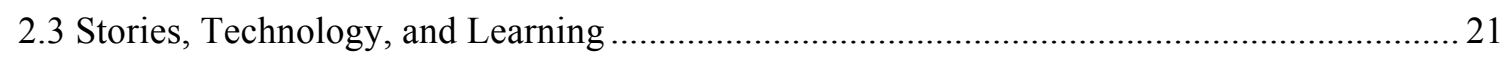

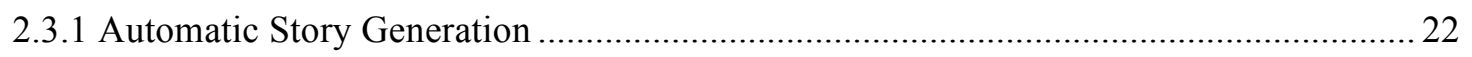

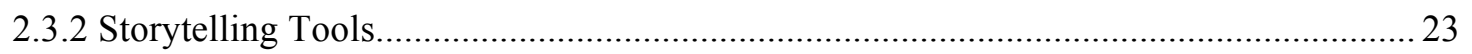

Chapter 3 Designing Suspenseful Applications.......................................................................... 25

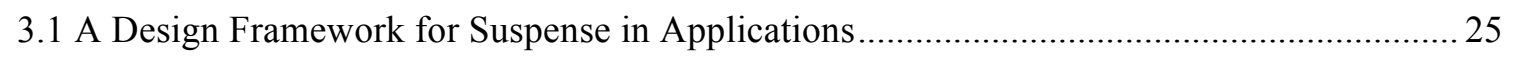

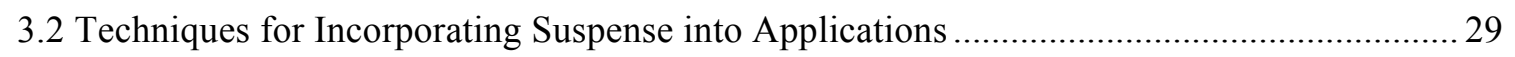

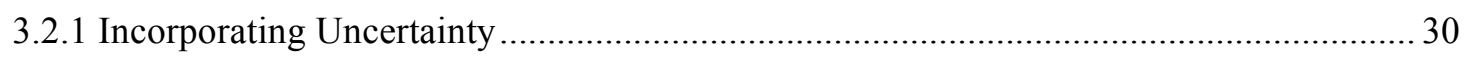

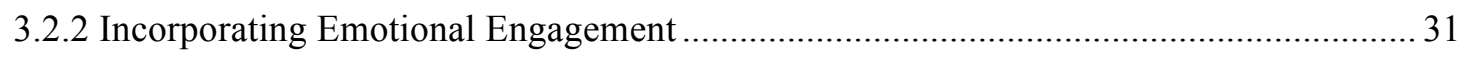

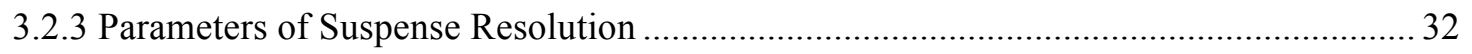

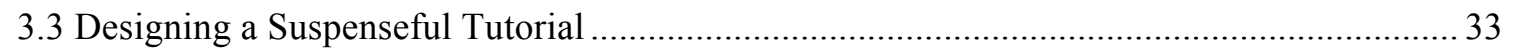

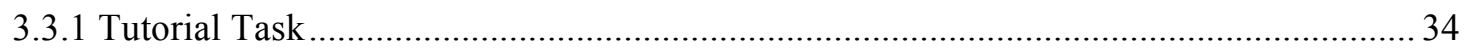

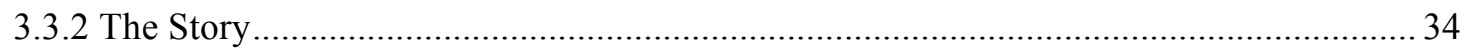

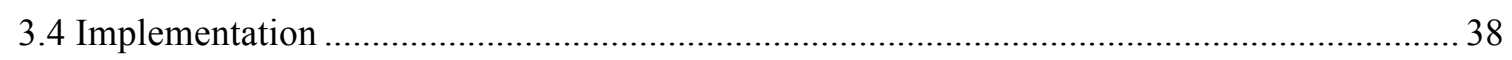

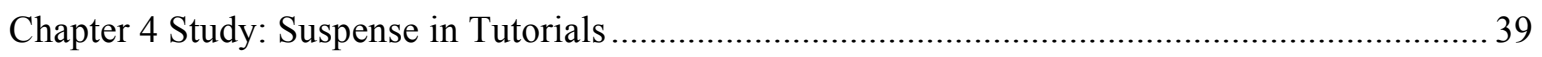

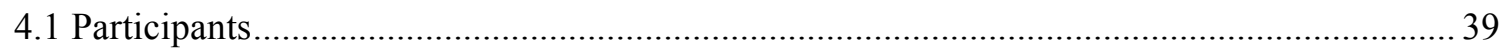

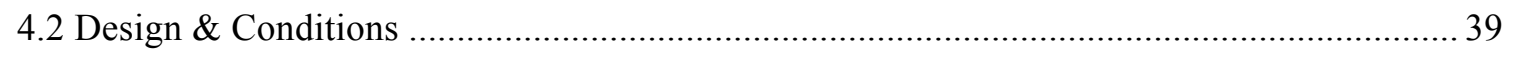

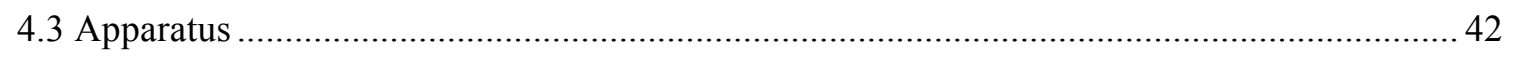

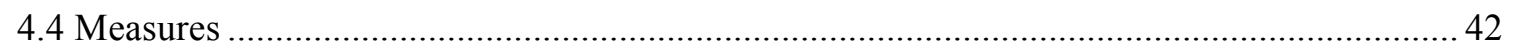

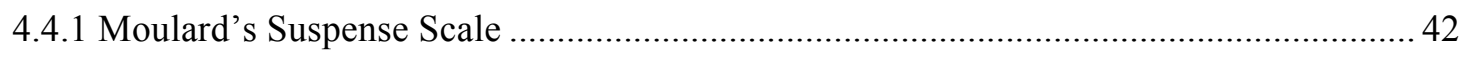

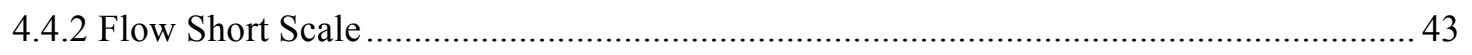

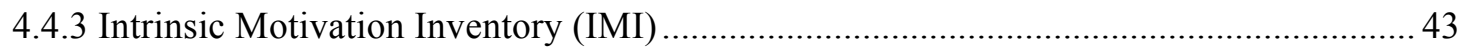

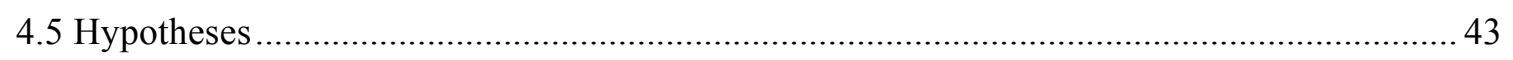

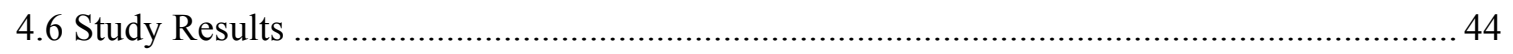

vii 


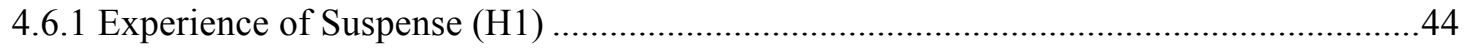

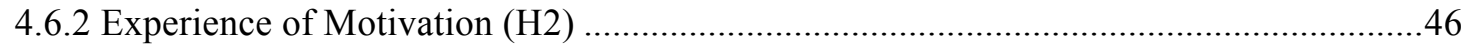

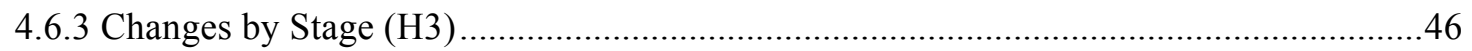

4.6.4 Interaction effects (stage * tutorial type) …........................................................... 47

4.6.5 Flow: Perceived Importance of Outcome................................................................. 49

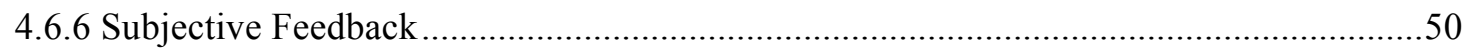

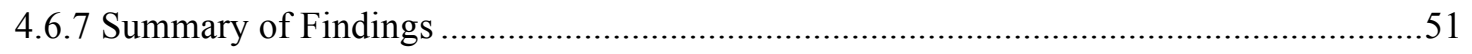

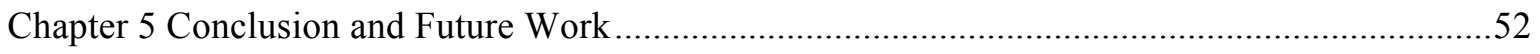

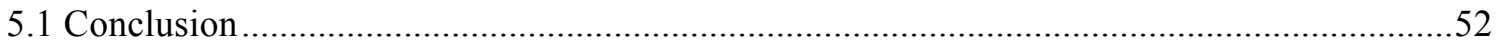

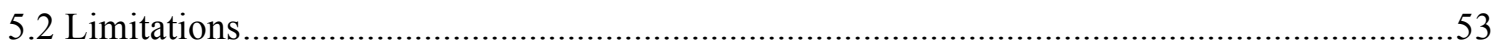

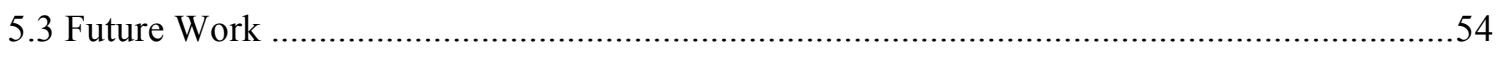

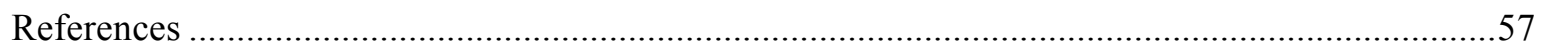

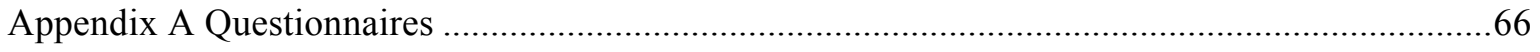

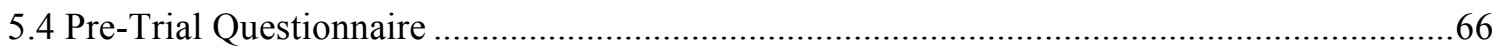

5.5 Mid-Trial Questionnaire (administered 5 times) ............................................................6

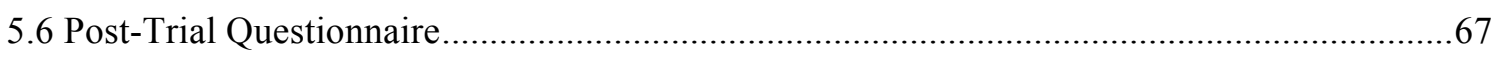

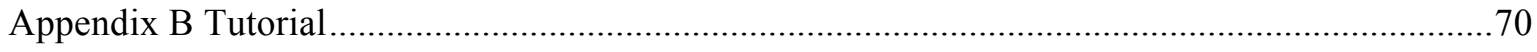

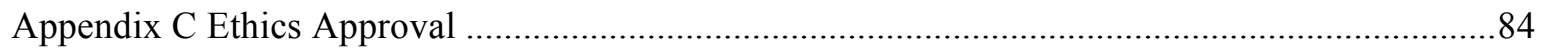

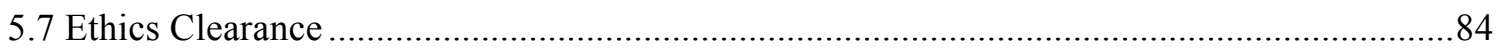

5.8 Ethics Clearance of Modifications, no comments (ORE \# 18268) …...................................85

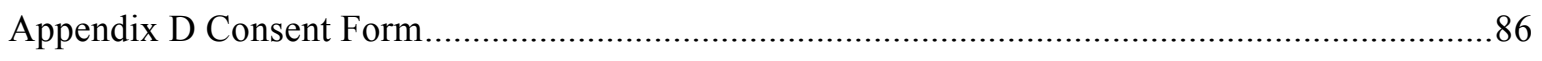

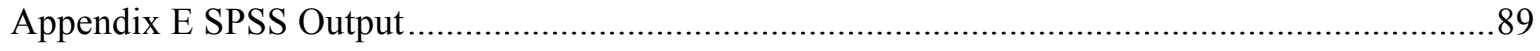

viii 


\section{Chapter 1 Introduction}

"Story isn't a flight from reality, but a vehicle that carries us on our search for reality, our best effort to make sense out of the anarchy of existence." (McKee, 2001, p. 12)

For as long as there have been people there have been stories, from earliest oral histories to books, movies, and video games. As human beings, we "thrill to an astonishing multitude of fictions on pages, and stages, and on screens - murder stories, sex stories, war stories, conspiracy stories, true stories and false. We are, as a species, addicted to stories." (Gottschall, 2012, p. xiv) Great speakers and writers rely on stories to connect with their audiences; novelists and screenwriters enthral us with stories of tragedy and joy, computer games enable us to actively participate in the construction of heroic narratives. In this thesis, I suggest that interface designers could benefit from using some of these same storytelling techniques.

Stories have many qualities that make them effective as a form of communication. Of particular interest to human-computer interaction researchers, is the ability of a well-told story to capture and hold an audience's attention. This power is mythologized in the story of The One Thousand and One Nights (Byatt \& Burton, 2009), in which the storyteller Scheherazade causes her execution to be delayed for 1,001 nights because the king who holds her captive cannot bear for her to be killed before he hears how her stories end. Like Scheherazade's stories, suspenseful narratives full of mystery and adventure, uncertainty, and perilous situations keep people transfixed with curiosity, waiting to find out what has happened, what is happening, or what will happen next.

While the term 'suspense' is strongly associated with dramatic fiction, it is by no means limited to that context. Many real life situations are also highly suspenseful. Sporting events can be suspenseful, particularly when one's favorite team is playing an important game, and if the score is close or tied. Close elections are also suspenseful, especially when there is a strong preference for one candidate over another and uncertainty over which will win. The thrill of gambling is intimately tied up in the suspense of waiting to see which card will be drawn or where a roulette wheel will land. People may feel enormous suspense when waiting to find out whether they have won an auction, landed a job, landed a job, or had an academic paper accepted. 
In this thesis, I explore the possibility of creating software applications that are suspenseful in the same way that a story or real life experience might be. This may be done by incorporating suspenseful fictional elements into the software application or by making the structure of the application itself more suspenseful, thereby increasing the emotional engagement and uncertainty experienced by the person using the application. Incorporating suspense into the experience of using an application may make difficult or tedious tasks more tolerable and motivate continued engagement over long periods of time. For this reason, complex software applications that require sustained attention and effort to master may benefit from the inclusion of suspenseful elements that maintain interest and motivate continued learning and exploration.

To introduce this work, I first explain the motivation for my research into suspenseful design (section 1.1). After that, I explain, in broad strokes, how my research relates to existing work in the fields of human-computer interaction (HCI), media studies, and psychology (section 1.2). I then state the research questions addressed by my work (section 1.3), and explain the methods I used to address them (section 1.4). Following that, I list the contributions of my work to the field of HCI (section 1.5) and provide an overview of the structure of this thesis (section 1.6).

\subsection{Motivation}

Many applications struggle to keep users interested, which can be a problem for applications that require prolonged attention or effort. For example, educational applications, such as tutorials and intelligent tutoring systems, often require learners to engage in a lengthy, challenging, and complex program of study. Similarly, applications that track fitness, energy use, and other goals may struggle to keep a user's interest, especially over the months and years it may take to build and maintain good habits. Without strong motivation, interest and engagement wither. However, by applying the techniques of suspenseful storytelling to interaction design, it may be possible to more effectively hold user interest for longer stretches of time and to motivate users to take actions in order to resolve the tension of a suspenseful scenario.

While researchers have studied motivation in a software context, particularly in games (Chen, 2007; Ryan et al., 2006), and in intrinsically motivating, flow-inducing software (Bederson, 2004; Chen et al., 2000), little is known about whether narratives and suspense can increase motivation and encourage continued use. Researchers who have investigated the connection between storytelling and 
human-computer interaction have primarily focused on ways in which computer systems can help tell stories (Hancock et al., 2010; Kelleher et al., 2007), or on ways to incorporate narrative into the design process (Quesenbery \& Brooks, 2010; Gruen et al., 2002), not with how the computer might more effectively convey information by mimicking the structure of a narrative or by taking on the role of a storyteller itself. My research is intended to address that gap.

\subsection{Scope and Context}

This thesis addresses the topic of creating suspenseful interactions. This area of research is investigated at an abstract, theoretical level through my formulation of a framework for suspenseful design, as well as at a more concrete level in my investigation of how a particular suspenseful tutorial design effects user motivation.

This thesis draws on many research traditions. In particular, it relies heavily on the following existing research:

- Research on suspense, largely carried out by researchers in the fields of media studies and psychology

- Research on motivation, originated by researchers in psychology and extended by HCI researchers

- Research on tutorial design, gamification, and digital storytelling, carried out primarily by HCI researchers.

The relationship of my research to existing research in the fields of HCI, psychology, and media studies is roughly depicted in the diagram below. 


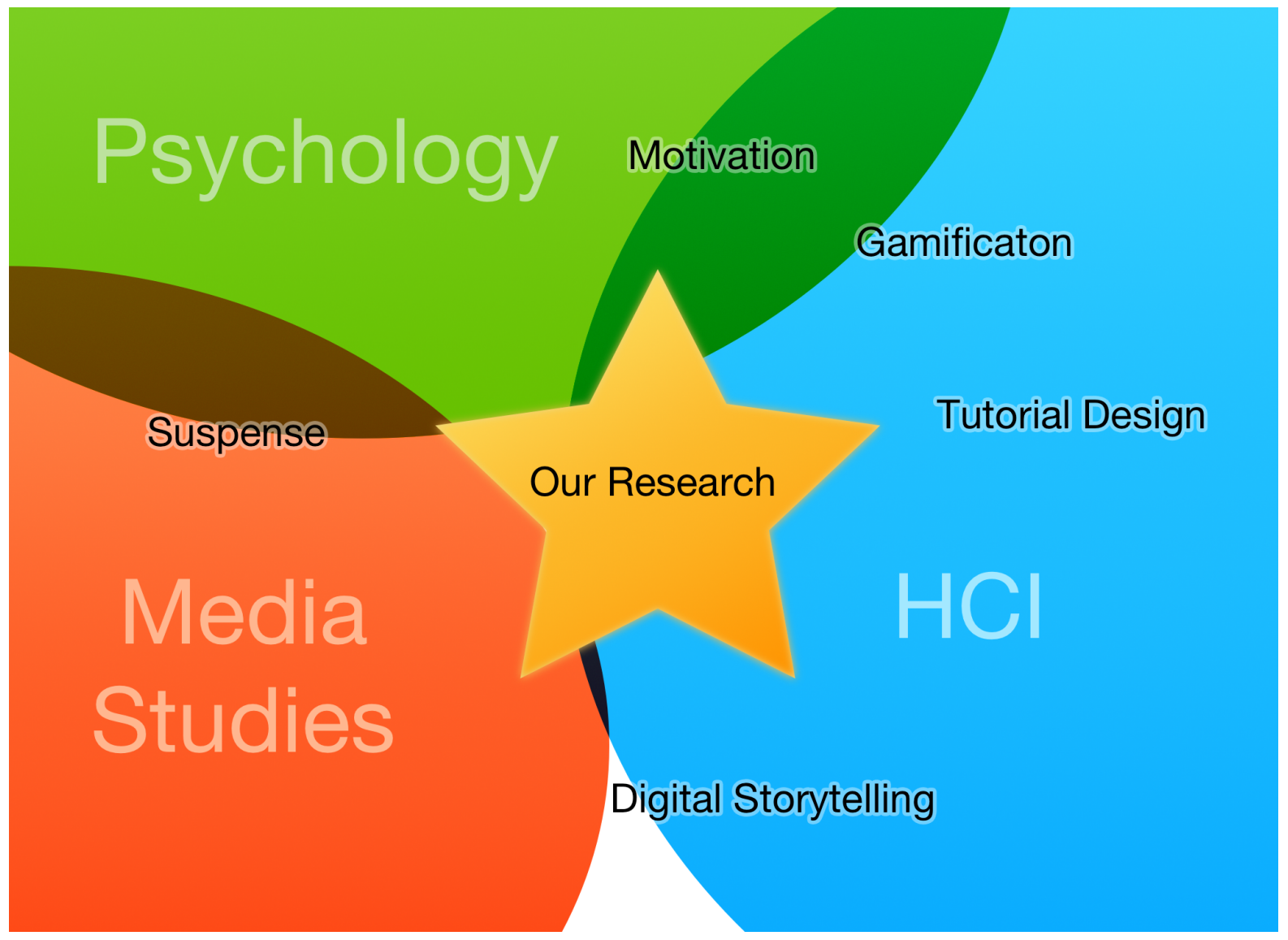

Figure 1. The context of my research

\subsection{Research Questions}

On a high level, this work revolves around an open-ended, speculative question: can we apply the principles of suspenseful storytelling to interaction design to create more engaging and emotionally compelling applications?

The experimental study I ran was designed to answer a narrower and more specific research question: Is a tutorial that incorporates suspenseful narrative elements more intrinsically motivating than a tutorial that does not include such elements?

\subsection{Method}

My work proceeded in several stages, encompassing review and synthesis of existing literature, formulation of a design framework, design and implementation of a prototype application, and 
experimental evaluation of that application. This is parallels the standard HCI methodology of iterative design (Nielson, 1993), implementation, and evaluation (See Figure 2).

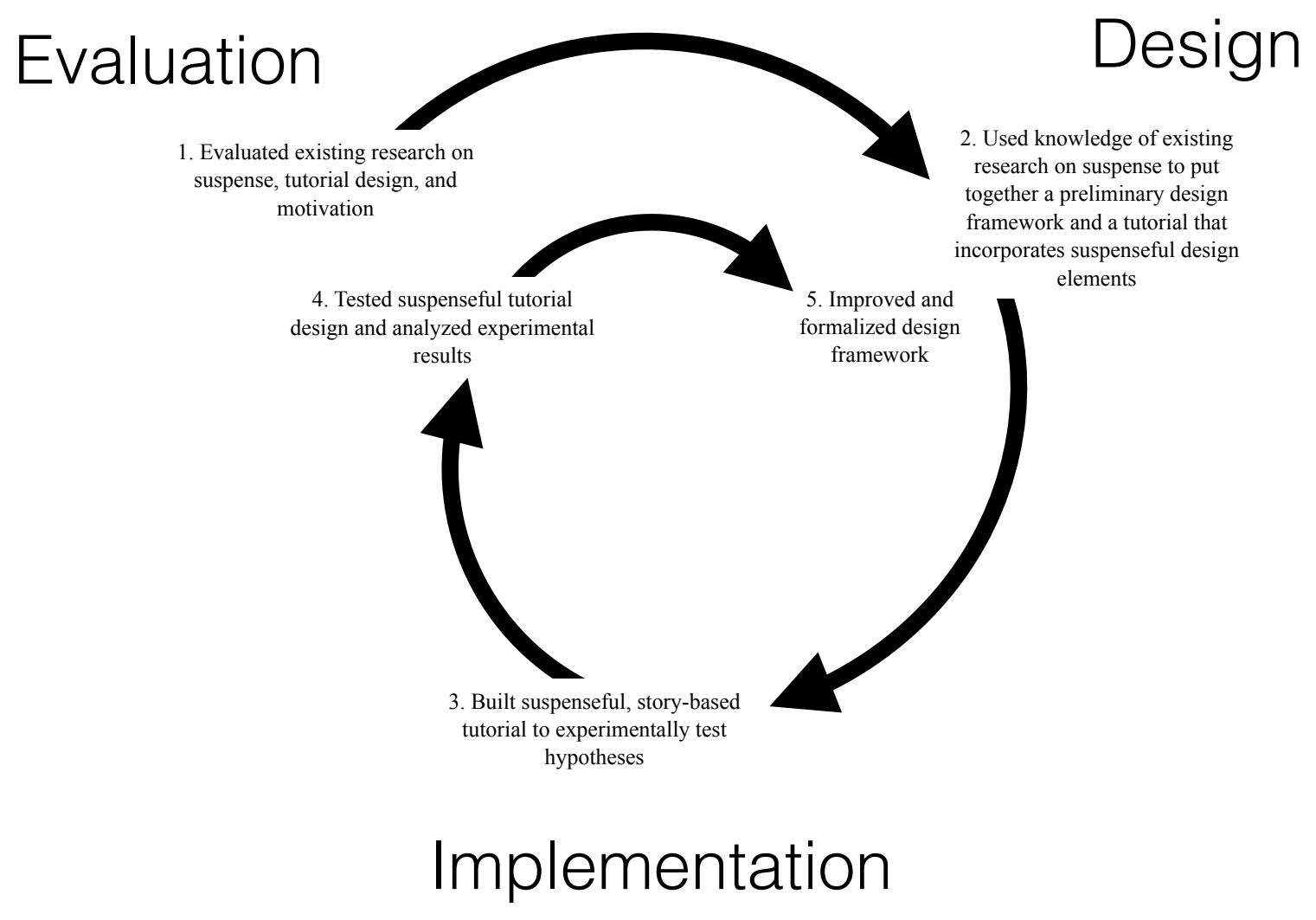

\section{Figure 2. The progression of my research}

The work described in this thesis began with an evaluation of existing research on suspense, motivation, and narrative. Next, I designed a simple, but suspenseful, tutorial that reflected previous research findings. I implemented the tutorial design and evaluated it, running a laboratory experiment to determine whether the suspenseful tutorial was more intrinsically motivating than traditional tutorial designs. Finally, I combined my experimental results with the results of my previous research to further refine my theoretical framework for designing suspenseful applications.

\subsection{Contributions}

This thesis makes three contributions to the study of suspense and human-computer interaction. First, it describes a theoretical framework for creating suspenseful interactions. Second, it describes the design, development, and implementation of a tutorial built around a suspenseful, fictional 
narrative using this framework (Figure 3). Finally, I present the results of a controlled study in which the suspenseful tutorial was compared to two more traditional tutorial designs, and was shown to evoke more hopeful suspense.
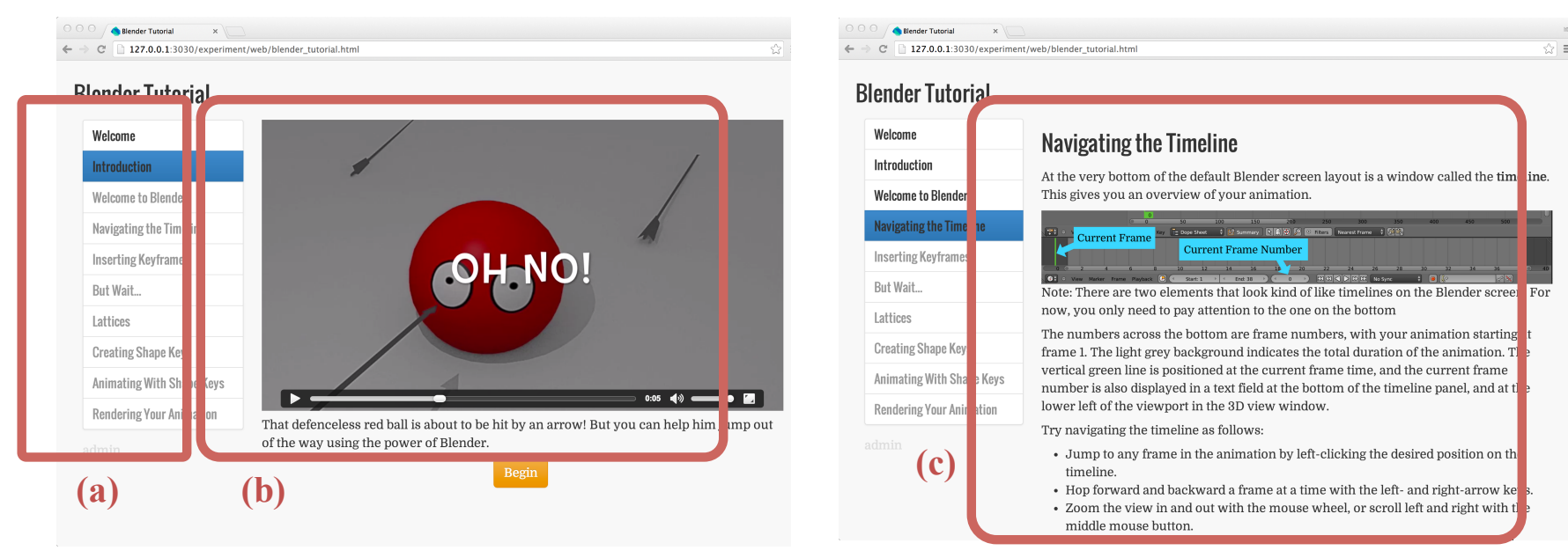

Figure 3. Screenshots of the story-based tutorial experience: (a) navigation bar, (b) suspenseful introduction video, (c) instructional content.

\subsection{Thesis Overview}

This thesis is comprised of the following 5 chapters:

\section{Introduction}

Explains, in brief, the goals and scope of the project as well as the broader context in which it exists.

\section{Related Work}

Contains an overview of HCI-relevant research that has been done in the fields of narrative, suspense, tutorial design, games, and motivation.

\section{Designing Suspenseful Applications}

Describes a theoretical framework for designing suspenseful applications, derived from a synthesis of prior research on suspense. This section also describes the design and implementation of a tutorial based on suspenseful design principles. 


\section{Study: Suspense in Tutorials}

Describes the design and implementation of an experimental investigation of the relationship between narrative, suspense, and motivation, as well as the results of this experiment and lessons learned.

\section{Conclusion and Future Work}

Reflects on the lessons I learned during the design process and the implications of my studies. It also lists several open questions related to or raised by my research that may warrant further exploration. 


\section{Chapter 2 \\ Related Work}

This chapter provides context for my research, describing related work on suspense, tutorial design, and digital storytelling. The research and theory described in this chapter spans many fields, including human-computer interaction, psychology, education, and media studies.

This chapter is divided into three sections:

- In section 2.1, I discuss existing work on suspense, including definitions of suspense, antecedents of suspense, and methods for measuring suspense.

- In section 2.2, I review prior work on computer-based tutorials, comparing and contrasting that work to the work described in this thesis. I also discuss the complex relationship between gamification and learning, with a particular focus on gameful tutorials.

- In section 2.3, I present a survey of existing work on digital storytelling, and discuss the relationship of this work to my research.

\subsection{Suspense}

The research described in this thesis relies heavily on existing theoretical and experimental work related to suspense. Indeed, one of the primary goals of this thesis is to synthesize existing research on suspense in order to construct a framework for designing suspenseful applications, as described in Chapter 3.

Research on suspense has been carried out by researchers in the fields of media studies, rhetoric, marketing, and psychology, among others. These researchers have sought to understand when and why suspense affect people, how it manipulates and heightens our emotions, and how it can be used to entertain and persuade.

\subsubsection{Definitions of Suspense}

Although exact definitions vary, there are some points on which suspense researchers generally agree. For instance, suspense is commonly defined as a kind of emotional arousal associated with uncertainty about an important outcome (Caplin \& Leahy, 2001; Guidry, 2004; Madrigal \& Bee 2005). However, there are many points on which researchers disagree as well, such as the valence of 
suspense (covered in section 0) and the role of uncertainty in creating suspense (section 2.1.3).

Furthermore, there is some disagreement over whether suspense applies only to uncertain future outcomes (Brewer \& Lichtenstein, 1982) or whether it applies to mysteries and uncertainty about emotionally significant past events as well. In this thesis, I have chosen to treat mysteries as a form of suspenseful narrative because the antecedents are so similar, but a case could certainly be made for treating mysteries - particularly those powered more by intellectual curiosity than emotional concern - as being somewhat different phenomena.

Although the above definition of suspense is most prevalent, there are a few less-used alternative definitions of suspense as well. Noël Carroll (1984) argues that suspense depends on moral judgment, and that the experience of suspense is essentially desire for a positive moral outcome, and the triumph of good over evil. Peter Vorderer (1996) argued that suspense in fiction is primarily an experience of empathy for characters in danger, which he refers to as "empathic distress", and that an element of problem solving must be involved. Brewer and Lichtenstein (1982) focus on the order in which story events are presented, categorizing stories as evoking suspense (in order), surprise or curiosity (hidden fact revealed). These definitions are not relevant to the work described in this thesis, but they demonstrate that the definition of "suspense", even in general terms, is still very much open to debate.

The definition of suspense used in this thesis is the above: "a state of emotional arousal associated with uncertainty about an important outcome" This definition is explained and explored in greater detail in Chapter 3.

\subsubsection{Valence and Suspense}

Suspense researchers do not agree on whether suspense is a positive or negative experience. Much research on suspense in fictional media has focused on negative, fearful suspense that "thrives on fear - empathic fear, to be precise”. (Zillman, 1996). This view of suspense as a negative experience is seen in the focus on suspense that arises from "anticipations about a forthcoming (harmful) outcome event for one of the main characters [of fictional narratives]" (p.325, de Wied et al., 1992). This view of suspense likely arises from the fact that fictional dramas typically revolve around a perilous central conflict of some kind, in which a story's heroes are threatened with death or other terrible fate.

However, though suspense can be tense and distressing to experience, there is substantial evidence that it can also be very enjoyable. The enjoyable, entertaining quality of suspense has been demonstrated in several different contexts. Zillman et al. (2000) found that audiences rated 
suspenseful television programs as more enjoyable than similar programs that did not include suspenseful elements. Even suspenseful programs with no resolution were liked more than control texts that did not include a suspenseful initiating event. Similarly, Brewer and Ohtsuka (1988) found that overall suspense rating correlated more strongly with the likeability of a story than any other factor they tested. Alwitt (2002) found that the effect extends to commercials as well, with study participants indicating a significant preference for suspenseful commercials over non-suspenseful commercials. Though 'likeability' and preference are not precisely measures of valence, they would seem to indicate at least that participants enjoyed the experience of suspense more than they enjoyed non-suspenseful media.

Researchers and theorists that study suspense in non-fictional contexts more often regard suspense as a positive or mixed experience. For example, in their study of expected utility theory, Caplin and Leahy (2001), describe suspense as “...the pleasure experienced immediately prior to the anticipated resolution of uncertainty" (p. 73). Studies of audience response to sporting events describe suspense as a mix of positive and negative, pain and pleasure, hope and fear. For example, in their study of racing sport spectators, media psychologists Hartman \& Daschmann (2008) discuss both positive and negative aspects of audience uncertainty, observing that spectators "hope for a happy ending and fear a negative ending."

Zillman (1996) attempted to reconcile these perspectives by making a distinction between dramatic narrative suspense, which he argues has a negative valence, and "real life" suspense, which may be either positive or negative. However, many common story tropes exist in which the audience is lead not just to fear for the protagonists' safety, but also to hope for their eventual triumph. For example, in romance stories the hope that two characters will eventually overcome all obstacles to be together is as important to the story as the fear that they will fail to do so. Even in many action movies we are not just relieved when the villain is stopped, we feel elated when the heroes find themselves in some way better off than when they began.

In this thesis I take the position that suspense can be either positive or negative or a complex combination of both. This is reflected in my framework for suspenseful design, detailed in Chapter 3 .

\subsubsection{Uncertainty and Suspense}

Suspense theorists have also disagreed about the role of uncertainty in creating suspense. Some researchers have argued that suspense arises from near certainty of a negative outcome, while others 
argue that a 50/50 chance of a negative outcome is most suspenseful. This divide is largely between those researchers who study suspense in fictional, storytelling contexts and those who study suspense in real-life and sporting contexts. For example, Brewer and Lichtenstein's (1981) experimental studies of suspense found that the more unlikely a negative outcome appears, the more suspenseful the story is considered by audiences; the only exception to this rule being when the audience is $100 \%$ certain the heroes will not survive, at which point the scenario is no longer considered to be suspenseful. This led them to conclude that "...suspense is viewed, on its simplest terms, as a high degree of certainty of a negative outcome" (p. 328).

Conversely, Hartmann et al. (2008) found that spectators of racing sports experienced most suspense when competitors were closely matched, and a desirable outcome was almost exactly as likely as an undesirable outcome. These seemingly contradictory results may be due to the fact that heroes of fictional narratives very often survive despite seemingly impossible odds. The audience's expectation of a happy ending may affect their response to suspense in fictional scenarios, causing people to view story protagonists in seemingly totally desperate situations as having more like a 50/50 chance of survival.

In this thesis, I take the position that the more uncertain a situation is, the more suspenseful it is. If suspense is created through a fictional narrative, that likely means putting characters in situations that strongly resemble certain doom. If suspense originates from a competition or other real life uncertainty, then 50/50 odds are likely to be most suspenseful.

Furthermore, unquantifiable uncertainty appears to be even more suspenseful than a $50 \%$ chance. For example, Guidry (2004) found that varying the level of certainty felt by the audience increases suspense. Anecdotally, this effect may also be observed in the success of, for example, paranormal horror in which characters are put in a situation so strange and unconnected from the usual rules of reality that it becomes impossible to even make an educated guess about what might happen next.

\subsubsection{The Paradox of Suspense}

One interesting property of suspense is the so-called "paradox of suspense" (Carroll, 1996): the ability of people to feel and enjoy suspense even when they already know the outcome of a story or event. For example, Gerrig (1989) found that even when reading a suspenseful non-fiction story about a known historical event - George Washington being elected $1^{\text {st }}$ president of the United Statesreaders appeared to voluntarily suspend their prior knowledge of the event, instead becoming 
absorbed in the tense, moment-by-moment uncertainty of the story. This work is largely outside the scope of my study; however, it is encouraging, as it would seem to indicate that suspenseful structures can be enjoyed even by people familiar with a story's twists and turns, perhaps making fictional suspense a workable design element even in applications that people are expected to use more than once.

\subsubsection{Measuring Suspense}

In many studies of suspense, suspense is measured by asking participants to rate their agreement with statements such as "This is suspenseful" (Alwitt, 2002; Gerrig \& Bernardo, 1994; Peterson \& Raney, 2008). Moulard (2012) developed a more comprehensive method of measuring suspense through questionnaires in consumer experiences. In the experiment described in Chapter 4, I make use of her validated scale for measuring suspense, which breaks suspense down into two component emotions, hope and fear, as well as a valence-neutral component that corresponds to both positive and negative tension. Hope is felt when someone believes that there is a chance of a positive outcome, while fear results from the belief that a negative outcome is possible.

Suspense can also be measured by monitoring study participants' physiological indicators. Suspense involves the experience of emotional arousal, which can correspond to physiological responses, including elevated skin temperature and heart rate. Researchers have found that study participants who viewed suspenseful content, such as footage of a lion attack or milling accident, exhibited physiological signs of arousal during the uncertain, suspenseful segments of the video. Furthermore, once the suspenseful scenario was resolved, physiological measures of arousal dropped precipitously, even if the resolution was unpleasant (Nomikos et al., 1968; Thayer \& Levenson, 1983). There is evidence that this increase in arousal is a critical part of what makes suspenseful experiences enjoyable. Zillman (1996) found that increased emotional arousal, due to suspense, increased the intensity of people's emotional reactions to the eventual outcome. For example, in a suspenseful sequence in which a character was shown desperately, hopelessly trying to escape a great and terrible danger, audience relief at the character's eventual escape would be greatly magnified. He hypothesizes that this effect occurs because emotional valence can change quickly, as the viewer's mental assessment of the situation changes, while, for physiological reasons, the intensity of emotional arousal changes more slowly. 
While the existing research on suspense is varied and informative, little research has been done examining the effect that suspense has on motivation, or how the experience of suspense might be leveraged to pique people's curiosity and keep them engaged with a lengthy, tedious, or difficult task. In this thesis, I have attempted to address that gap by investigating how suspense might be usefully applied to software applications, and in particular whether suspense increases learner motivation when applied to a computer-based tutorial system.

\subsection{Tutorial Systems}

Although, on a high level, this thesis is concerned with the application of suspense to many kinds of software, the test case described in Chapter 3 and Chapter 4 is a tutorial system. Tutorials have long been a subject of interest in the HCI community. While in an ideal world, no computer system would be difficult to learn or use, in practice many powerful and efficient systems are so complex or unconventional that they require extensive training to master. Applications that are extremely flexible or customizable often require training, as do applications that provide a huge number of options and features, or that require an understanding of difficult concepts or abstract representations.

When faced with a complex application or task, people often rely on tutorials for orientation and assistance. In a study of online tutorial use, LaFreniere et al. (2013) found that most people seek online tutorials out either because they are looking for assistance with a specific task, because they are attempting to expand their repertoire of skills, or because they simply enjoy being led through the process of creating an impressive end product that would otherwise be outside of their abilities (expert shadowing). Whereas minimalist help systems can be tremendously useful in helping people who are stuck or searching for a particular tool, tutorials are able to help people truly master a system, exposing them to tools and workflows that they might never have discovered on their own.

Still, while some people will work through tutorials to proactively expand their skill set or simply for the fun of it, many others rarely, if ever, engage with tutorials. When using a system, people are typically engaged in an attempt to achieve some particular goal, and have little patience for tasks that are superfluous to that goal. Carroll (1987) called this reduced motivation to spend time just learning about the system production bias. A person's production bias often prevents them from engaging with tutorial systems; if they do not have an immediate reason to care about the tutorial, they are unlikely to use it and learn from it. 
This thesis continues this tradition of human-tutorial interaction research on tutorial systems. In particular, it is closely linked to the existing research on gameful tutorials, which are also concerned less with raw efficiency and more with finding methods to increase motivation and enjoyment.

\subsubsection{Generating Tutorial Content}

Much work has been done to devise new and more efficient methods of generating tutorial content. Techniques have been devised to create a tutorial by extracting information from a recording of an expert performing a task (Grabler et al., 2009; Chi et al., 2012; Wang et al., 2014), by crowdsourcing the task of tutorial creation (Knabe, 1995; Lafreniere et al., 2013; Dontcheva et al., 2014), or by taking the desired final product and automatically reverse-engineering the process necessary to create it (Li et al., 2013).

This thesis does not directly pertain to the question of how to more efficiently generate tutorials. Indeed, tutorials made according the precepts described in this thesis would be considerably more laborious to produce than traditional tutorials, as they require storytelling skill, technical writing skill, and the ability to match story events to instructional goals. However, in the future, it is conceivable that techniques similar to those described in this section might be used to make the process at least somewhat easier.

\subsubsection{Presenting Tutorial Content}

The primary purpose of a tutorial is to teach a person how to perform a task, so a significant amount of research has focused on the question of how a tutorial's instructional content can most effectively be communicated to a learner. "Effectiveness" has many components, encompassing memorability, speed, enjoyment, versatility, power, engagement, and motivation.

HCI studies of tutorial design often seek to reduce complexity and confusion, aiming to make tutorials simpler and easier to follow, as is the case for all the presentation techniques described in this section. In theory, tutorials that are simple to follow may enable learners to accomplish tasks more quickly and with greater motivation and enjoyment. Simple tutorials help users complete tasks more quickly because the learner is less likely to become confused or stuck. Greater motivation and enjoyment might be expected because, in accordance with self-determination theory (Ryan \& Deci, 2000), easier tutorials will make learners feel more competent, and feelings of competence can improve motivation. However, this relationship has not yet been experimentally proven. In some 
cases, reducing the complexity and difficulty of a tutorial will also better match the level of challenge presented by the tutorial to the level of skill possessed by the learner, perhaps enabling the learner to enter a flow state in which they are wholly absorbed in the tutorial task (Chen et al., 2000; Fernquist et al., 2011)

Some tutorial systems make things simpler and easier by constraining learners' actions and reducing their ability to take wrong actions. One example of this approach is Kelleher and Pausch's stencil-based tutorials system (2005). Stencil-based tutorials only allow learners to take actions appropriate to their current step in the tutorial, keeping them from accidentally performing incorrect actions. Because the stencil prevents interaction with any part of the application other than that proscribed by the tutorial, learners are less likely to make mistakes that may cause confusion or disrupt the flow of the tutorial. Another, example is Pongnumkul et al.'s (2011) Pause-and-Play, which is designed to prevent learners from getting confused or stuck. Pause-and-Play makes video tutorials easier to use by applying computer vision techniques to automatically pause the video when the learner needs to complete a step, and then resume playing once they had completed that step.

Tutorials may also be made simpler and easier to follow if the tutorial content is embedded directly into the application that the tutorial describes, reducing the need for context switching while following the tutorial's instructions. Several research projects have emphasized the importance of incorporating tutorial content directly into the interface of the application. For example, Grossman \& Fitzmaurice's ToolClips (2010), provides contextual video assistance within an application. Like textonly tooltips, which are common in many commercial applications, ToolClips are embedded into an application's interface. The videos provide detailed instructional information in context, without significantly disrupting users' workflows. Studies of this system indicated that participants using a modified version of the application Paint.NET that provided embedded ToolClips videos successfully completed seven times as many unfamiliar tasks as those who only had access to a standard online help system. In addition, when they returned to the lab for a second session one week later, participants who used ToolClips remembered more of what they'd learned than those in the control condition. Bergman et al.'s DocWizards (2005) is another example of an experimental tutorial system that attempts to incorporate tutorial elements directly into the applications. DocWizards guides users through a tutorial by highlighting controls in the actual application interface. Study participants were found to strongly prefer the DocWizards interface to a tutorial that did not highlight controls in the target application. 
Yet other tutorials blur the lines between image editor and tutorial. For example, tutorial-based image editing applications by Laput et al. (2012) have the step-by-step structure of a tutorial, but can also automatically apply each tutorial step to a given image with the user only required to select image elements adjust parameters such as opacity or contrast to their liking. Tutorial-application hybrids such as this can make following a tutorial so simple that engagement with the underlying software becomes essentially unnecessary.

It is not just interacting with software that a tutorial can make simpler and easier. The SketchSketch Revolution tutorial system, developed by Fernquist et al. (2011), both helps users learn to use a drawing application and assists users with the actual sketching. This work simultaneously addresses both the difficulty of learning to use a specific software interface and the difficulty of acquiring the underlying domain skills necessary to use the software at an expert level. Sketch-Sketch Revolution is designed to keep users engaged by providing the support necessary to keep even people without strong drawing skills in a state of flow, where they feel that their abilities are well matched to the challenges presented by the tutorial, thereby creating a tutorial experience that is not just easy to follow, but also intrinsically rewarding. Fernquist et al. (2011) argue that tutorials should be as compelling as possible, and that keeping users engaged with the tutorial experience is of the utmost importance, and that supporting flow is one way to keep users engaged.

In this thesis Ido not directly engage with the question of how to make tutorials simpler and easier to follow, though like Fernquist et al., I am very interested in increasing user engagement and enjoyment. Techniques for preventing user error, embedding tutorial content directly into an application, and supporting the acquisition of domain skills are all entirely compatible with my work, and could easily and fruitfully be combined with suspenseful tutorial design.

\subsubsection{Gameful Tutorials}

While much research attempts to make tutorials more appealing and easy to use by making it simpler and more direct, there has also been considerable work that is instead primarily focused on maximizing interest, motivation, and engagement. The bulk of this work emerges from the field of gamification, defined as "the use of game design elements in non-game contexts" (Deterding 2011). My work is in many respects an extension of this existing research into gamification and gameful design. Specifically, my work is concerned with adapting and applying one particular game design element, suspense, to non-game contexts, such as tutorial software. 
Research on gameful tutorials is itself a sub-discipline of the more general study of gamification and learning. The application of gamification to education and learning has been a subject of intense interest and study. (Domínguez, 2013; Muntean, 2011; Kapp, 2012; Coller \& Scott, 2009). It appears to be a promising area of study, as all games are, in a sense, educational. Indeed, the appeal of a game is very often primarily the appeal of learning to master a complex system: the rules and controls of the game. Gee (2005) lays out the argument for video games as "learning machines". He observes that games are very often long, complex, and difficult, and that players often start a game with very little knowledge of how to play. However, well designed games make the process of mastering their systems - often very difficult systems that take many hours or days or months to learn - into an experience that is compelling, fun, and even addictive.

There are a wide range of approaches to combining games and education. Some gamified learning environments contain only a few minor game elements, included to provide extra motivation or structure. Khan Academy ${ }^{1}$ is an example of this style, where points, badges, and skill trees are mostly treated as an optional supplement to the learning experience. On the opposite end of the spectrum are games that mostly resemble games created solely for entertainment, but also happen to include an educational metaphor of some kind. "The Code of Everand" (Dunwell et al., 2014), for example, is a game for children that is mostly an ordinary game about fantastic monsters. However, its gameplay also serves as a metaphor for road safety, and the game requires players to cross road-like "spirit channels" without hitting any of the dangerous monsters that travel through them. Though the game does not have an instructional format, it was shown to affect the real life attitudes of the children who played it. Many serious games and gamified learning environments fall somewhere in between these extremes, being clearly designed to educate players about a particular subject, but conveying their lesson through gameplay mechanics rather than lectures, readings, or assignments. (Kapp, 2012) Still other games are not themselves educational at all, but are instead designed to motivate educational activities that take place outside the game. (Watson et al., 2013)

One thing that nearly all of these efforts have in common is an interest in increasing learner motivation and interest. Motivation is a complex phenomenon, however, and there are many different

\footnotetext{
${ }^{1}$ https://www.khanacademy.org/
} 
facets of motivation that gamification acts on in various ways. Two fairly prominent measures of intrinsic motivation are flow (Csikszentmihalyi, 1988) and self-determination theory (Ryan \& Deci, 2000). Well-constructed video games create a feeling of flow and enjoyment in their players by providing clear, achievable but challenging goals in combination with immediate and informative feedback. (Malone, 1982; Sweester \& Wyeth, 2005). In theory, a gamified learning experience can create flow by employing similar design elements. Similarly, games can be enjoyable because they satisfy players' intrinsic psychological needs for competence, autonomy, and relatedness. (Ryan et al., 2006) These same kinds of intrinsic motivation can apply to gamified learning experiences as well.

There are other ways in which learning games can potentially increase engagement. O'Rourke (2014) has shown that educational games with an incentive structure that promotes a growth mindset (belief that intelligence in malleable), incentivize effort, use of strategy, and incremental progress. When an incentive structure that promoted a growth mindset was used, low-performing students showed greater persistence compared to those in a control group, spent more time playing, played more strategically, and were more likely to persevere when challenged. In addition, different types of gameplay engage different players. For example, Hamari and Tuunanen, in their meta-synthesis of player typologies (2014), segment players according to their interest in five key dimensions of play: Achievement, Exploration, Sociability, Domination, and Immersion. Some players may be motivated mostly by the ability to accumulate points and achievements, while others are drawn into a game primarily because it enables them to feel immersed in a story. Orji et al. (2013) have shown that player type also affects the ability of serious games to alter player behaviors and attitudes.

Tutorial are a type of learning environment that seems particularly well suited to gamification, as tutorials are a form of education that happens to already be tied to the environment of computer systems, the same kind of systems on which video games are played. Tutorials are also well suited to gamification because, like other kinds of learning experiences, tutorials share many inherent structural similarities with games. In both games and tutorials, users are confronted with an unfamiliar environment that they must struggle to understand and master. However, in tutorials, difficulties are generally perceived as burdensome and discouraging obstacles, while in games, problems are presented as entertaining and engaging challenges that provoke interest and exploration. In a game, players are encouraged to be inventive, and the struggle of learning something new is just part of the fun. (Carroll, 1982) 
Li (2012) identified several gamification elements that are appropriate for incorporation into a software tutorial system. Although his focus was not on narrative and suspense, several of the elements he lists are related to those topics:

Fantasy: Fantasy creates emotional appeal by evoking fictional themes, images, situations, characters, often by means of a narrative shaped and reinforced by gameplay. If there is a narrative, suspense will likely be involved as well. Maloney (1982) showed that fantasy elements in a user interface could increase its appeal, but only if the fantasy itself was an appealing one.

Feedback and Guidance: Much of the fun of video games comes from being set interesting problems and then getting immediate interesting feedback in response to ones' actions. In some games, clear goals may be communicated in part through a narrative, which gives players strong "inuniverse" reasons to take certain actions or work towards certain outcomes, though this is not the case in all games. Feedback is what makes players feel like they have power in the virtual world of the game, that their actions matter. This increases emotional engagement, which can in turn increase suspense. Conversely, in scenarios where players are uncertain about what the results of their action will be, a suspenseful setup may heighten emotional response to the resulting feedback.

Progressive Disclosure: Games often start out simple, and grow increasingly complex as the player progresses. This progressive disclosure of knowledge and challenge makes it easy for players to get started, and enables them to steadily ramp up their skills without getting overwhelmed. It also helps keep players in a flow state, where the game is neither too easy nor too difficult. (Csikszentmihalyi, 1988; Sweester \& Wyeth 2005) Progressive disclosure is a part of suspenseful storytelling as well, in which key information is carefully, deliberately withheld to keep the audience interested.

Time Pressure: Time pressure is a straightforward and easily understood challenge that is common in games. (Malone, 1982) Time pressure is also a classic way of generating suspense. It is what makes ticking time bombs and countdowns exciting. Though this is not an element of suspense that I explored in my design and study, it is considered in my framework and is very much a suspenseful element that could be leveraged to make tutorials, and other applications, more exciting.

Rewards: Rewards are a clear, simple form of motivation. Virtually all games involve rewards of some kind, though their precise nature can vary enormously, from points and badges to extravagant animations to the respect and fellowship of non-player characters. Performance feedback and the 
unlocking of new content are particularly suitable rewards for a gamified tutorial, as they directly encourage learning activity and are informational rather than controlling. (Reeve, 2009) A suspenseful lead up can make an eventual reward even sweeter (or even more disappointing). In many cases it is really the promise of the reward that is motivating, not the reward itself. If there is uncertainty over what exactly the reward will be or whether the player will be able to claim it, that is a suspenseful situation. In addition, resolving a suspenseful situation - in a narrative or otherwise may be a motivating reward in itself. For example, solving a mystery, or enabling one's avatar to escape from harm.

Furthermore, there are several elements of game narrative, specifically, that can assist in learning. One of the remarkable things games can do is provide worlds where people can have experiences that would not otherwise be available to them, or any human being. Players can imagine themselves in other roles, in other worlds, with other kinds of responsibility - ruler of a nation, a fugitive on the run, and so on. These fictional elements can increase interest, help learners explore a skill area by playing an aspirational role. For example, someone studying science might play at being a scientist, trying on the identity and expected behavior as well as testing their skills By impacting a fictional world, a learner can feel like an active, creative agent that shapes the world; that their choices and work have weight. This encourages engagement, ownership, and a feeling of efficacy. Furthermore, a story will typically ground the learners actions in concrete events and actions. This helps learners build understanding by synthesizing many discrete, memorable experiences. This enables learners to start not with general definitions, high level abstractions, and logical principles, but with visceral experiences, activities, and stories. (Gee, 2005)

These principles and others have been employed in various gamified tutorial systems created for the purposes of experimentation and study.

Jigsaw (Dong et al., 2012) is a gamified tutorial that emphasized exploratory, discoverybased learning. Players are challenged to use Adobe Photoshop to solve virtual jigsaw puzzles, adjusting the position, size, brightness, layer position, and other properties of the pieces until they come together to make complete and continuous image. If players got stuck, they could call up a hint that would help them find the right tool for the job or they could view a complete tutorial that would explain the necessary technique in detail. Study participants who used Jigsaw described it as a fun and effective way to learn. The open question of the initial challenge, combined with the not-quite- 
satisfying vagueness of a hint, create a tension that demands to be resolved. This is not exactly suspense, but it is an example of manufactured uncertainty being used to motivate learning.

Another example of a prototype system that applies the principles of gamification to tutorial design is the GamiCAD tutorial system, created by $\mathrm{Li}$ et al. (2012). GamiCAD resembles an intelligent tutoring system, evaluating whether the learner has been successful in completing tutorial tasks, and providing real-time visual and audio feedback based on their performance. GamiCAD was designed to make repetitive learning tasks more enjoyable through level unlocking mechanics, less-structured "arcade style" bonus levels, and alternate methods for completing a given task. The game also included a narrative frame: helping NASA build components of a spacecraft. Though no deliberate attempt was made to include elements of suspense, progressive disclosure of level unlocking is a kind of suspenseful experience. In a within-participants experimental study, the GamiCAD system was compared to a tutorial with identical instructional content but no game-like element. Compared to the more traditional tutorial, GamiCAD was rated substantially more enjoyable, fun, and engaging. In a skill test following the tutorial training, learners who had used GamiCAD were able to complete more tasks and completed those tasks more quickly.

An even more game-like tutorial is CADament, an extension of GamiCAD that includes multiplayer challenges and competitions ( $\mathrm{Li}$ et al., 2014). This approach was shown to be better than pre-authored tutorials in performance, motivation, and knowledge transfer. The competitions employed in CADament are also a kind of suspenseful interaction, as players are uncertain of the outcome of the competition, but emotionally invested in the results.

Still, though these gamified tutorials employ some suspenseful techniques and structure, that is largely a coincidental result, due to the fact that many popular game mechanics involve an element of suspense. In contrast, my work is primarily concerned with suspense and the importance of narrative structure, presentation, and pacing.

\subsection{Stories, Technology, and Learning}

At the core of my work is the idea of combining the ancient technology of storytelling with the very new technology of computers to better support learning. Though my particular approach is novel, there have been many previous studies that have examined the relationship of stories, technology, and learning through various different lenses.Stories and Learning 
To a great extent, the human mind runs on stories. According researchers the field of narrative psychology, narratives are how people explain, contextualize, and organize their lives. By constructing personal narrative, people are able to give their lives structure and meaning, coherently integrating experiences into their identity. People with coherent, positive personal narratives display better mental health, academic performance, and even physical health. (Pennebaker and Seagal, 1999; Gergen and Gergen, 1988) In addition, there is evidence that we humans use cognitive models similar to the ones used for narrative to represent real events in our lives and to better understand the world around us. (Bruner, 1990)

Narrative also appears to be helpful for learners trying to assimilate new knowledge. Stories provide context and a way of linking new facts back to known, related concepts, helping learners understand instructional content and set good goals (Laurillard, 1998). In short, stories make it easier to apply our innate "narrative intelligence" (Mateas \& Sengers, 1999) to the task of learning and understanding.

In addition, the emotions that stories inspire can also help learners to retain new information. Emotion and long-term memory are linked: emotion seems to activate and prepare the brain for storing information, making even otherwise dry facts easier to recall. This memory enhancement has been observed in several studies and associated with stories conveyed through a variety of media, including printed text, pictures, and narrated slide shows. (Cahill, 1995) The effect is also observed in autobiographical recall of events in individual's own lives, where the most emotional events are also the most clearly and easily recalled (Kensinger, 2004) The connection between emotion and memory is particularly relevant to the use of suspense in learning environments; if suspense can be used to heighten emotional arousal, it may consequently aid memory formation as well.

\subsubsection{Automatic Story Generation}

While stories can be laborious to create - and interactive, non-linear stories even more so - in the future, this work of constructing may be significantly aided by special-purpose storytelling AIs that can craft and shape stories automatically. While my research does not make use of a storytelling AI, instead relying entirely on human storytellers, AI assistance could be of critical assistance in creating more open-ended, reactive systems that shape themselves around a user's interests or informational requirements, inventing or adapting stories to better fit a user's individual interests and abilities. (Roberts \& Isbell, 2009) 
Storytelling AIs are designed to reason about how to generate a comprehensible, logically consistent, and entertaining story. There are several different approaches that have been tried to achieve this goal. Simulation-based narrative generation systems use bottom up approaches, creating a world of autonomous agents that interact with each other and the player in accordance with their internal rules. (Riedl \& Young, 2010; Gratch \& Marsella, 2001; Vizzari et al., 2007). In contrast, deliberative systems include an omniscient, controlling element that acts like an author, reasoning about the global structure of a narrative and manipulating events to make the overall experience as interesting and satisfying as possible, creating stories that are both 'in character' for the non-player character (NPC) agents and that have an interesting, story-like structure (Cheong \& Young, 2008; Mateas \& Stern, 2003). A storytelling AI may also dynamically adapt the narrative to an audience's inferred interests (Gilroy et al., 2012), style of play (Riedl \& Bulitko, 2012), or educational goals (Querrec \& Chevaillier, 2001). Building one of these systems is currently much harder and more unreliable than just writing a story, even an interactive story. However, this may all change as the theory and technology mature.

\subsubsection{Storytelling Tools}

Computers can be an effective medium not just for conveying a story to an audience, but also for enabling people to tell their own stories. Substantial research has gone into creating and evaluating software tools that help people more easily tell stories through computers.

Some of these digital tools simply record and present the story they are given (Robertson \& Good, 2005; Carbonaro et al., 2008; Bonsignore 2011). Tools such as these could be adapted to make it easier for people with little or no programming experience to create story-based or suspenseful applications.

Storytelling tools can also assist educational designers in creating engaging lessons or tutorials (Marchiori et al., 2011). They can also be educational in their own right, as with Storytelling Alice (Kelleher and Pausch, 2007), a program designed to teach children to program by engaging them in storytelling. As children's programming skills increase, the complexity of stories they can tell with the Storytelling Alice system increases, and the reward for learning more about programming is simply the ability to tell richer and more interesting stories.

Other storytelling tools are more game like, affording people the opportunity to co-create a narrative in collaboration with the application. For example, The Department of Hidden Stories 
(Wood et al., 2014) is a game for children that assists children in writing a story, providing prompts in the form of surprising developments and potential conflicts to help keep the game interesting and suspenseful. One day, this kind of collaborative storytelling applications could be integrated with a storytelling AI specifically designed to collaborate with a human storyteller, such as the AI created by Swanson (2012) to retrieve and adapt template stories from its knowledge base in order to coherently extend users' stories. Such techniques could be used to help create structured, suspenseful stories that more exactly reflect a learner's goals and interests. 


\section{Chapter 3 \\ Designing Suspenseful Applications}

In this chapter, I present a general, theoretical framework for designing suspenseful applications and describe how I used that framework to design a story-based tutorial. The framework described in this chapter is in part a synthesis of prior work on suspense from many fields (see section 2.1), from which I have built a unified, systematized model of suspense. I then extend this model of suspense into the realm of human-computer interaction, with a particular focus on how suspense can theoretically be used to increase motivation and excitement. Finally, I describe the process of applying this framework to the specific domain of tutorial design. I explain how I used an early version of the framework to help create a story-based tutorial, which was later used in the experimental study described in Chapter 4.

The theoretical model and design framework detailed in this chapter represent several novel contributions: the theoretical model extends existing models of suspense in that it provides a new way of visualizing the relationship between uncertainty, emotional engagement, valence, and emotion. The design framework addresses a gap in the existing HCI literature, showing how various techniques for increasing suspense can be applied to interaction design, as well as exploring the breadth and variety

of possible suspenseful experiences and speculating on the circumstances in which such an approach is likely to be most beneficial. The model of suspense could be useful to almost anyone working with suspense, while the framework for application design is primarily of use to HCI researchers and software designers.

\subsection{A Design Framework for Suspense in Applications}

As explained in Chapter 2, suspense is commonly defined as an emotional reaction to uncertainty about an important outcome (Guidry, 2004). Although some more theoretical and fiction-focused researchers disagree (Vorderer et al., 1996), the majority of experimental studies - particularly experimental studies that observe suspense in non-fictional contexts- have found that suspense is most intense when both emotional engagement and uncertainty are maximized (Moulard et al., 2003; Zillman, 1996). Real life situations tend to be most uncertain when a positive outcome is almost exactly as likely as a negative outcome or, better yet, impossible to calculate due to fluctuating odds or limited information. 
Although some researchers define suspense as an emotional experience with exclusively negative valence (de Wied et al., 1992; Vorderer et al., 1996), in practice it is common for people to report feeling "suspense" in response to a possible positive outcome or in situations where either a 'win' or 'loss' is possible. Indeed, many suspenseful situations elicit such a complicated mix of hope (positive valence) and fear (negative valence) that the positive and negative aspects are near impossible to separate.

With this prior research in mind, I have built a framework around the three dimensions of suspense described above: uncertainty, emotional engagement, and valence (Figure 4). Uncertainty and emotional engagement give rise to suspense, which may be either hopeful (positive valence) or fearful (negative valence) (Guidry, 2004). Both high uncertainty and high emotional engagement are required for suspense to be felt. If uncertainty is high but emotional engagement is low, one experiences curiosity (positive) or confusion (negative). Similarly, if a person's emotional engagement is high, but they feel certain that they know how the situation will resolve, instead of suspense they will feel anticipation (if they expect a positive outcome) or dread (if they expect a negative outcome). When a person experiences neither uncertainty nor emotional engagement, they may be either calm (positive) or bored (negative). 


\section{Curiosity (+) Hopeful Suspense (+) Confusion (-) Fearful Suspense (-)}

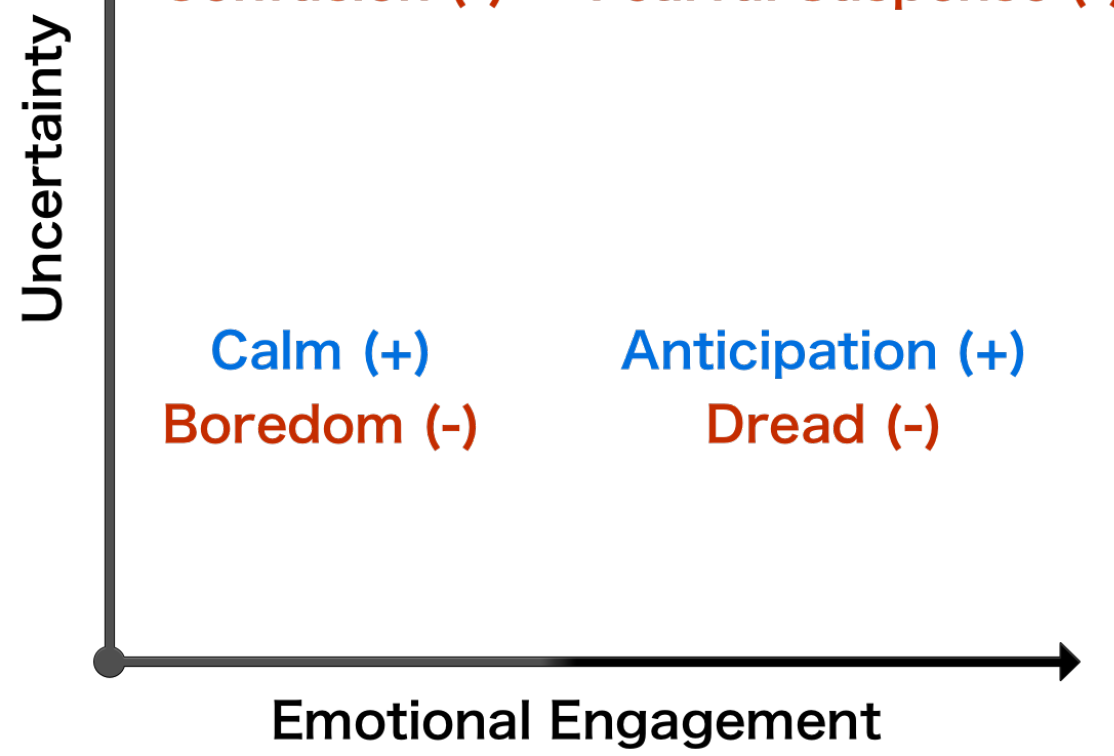

Figure 4. Interaction of uncertainty (y-axis), emotional engagement (x-axis), and valence (+/-).

This framework is reflected in books, movies, games, and other fiction. Much well-loved fiction is effectively designed to maximize suspense, putting interesting, sympathetic characters (with whom the audience becomes emotionally engaged) in situations that are both difficult to predict (uncertain) and which will have a major effect on the characters or their world (emotionally engaging). There are stories that defy this trend - Brewer \& Lichtenstein (1982) and McKee (2001) note that in some cases a story can be sustained by pure intellectual curiosity (as in some puzzle-driven mysteries), which corresponds to the top-left quadrant of Figure 1, or by dramatic irony and anticipation (as in some stories focused on creating empathy for characters whose ultimate fate is already known), which corresponds to the bottom-right quadrant. However, in most genres suspenseful stories predominate. 
The framework for suspense described in this chapter can also be seen at work in sporting events. People typically get most excited about games in which a team or individual they root for is facing off against a rival in a high-stakes match, where both competitors have a roughly similar level of skill. Emotional engagement comes from personal identification with and knowledge of a team, the importance of the game for the competitors' future prospects, and the antagonistic relationship with the rival competitor or team. Uncertainty comes from the closeness of the match and the intrinsic uncertainty built into the game. Sports commentary often attempts to heighten the suspense felt by people viewing a sports game by providing personal details about the players, emphasizing the importance of the match, and highlighting the uncertain elements of the game, thereby increasing the audience' experience of suspense.

It is perhaps less immediately obvious how this framework for suspense relates to software design. However, designers, like writers, directors, and sports commentators, are in the business are in the business of crafting experiences, and they too can benefit from more fully understanding the dynamics of suspense. For example, a designer might make use of this framework by considering what quadrant of Figure 4 a person would be expected to experience when using their interface and how this might change as they progress through a task. For example, a novice may start to use an application in a state of curiosity (high uncertainty, low emotional engagement, and positive valence). As they use the interface, if they encounter difficulty or become overwhelmed, their valence may become negative transitioning into confusion. This kind of transition might be seen various deeply and unavoidably complicated applications, such advanced creative and technical software, as well as training materials for that software. In this condition, increasing emotional engagement might be able to turn that confusion into pleasant suspense. The designer could increase emotional engagement, say by connecting the application to the user's personal goals or by incorporating elements of an engaging narrative, thereby shifting a merely difficult experience into an interestingly suspenseful one. Building emotional engagement may also require the designer to explicitly build trust, as people will likely become disengaged from an experience that feels too arbitrary, unplanned, or punitive.

Alternately, an application might be expected to become less uncertain and more boring/calm over time. This could be a major problem for an application that aims to keep users coming back over a long period of time, such as an e-commerce site or self-monitoring application, such as those that measure fitness, energy use, or adherence to desired habits. In this case, an added element of uncertainty could be used to keep things interesting. For example, eBay makes buying things online 
exciting (even addictive), because it incorporates an uncertain, suspenseful auction element; it is uncertain whether or not one's bid will be the winning one, turning a successful online purchase into a gratifying victory.

Finally, it is possible that the designer will be able to transform otherwise unpleasant or uninteresting experience into suspenseful ones. For example, in situations where a user might experience anticipation or dread, such as watching a progress bar or receiving a notification of operating system updates that may require a system restart, the designer might consider increasing positively-valenced uncertainty by introducing a hint that some special event will occur or awesome new features will become available when the progress completes or the system restarts.

In addition, even in very conventional applications, small elements of suspense may be appropriate to include. A brief moment of uncertainty, such as a gradual reveal of steps walked in a day or amount of electricity saved, may give the outcome greater emotional weight.

Even if a designer's goal is to create the calmest, most soothing possible experience, the framework for suspense detailed above is valuable for identifying situations and design choices that are likely to give rise to unwelcome, intense emotions such as fearful suspense.

\subsection{Techniques for Incorporating Suspense into Applications}

Even knowing that emotional engagement and uncertainty are the factors that make an event suspenseful, it may not be immediately clear how a designer can best incorporate suspense into an application and move users of that application towards the upper-right, suspenseful quadrant of Figure 4. Suspenseful situations are diverse, and emotional engagement and uncertainty can take many different forms. For designers contemplating adding an element of suspense to their application, it may be useful to consciously consider the full range of possible suspenseful interactions and choose the characteristics that best match their design vision and the constraints of the problem that they are trying to solve.

In the following sections, I detail several parameters for incorporating uncertainty (3.2.1) and emotional engagement (3.2.2) into a design. These parameters distinguish one kind of suspenseful situation from another and help make clear the great variety of possible ways suspense can be created and employed. I also discuss parameters for how to resolve suspense, once it has been incorporated (3.2.3). None of these parameters is strictly binary, they are spectrums along which a suspenseful 
scenario might be located. When designing for suspense, some of these parameters may be intrinsic to the application and some may be manipulated according to a designer's whim. Keeping these parameters in mind can help designers to consider and evaluate a wider variety of possible design options.

\subsubsection{Incorporating Uncertainty}

Parameters of uncertainty determine the type of uncertainty experienced by people who use a successful application. These parameters include:

Temporal Locus - the uncertainty at the core of a suspenseful scenario may revolve around an event that occurred in the past (as in a murder mystery) or an event that will occur in the future (as in an adventure story). In an application, suspense might be built by creating uncertainty about future outcomes, as in a competition, or by presenting users with the opportunity to uncover existing, hidden functionality; in solving the application, one might solve a mystery.

Number of Potential Outcomes - the suspenseful situation may concern a situation in which only a small set of outcomes are possible (as in a sporting event where a team can only win or lose) or the range of possible outcomes may be unimaginably vast and uncertain (as in some surreal or paranormal stories). In an application, suspenseful situations may revolve around clearly defined possible outcomes, for example, meeting or failing to meet a target, or the whole application could be suffused with an aura of mystery, where surprising, delightful discoveries result from any interaction.

Some techniques for increasing uncertainty are listed below. These techniques allow a designer to adjust an application so that it can induce greater uncertainty, potentially leading to curiosity, confusion, or suspense. These techniques are independent of the parameters above, and can be combined with those parameters in whatever manner seems most interesting. For example, the countdown technique could apply to the amount of time given to solve a mystery about the past or to complete a series of tasks in the future, it could limit the amount of time available to win a clearly defined competition or the countdown could be an unexplained and threatening element of uncertain purpose, counting down to the user knows not what.

The techniques are as follows:

A countdown or deadline: a task that would be no challenge to complete given unlimited time can become thrillingly uncertain when there is a strict deadline to race against. 
Competition: battles, literal and figurative, are exciting when it is not clear which side will win. This dynamic is a part of what makes auctions, sporting events, and spelling bees exciting.

Variable or randomized rewards: variable, uncertain rewards are at the core of gambling's addictive suspense. They are also at play with social media and text messaging notifications, where every bleep of a newly arrived message may indicate the arrival of an exciting message from a friend, a boring promotional email, or terrible news of some kind.

Removing resources, fluctuating uncertainty: familiarity breeds complacency. However, removing a tool that someone has previously relied on makes an experience much more exciting [15]. This technique may have some natural overlap with the technique of "scaffolding" used in many computer-based teaching tools, as scaffolding involves gradually removing assistive elements until the learner is able to complete a task without any help at all.

Foreshadowing and flash-forwards: providing vague hints of what is to come can build tension and excitement. In an application that may mean providing hints (but only hints) about unlockable features, advanced modes of operation, and upcoming content. This technique has been used in video games such as Assassin's Creed and Dragon Age 2, which give players a safe but tantalizing taste of advanced gameplay before putting them back in simpler and more limited training mode.

\subsubsection{Incorporating Emotional Engagement}

Parameters of emotional engagement determine the kind of emotional engagement experienced by people who use a suspenseful application. These parameters include:

Valence - suspense may be primarily hopeful (for example, if one is hoping to win the lottery) or primarily fearful (for example, if one fears being diagnosed with a deadly disease). When using an application, one might feel hopeful that interesting new content or functionality might be revealed, or one might feel fearful that, for example, a mistake will prove impossible to recover from. Most application designers will want to create a positive valence, though the possibility of failure can make some activities more engaging if the risk is not too severe. For example, a training application in which users can fail (but recover) may be more engaging than one in which the user can only succeed.

Vicariousness - suspense may revolve around events in one's own life or events in the life of fictional characters. In an application, emotional engagement may arise from alignment with a user's own hopes and fears, or through identification with a fictional entity of some kind. 
The techniques listed below can be used to increase emotional engagement, and thereby suspense: Sympathetic characters or individuals: suspense in fiction is entirely dependent on an audience's interest in and concern for its characters. If the audience does not care what happens to the characters, suspense is impossible. Sympathetic characters may be incorporated into an application through a fictional narrative or by incorporating real live people that the user cares about into the application.

Team affiliation: people are social creatures, and very much prone to group identification. Just as people feel suspense when a character they sympathize with is threatened, so too they feel suspense when a group that they identify with is at risk of failure or uncertain great success. This technique combines well with competition.

Raising the stakes: the bigger the potential reward and/or potential loss, the greater the suspense. One example of this technique in use is the application $\mathrm{StickK}^{2}$, which gets people to keep working towards their goals (and engaging with the site) by getting them to put significant amounts of real money on the line. If they do not stick to their goal, their money is forfeit.

Communicating the importance of the outcome: many applications deal with intrinsically important problems. However that importance may not be strongly felt from moment to moment. If an application can clearly convey importance, and the critical role in ensuring a positive outcome, the interaction will likely be more emotionally engaging.

\subsubsection{Parameters of Suspense Resolution}

When incorporating suspense into a narrative, it is also important for designers to consider the various ways in which that suspense might be resolved. These parameters are not directly related to uncertainty or emotional engagement, but rather determine the structure and context in which uncertainty and emotional engagement are experienced:

Interactivity - a suspenseful situation may be resolved by working to achieve some task (as in a video game) or simply by waiting and watching (as in a movie). As most applications are highly interactive, it might be expected that any suspense engendered by the application would be resolved

${ }^{2}$ http://www.stickk.com/ 
through the user's actions. However, in cases where the goal is simply to keep someone engaged for a period of time, a more passive reveal may be effective.

Timeframe - a suspenseful situation may be resolved in a matter of seconds (as with a slot machine) or may be spun out over months or years (as in a series of epic fantasy novels). Similarly, an application may create brief moments of suspense simply by revealing information with a theatrical pause and flourish, or it may spin out a mystery over the course of months or years.

In addition, chaining multiple suspenseful interactions together to create an extended narrative or experience may increase or decrease overall suspense. If, in a fictional narrative, the outcome of each smaller suspenseful situation proves to be consistently surprising but logical, the creator both builds trust and makes the story feel more unpredictable. That trust is essential to audience enjoyment: if the audience ceases to believe that a meaningful and logically consistent resolution is forthcoming, emotional involvement may wither, taking suspense with it. Conversely, without surprise, uncertainty may be reduced to nothing, a situation equally as fatal to suspense. Creating a series of resolutions that are both surprising and logical is a difficult task, and likely part of the reason why writing a good suspense story is so challenging.

\subsection{Designing a Suspenseful Tutorial}

While the framework described in the previous sections helps to identify how suspense can be incorporated into a wide variety of applications and online experiences, it is as yet unproven. I chose to begin the exploration and experimental testing of the framework for suspenseful application design by creating a single application: a tutorial built around a simple, suspenseful narrative.

I chose to begin with a tutorial for several reasons. For one, lengthy or complicated tutorials often make people feel uncertain and confused, and then frustrated and demotivated. To make the experience of working through a difficult tutorial more bearable, tutorial designers often try to reduce the experience of uncertainty as much as possible by providing a lot of guidance and clear structure (see section 2.2.2). However, while reducing uncertainty should reduce confusion and lead to greater calm when interacting with the tutorial, it is an approach that also risks making the tutorial boring (Figure 4). This is not a problem if a person has a strong, immediate motivation to work through a tutorial, for example if they are using the tutorial to help complete a task that they already care about. However, if someone is using a tutorial to proactively expand their skills or to experience an expert's workflow (Lafreniere, 2013), they may come to the tutorial with less determination to complete it and 
no clear goal to keep them motivated when they become confused, frustrated, or bored. In these cases, structuring the tutorial to provide additional motivation may be helpful.

This design is an attempt to use suspense to generate that motivation. Instead of trying to minimize uncertainty, I instead added emotionally engaging elements to the tutorial in an attempt to transform simple uncertainty and irritating confusion into enjoyable, captivating suspense. If suspense is a combination of uncertainty and emotional engagement, then adding emotionally engaging elements to a merely uncertain situation should transform it into a suspenseful experience.

To that end, I chose to present the tutorial's instructional content in the context of a simple, suspenseful narrative. This approach had the advantage of building on the already somewhat storylike structure of a typical tutorial: a difficult challenge is presented and the protagonist (or learner) must increase their skills to overcome the challenge, ultimately achieving a decisive victory through cleverness and hard work.

\subsubsection{Tutorial Task}

The tutorial I created teaches participants how to make a 3D animation of a bouncing ball in Blender, an open source 3D modeling application. This task was chosen to be challenging but accessible to novices, an assessment which I confirmed in a series of pilot studies. It was a task that could be completed in less than an hour, but nevertheless one that I expected most participants to struggle with. 3D animation was also an appealing task because (like any animation) it lends itself to storytelling.

The choice of the 3D modeling application Blender was also deliberate, as it exemplifies many of the strengths and weaknesses of complex applications. Experts find Blender to be extremely powerful and efficient, but for novices it can be extremely intimidating ("Blender: easy or hard to learn and use.”, 2012). My intention was to introduce engaging, suspenseful narrative elements to the tutorial that would give learners the extra motivation necessary to push past the initial frustration and intimidation of working with Blender, and ultimately succeed with learning the tool.

\subsubsection{The Story}

Perhaps the most challenging part of building a suspenseful tutorial was creating a story that people would find emotionally engaging. The motivating story was designed to be simple enough that it could be conveyed quickly, without slowing the study participants down. However, in that brief time, 
the story needed to capture learners' imaginations and sympathies at least enough to influence their behavior.

I designed the tutorial through an iterative process of creating stories, mapping those stories to the tutorial's educational goals, assessing the effectiveness of both story and instructional content, and revising as necessary. The first draft of the story cast the learner as a professional animator with a tight deadline to meet. However, this draft of the story was judged to be both too convoluted and too boring. In my next attempt, I tried to create something simpler and more directly tied to the specific animation learners would be building. Because the animation that the tutorial was focused on involved moving a sphere around a virtual space, I chose to make the sphere, the most active part of the scene, into the protagonist of the story. I created a very simple story in which the sphere would dodge a falling anvil by scooting across the ground, then jump onto a wall to dodge some arrows that were being shot at it. The next iteration made the story even simpler; I eliminated the anvil and wall, leaving only the sphere and arrows. The final story was this: a cute, innocent character - a sleeping red ball - is being shot at by an unknown assailant. Arrows whiz through the air, striking left, striking right, just barely missing the defenseless ball. Just as another, perfectly aimed arrow is about to hit the unfortunate ball in its face, time freezes, and the study participant is given the chance to save the ball, by making it jump out of the way of the oncoming arrow. But to do that, they must learn to master some of Blender's basic animation tools.

This story has a suspenseful structure and heightens emotional engagement through three of the suspenseful design techniques mentioned in Section 3.2.2. Concern for a sympathetic character is created through the character of the innocent, cute, and goofy red ball. The stakes are raised by putting the ball in mortal peril, where the learner's success will be the ball's salvation, their failure will be the ball's doom. Finally, the introductory video communicates importance directly by telling the learner outright "Only you can save [the ball]". Uncertainty arises naturally from the tutorial format, and by putting the ball's fate in the learner's hands. 


$\leftarrow \quad \mathrm{C}$ Blender Tutorial

\section{Blender Tutorial}

\begin{tabular}{|l|l|}
\hline Welcome \\
\hline Introduction \\
\hline Welcome to Blender \\
\hline Navigating the Timeline \\
\hline Inserting Keyframes \\
\hline But Wait... \\
\hline Lattices \\
\hline Creating Shape Keys \\
\hline Animating With Shape Keys \\
\hline Rendering Your Animation \\
\hline
\end{tabular}

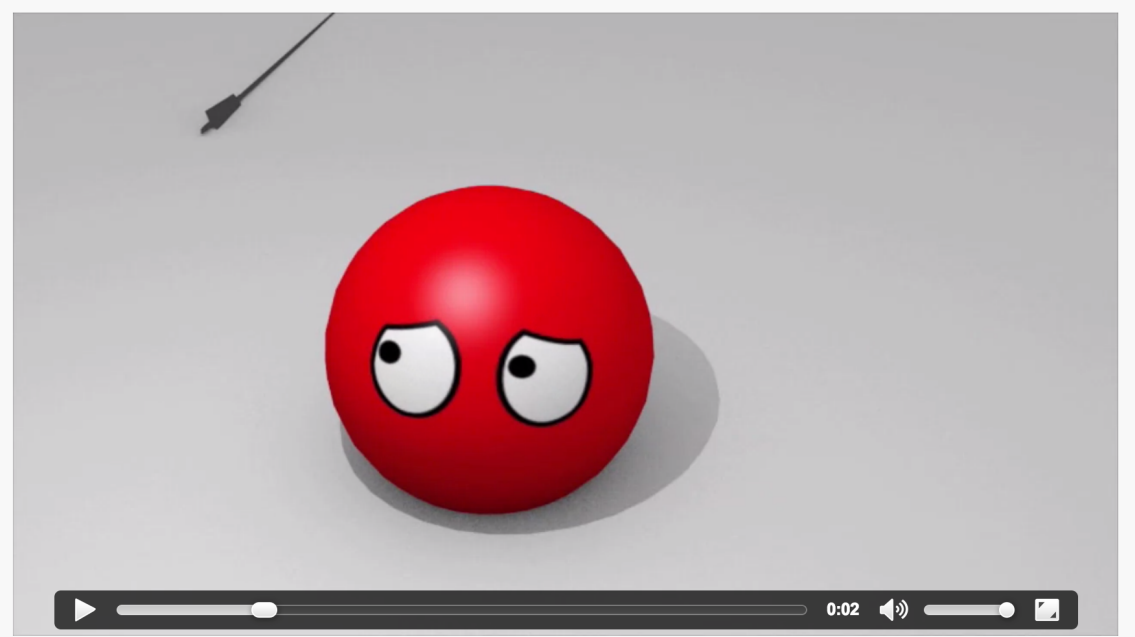

That defenceless red ball is about to be hit by an arrow! But you can help him jump out of the way using the power of Blender.

\section{Begin}

Figure 5. In the story condition, the tutorial begins with a video of the personified ball about

\section{to be shot.}

The story was primarily communicated through a brief movie that preceded the main text of the tutorial (Figure 5). The movie included dramatic music and thunderclaps to further increase tension. A brief movie format was chosen because it is a quick, efficient way to convey action and personality, and because the final product of the tutorial was going to be a $3 \mathrm{D}$ animated movie, which was thus foreshadowed.

The tutorial text was presented in a traditional tutorial format: numbered steps in the imperative mood, interspersed with screenshots and occasional animated GIFs. The tutorial was constructed using excerpts from the Wikibook "Blender 3D: Noob to Pro" (2013) and an online tutorial (Motion Module, 2013), edited and expanded for clarity and to match the version of Blender being used. The text was minimalist and factual, with numbered steps illustrated with screenshots from Blender. However, the narrative frame was reinforced in small ways through task phrasing. For example, the story-based tutorial introduced the section on frames and keyframes as follows: 
You can use Blender's animation tools to move the red ball out of the path of the oncoming arrow. However, before you begin animating, you need to learn about how 3D animation works, starting with the concept of frames and keyframes.

The tutorial starts out using basic keyframe animation to move the sphere straight up and down, and gets more complicated as it goes along, introducing lattices, object deformation, and squash and stretch animation.

Midway through, after successfully moving the ball upwards, there is a brief twist that changes the focus of the suspense from dodging the arrow to making a safe squishy landing. This foregrounds the narrative element and motivates the second half of the tutorial, which deals with squashing and stretching objects.

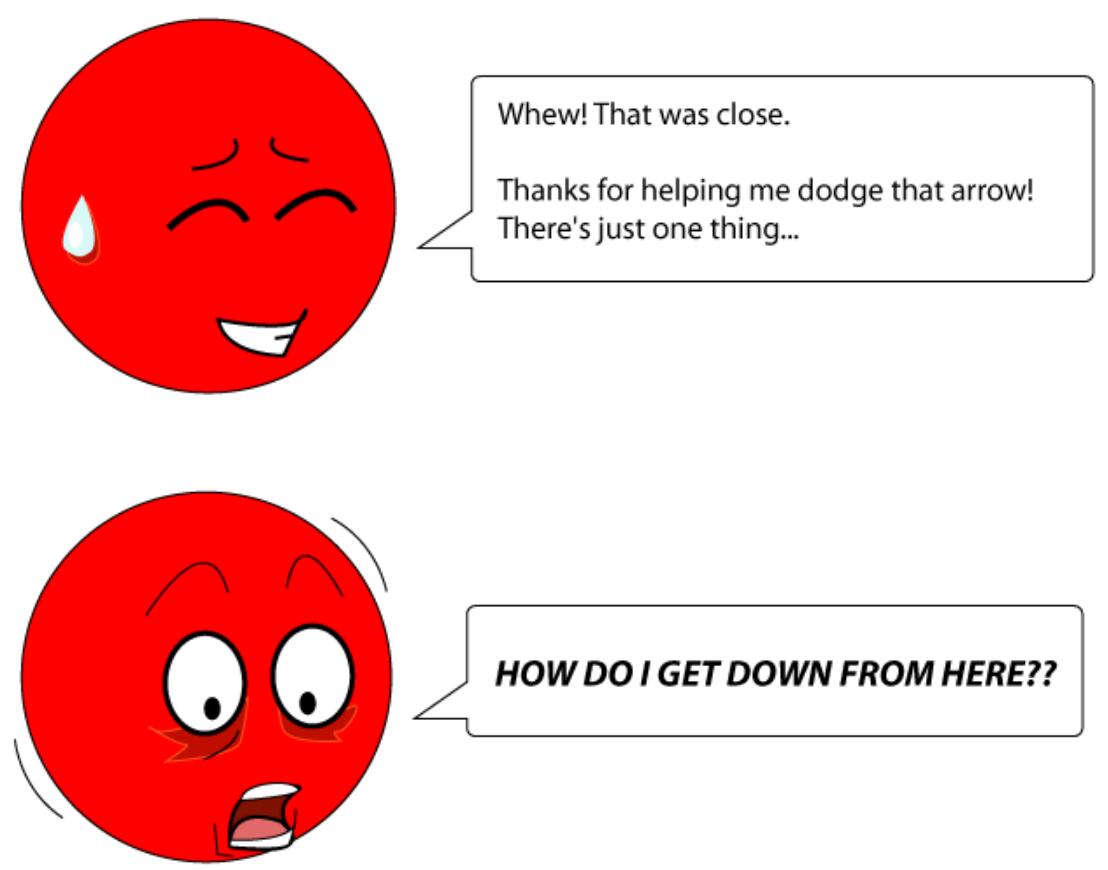

Figure 6. Transitioning from making the ball jump to giving it a safe, squishy landing. 


\subsection{Implementation}

The tutorial was presented as a series of web pages, created using the Angular Dart ${ }^{3}$ web framework. A navigation bar at the left side of the browser window, shown in Figure 4, enabled participants to return to earlier pages for reference, but did not allow them to jump ahead as pages in the navigation bar had to be unlocked in linear order, on

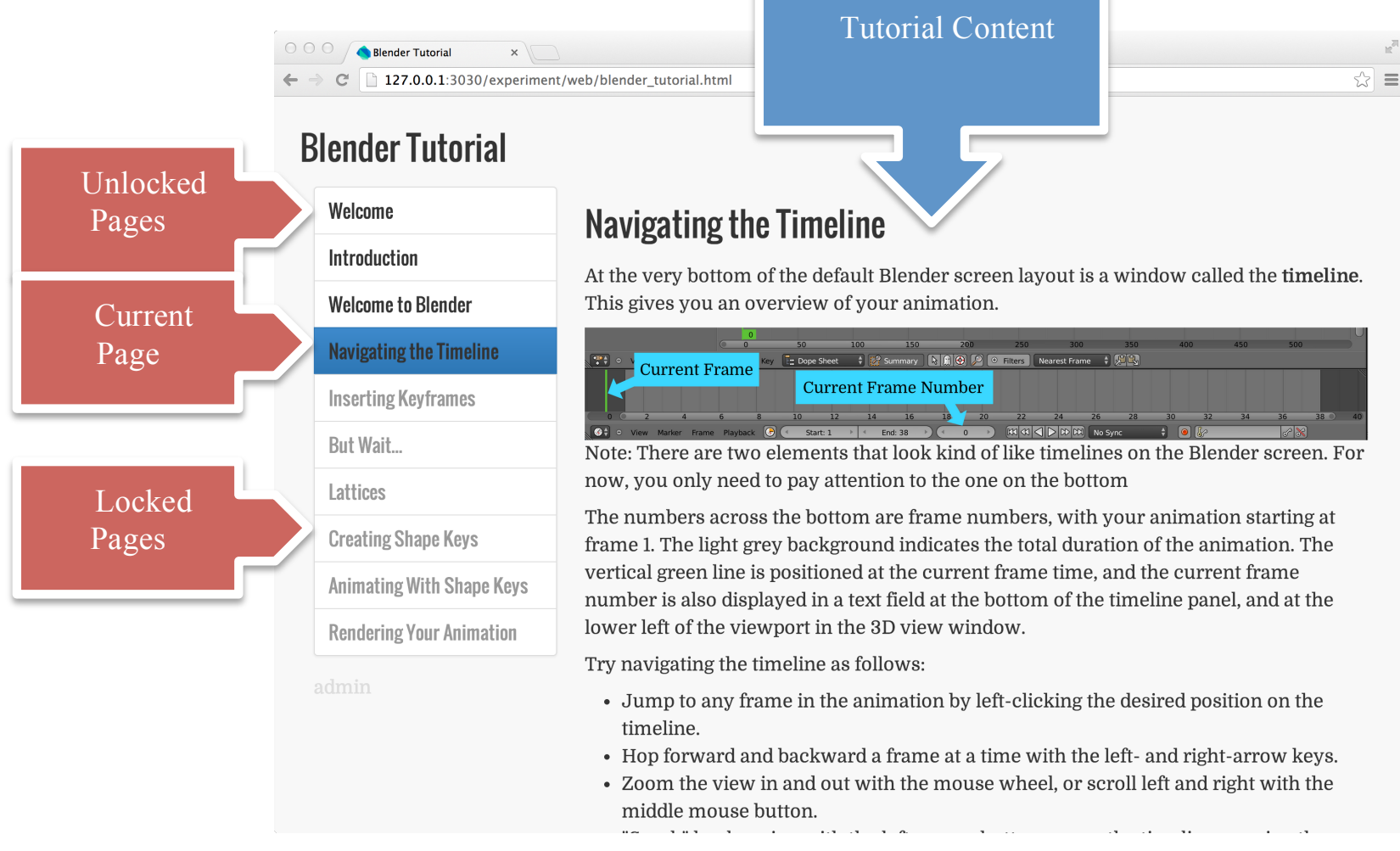

Figure 7. Tutorial navigation

${ }^{3}$ https://angulardart.org/ 


\section{Chapter 4 \\ Study: Suspense in Tutorials}

In this chapter I describe a laboratory study I conducted to evaluate the effectiveness of the suspenseful tutorial described in Chapter 3. The study was designed to investigate the relationship between the tutorial's narrative elements and the intrinsic motivation of study participants.

I compared the effects of the suspenseful tutorial to two baseline conditions: a tutorial without a story frame or introduction, designed to create an experience of high uncertainty and low emotional engagement, and a tutorial without a story but with a clear explanation at the beginning of what the tutorial would teach people to build, designed to lower uncertainty relative to the no intro condition without affecting emotional engagement. The intention of this study was to determine whether presenting tutorial instructions in the context of a suspenseful narrative would increase participants' intrinsic motivation to complete the tutorial relative to these other two more traditional tutorial formats.

\subsection{Participants}

Forty-one participants took part in the study, 14 female and 27 male. Participants were recruited from the local community and through the University of Waterloo graduate studies mailing list. Participants' ages ranged from 18-42 years $(M d n=24) ; 12(29 \%)$ participants had some prior experience with 3D modeling software, and $13(32 \%)$ had some experience with animation software. One participant had previous experience with Blender, but had only used it to create primitive solids such as cones and spheres for use in a class assignment.

\subsection{Design \& Conditions}

The primary factor in this study was tutorial type. I created three tutorials for the 3D modeling application, Blender. All three versions of the tutorial guided participants through the process of creating a simple 3D animation. The tutorials in all three conditions were made as similar as possible, presenting the same steps in the same order (Figure 6). They differed only in the way the tutorial content was introduced and framed. 


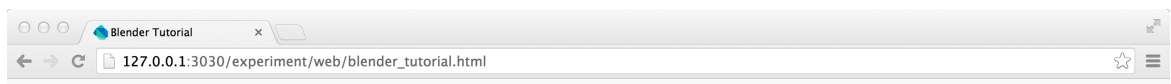

\section{Blender Tutorial}

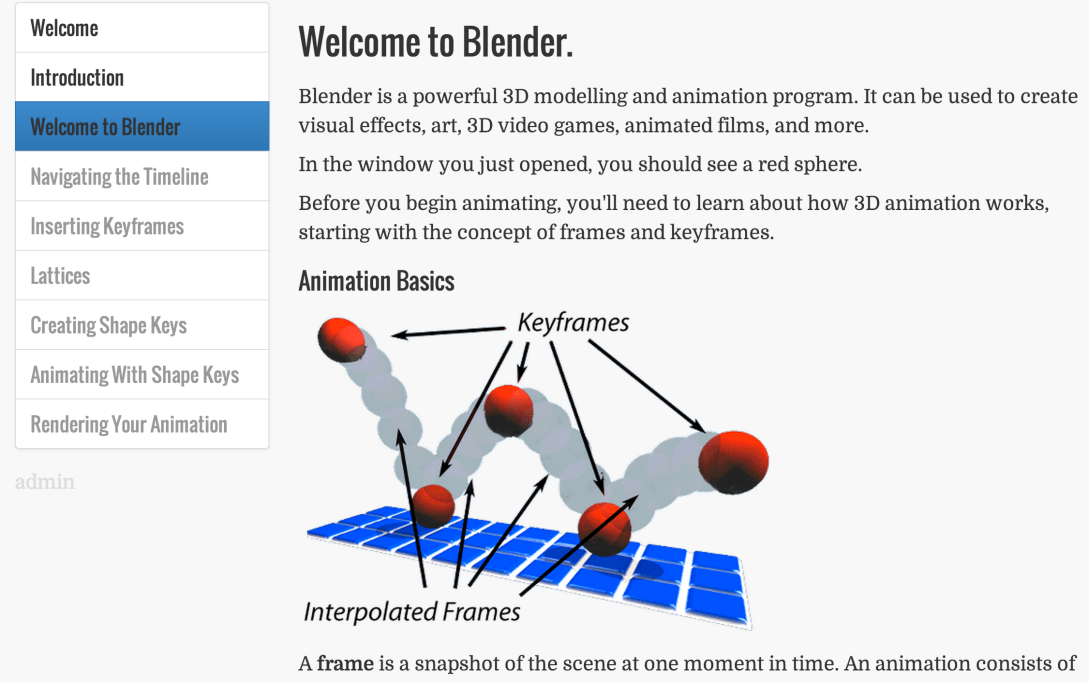

\section{Figure 8. Screenshot of the tutorial instructions.}

The three tutorial types were as follows:

Story: The story-based tutorial, described in Chapter 3, incorporated a suspenseful video introduction and occasional mentions of the story in the text of the tutorial. In this condition, emotionally engaging elements were included to create a more suspenseful experience.

No Intro: In this condition, participants were provided with a sequence of steps without any introduction, narrative frame, or information about what it is that they would be building. This tutorial type was included because it provided a minimalist baseline against which the other conditions could be compared, and because it is a condition in some confusion would be expected. This is the high uncertainty, low emotional engagement condition (Figure 9).

Preview: In this condition, the tutorial began by showing participants a video of the animation they would be making, without any narrative frame, and then provided participants with the same sequence of tutorial steps as in the other conditions. This tutorial type was included because it is a very common format for tutorial instruction, in which uncertainty is reduced, with the intention of creating a more calm (or boring) experience (Figure 9). 


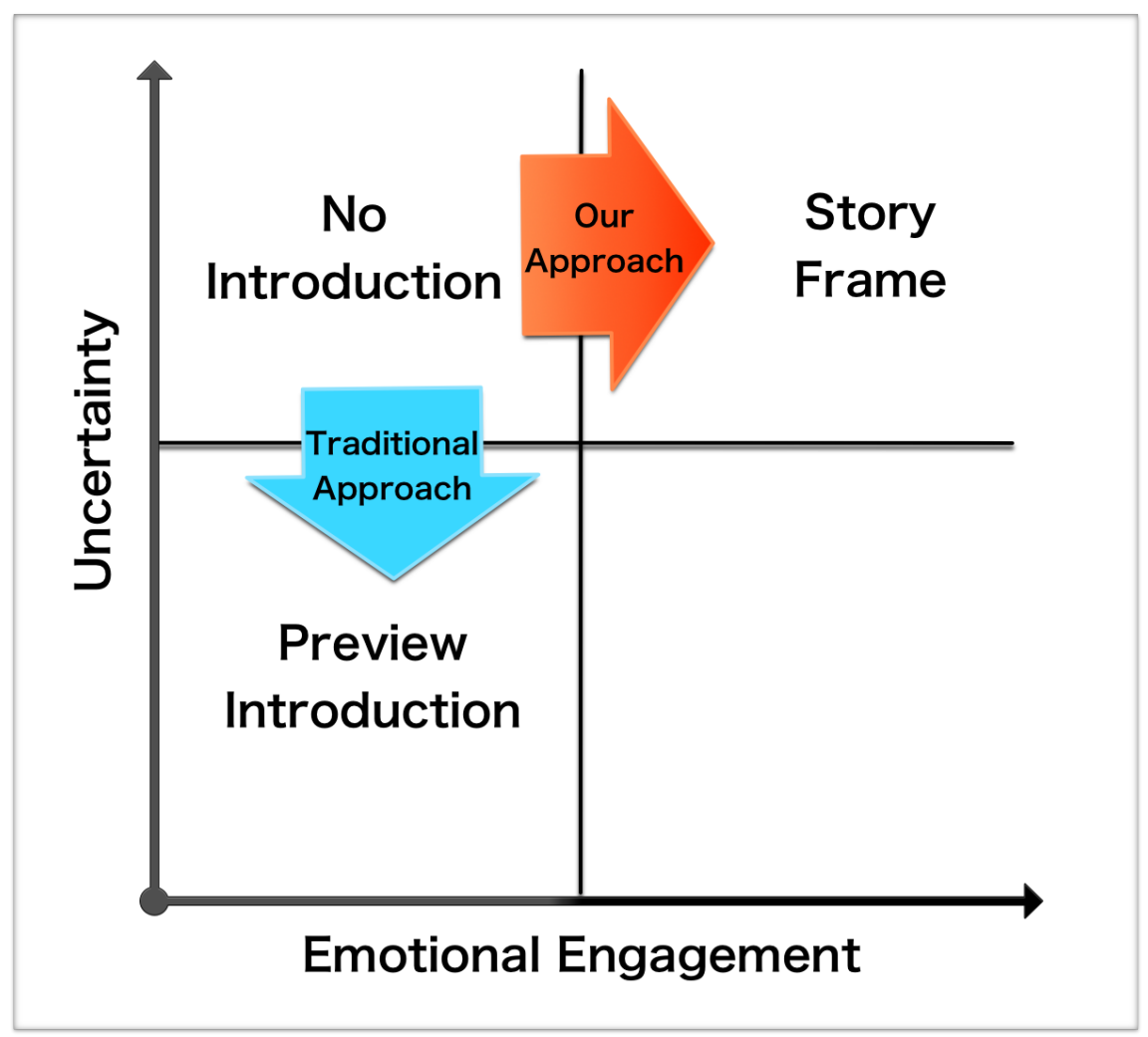

Figure 9. The story-based tutorial was designed to increase emotional engagement while the preview condition was designed to decrease uncertainty.

I also incorporated the secondary factor of tutorial stage in the study design. In each tutorial stage, participants were presented with a new (and, with the exception of stage 5, increasingly difficult) concept followed by a short questionnaire measuring suspense and flow (Figure 10). This factor was included because I expected that feelings of suspense and motivation might fluctuate over the course of the tutorial.

I used a mixed design with between-participants factor tutorial type (each participant only experienced one type) and within-participants factor tutorial stage, with stages $1-5$ in the same order for all participants. 


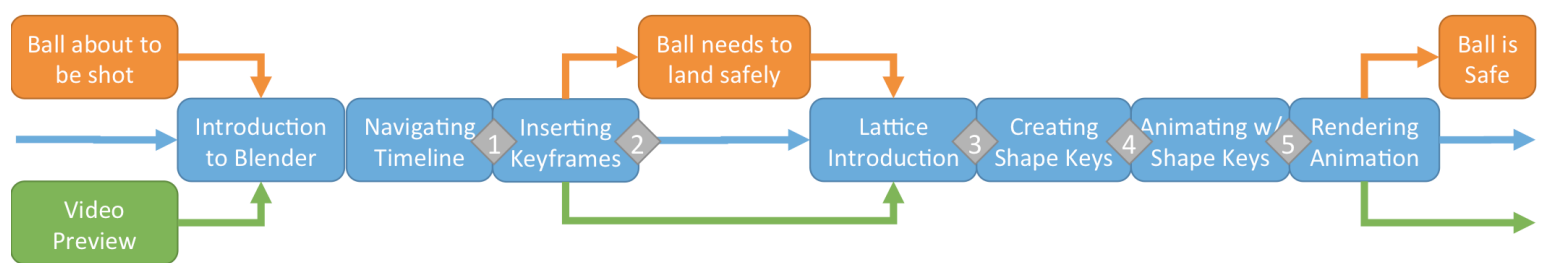

Figure 10. Progression of tutorial in story (orange, top), no intro (blue, middle), and preview (green, bottom). Questionnaires were presented between each major stage (grey, numbered diamonds).

\subsection{Apparatus}

Study participants worked through the tutorial on a 15 -inch $2880 \times 1800$ pixel MacBook Pro laptop connected to an external 15 -inch $1920 \times 1080$ pixel monitor and a mouse with scroll wheel. Blender was displayed on the external monitor, while the tutorial and questionnaires were displayed on the laptop.

\subsection{Measures}

After finishing each stage of instruction, participants were asked to fill out a 29-question questionnaire to gauge their experience of suspense, flow, perceived outcome importance, and desire to continue. Specifically, participants were asked to fill out Moulard's suspense scale (Moulard et al., 2012) and the flow short scale (Rheinberg \& Vollmeyer, 2003). Participants were also asked if they "would be upset if the tutorial ended now". At the end of the session, participants completed the intrinsic motivation inventory (Plant \& Ryan, 1985), and provided subjective feedback on their experiences through open-ended written survey questions.

\subsubsection{Moulard's Suspense Scale}

Moulard's suspense scale (Moulard et al., 2012) asks participants to rate their feelings of hopeful suspense, fearful suspense, and valence-neutral suspense using a 7-point Likert scale. Hopeful suspense was probed by the following statements: "I feel eager", "I feel excited", "I feel enthusiastic", and "I am looking forward to what happens next." Fearful suspense was probed by the statements "I am afraid", "I am frightened", “I am petrified", and "I feel fear". Valence-neutral suspense was probed by the statements "This is a tension-filled experience", "This is a gripping experience", "I am on the edge of my seat", and "This is a nail-biting experience". 


\subsubsection{Flow Short Scale}

Flow theory posits that people are intrinsically motivated by flow experiences - states of intense concentration in which the mind is wholly fixed on a particular task to the exclusion of all else. Flow is more likely in situations that involve clear goals, immediate feedback, and challenges just at the limit of a person's abilities (Csiksczentmihalyi et al., 2004). The flow short scale (Engeser \& Rheinberg, 2008) measures fluency of performance, absorption by activity, perceived importance of outcome, and perceived fit of demands and skill. Sample questions include: "I know what I have to do each step of the way" (performance fluency), "I do not notice time passing" (activity absorption), "I must not make any mistakes here" (outcome importance), and "Compared to all other activities which I partake in, this one is... Easy - Difficult" (skill fit).

\subsubsection{Intrinsic Motivation Inventory (IMI)}

According to self-determination theory, people are intrinsically motivated by activities that satisfy their needs for autonomy, competence, and relatedness (Ryan \& Deci, 2000). To measure this form of intrinsic motivation, I used the intrinsic motivation inventory (Deci \& Ryan, 1985), a validated scale measuring interest/enjoyment, perceived competence, effort, and tension. Example statements include "I would describe this activity as very interesting" (interest/enjoyment), "I think I am good at this activity" (perceived competence), "I tried very hard on this activity" (effort), and "I was anxious while working on this task" (tension).

\subsection{Hypotheses}

My hypotheses were as follows:

Hypothesis 1. Participants would experience more suspense (hopeful, fearful, and/or neutral) in the story condition than either the preview or no intro conditions.

a) Participants would experience more uncertainty in story and no intro, but not in preview.

b) Participants would experience more emotional engagement in story than either preview or no intro.

Hypothesis 2. Participants would be more intrinsically motivated to continue in the story condition than in the other two conditions. 
Hypothesis 3. The effects of suspense and motivation would vary over the duration of the tutorial (e.g., as suspense is introduced or resolved across stages 1-5).

I tested $\mathrm{H} 1$ using the suspense scale, and separated $\mathrm{H} 1 \mathrm{a}$ and $\mathrm{H} 1 \mathrm{~b}$ using subscales from the flow short scale of absorption by activity, perceived importance of outcome and using the interest/enjoyment subscale of the IMI. I used the remaining flow and IMI subscales to test H2.

\subsection{Study Results}

Participants' time to completion varied greatly ( $M d n=40 \mathrm{~min}, M i n=22 \mathrm{~min}, M a x=66 \mathrm{~min})$. In contrast to the pilot studies, several participants found the tutorial to be excessively challenging; some had a great deal of difficulty following the tutorial, repeatedly skipping or misinterpreting important steps. To reduce statistical noise resulting from the overwhelming confusion and frustration experienced by these participants, the 8 participants who took more than 50 minutes (advertised maximum time of study) to complete the instructional part of the tutorial have been removed from the following analysis.

I analyzed data from the remaining 33 participants using a 3 (tutorial type, between) $\times 5$ (tutorial stage, within) repeated measures analysis of variance (RM ANOVA) for each measure in the suspense, flow, and IMI scales. For all tests performed, there were four main effects and one interaction effect that were significant ( $p>.07$ for the remaining 26 main effects and 14 interactions). The Bonferroni correction was used in all post-hoc analyses to correct for the large number of measures.

\subsubsection{Experience of Suspense (H1)}

I hypothesized that participants in the story condition would experience more suspense than those in the preview and no intro conditions. In accordance with the theoretical model of suspenseful design outlined in Chapter 3, I expected that participants in the story and no intro would experience more uncertainty than those in the preview condition, and that participants in the story condition would experience more emotional engagement than participants in the preview or no intro conditions.

This hypothesis was partially confirmed: there was a significant main effect of tutorial type on participants' experience of the 'hope' component of suspense $\left(F_{2,30}=3.7, p=.04\right.$, Figure 7). However, no significant difference was found in reported 'fear' $\left(F_{2,30}=.1, p=.90\right)$ or valence-neutral suspense $\left(F_{2,30}=2.8, p=.08\right)$. 
Pairwise comparisons showed that the story condition $(M=5.4, S E=0.2)$ produced marginally higher hopeful suspense than the preview condition ( $p=.06, M=4.7, S E=0.2)$, as predicted by H1. The no intro condition was not significantly different than either the story $(p>.99)$, or preview $(p=.12)$ conditions.

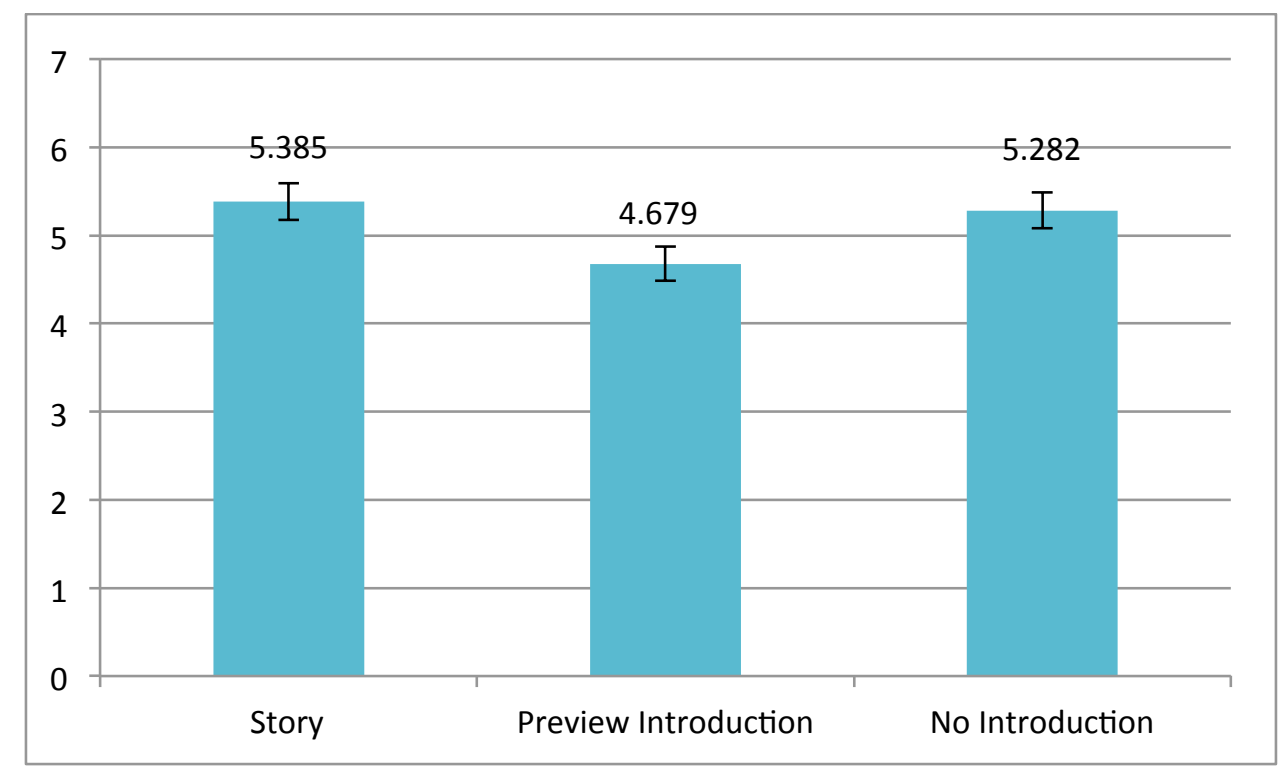

Figure 11. Participants in the story condition reported significantly greater hopeful suspense than those in the preview condition. Error bars display standard error (SE).

At first glance, the fact that only the measure of hopeful suspense was significantly different between conditions would seem to indicate that the story condition only increased positively valenced, hopeful suspense. However, it is worth noting that the questions measuring fear were worded quite strongly, so small changes in negatively valenced or neutral suspense, such as mild concern for the ball, may have gone undetected. In addition, some participants who spoke English as a second language may not have fully understood some of the more colloquial statements in the questionnaires. In particular, several participants asked for explanation of the statements: "I am on the edge of my seat", "this is a nail-biting experience", and "I am petrified".

The lack of significant difference in reported hopeful suspense between the story and the no intro conditions may be because participants in the no intro condition were not told what they were meant to be creating, and that uncertainty combined with the emotional engagement inherent to the task and 
setting to give rise to a feeling of suspense. Participants might wonder "what am I building?", "how might the work I've done so far fit into a bigger and more complicated final animation?", and "how will I recover if I make a mistake?” These questions may have been enough to bump their reported hopeful suspense up to a range close to that experienced by participants in the story condition.

\subsubsection{Experience of Motivation ( $\mathrm{H} 2)$}

My second hypothesis was that participants in the story condition would be more intrinsically motivated to continue working through the tutorial than those in the other two conditions. I was unable to confirm this hypothesis. Participant responses to the flow short scale and IMI did not reveal a clear link between the story condition and intrinsic motivation as measured by the Flow Short Scale (Fluency: $F_{2,30}=2.0, p=.15$; Absorption: $F_{2,30}=1.7, p=.20$; Outcome Importance: $F_{2,30}=4.6, p=.02$; Skill Fit: $F_{2,30}=1.3, p=.28$ - see Section 4.6.5 for post hoc analysis of outcome importance) or IMI (Interest/Enjoyment: $F_{2,30}=.9, p=.41$; Perceived Competence: $F_{2,30}=.8, p=.46$; Effort/Importance: $F_{2,30}=1.6, p=.22$; Pressure/Tension: $F_{2,30}=.1, p=.90$; Perceived Choice: $F_{2,30}=.1, p=.93$; Value/Usefulness: $F_{2,30}=1.1, p=.35$; Relatedness: $F_{2,30}=1.5, p=.23$ ), nor was there a statistically significant difference in agreement with the statement "I would be upset if the tutorial ended now" $\left(F_{2,30}=.6, p=.55\right)$. While it's possible that there was simply no effect of suspense on motivation, it's also very possible that there was a motivational effect that was not captured by the measures used in this study. For instance, the story may have provided a kind of extrinsic motivation, making participants eager to complete the tutorial not because they were intrinsically motivated, but because the story provided extrinsic motivation in the form of tense uncertainty they wanted to see resolved. It is also possible that the story was insufficiently engaging to have a measurable effect on emotional engagement or that a small effect may have been obscured by statistical noise resulting from betweenparticipants comparisons.

The significant difference in perceived importance of outcome (demand) as measured by the flow short scale is discussed in greater detail in section 4.6.5.

\subsubsection{Changes by Stage (H3)}

A two-way, RM ANOVA was performed to gauge the effect of tutorial stage on suspense, flow, and desire to continue. Mauchy's test indicated that the assumption of sphericity had been violated for 
all measures of suspense and flow, therefore degrees of freedom were corrected using the Greenhouse-Geisser estimates of sphericity.

This analysis revealed a significant effect of stage on fluency $\left(F_{3.2,95}=4.1, p=.008, \varepsilon=.79\right)$ and skill

fit $\left(F_{2.4,73}=3.1, p=.04, \varepsilon=.61\right)$. Specifically, a post-hoc analysis revealed that during stage 4 , the most difficult stage, participants were more likely to report that the tutorial was difficult $(M=3.9)$ than during stages $1(M=3.4, p=.03, S E=.14), 3(M=3.6, p=.005, S E=.07)$, and $5(M=3.4, p=.002, S E=.11)$. This is unsurprising, as the tutorial was designed to start out easy and get increasingly more difficult and consequently more frustrating, with difficulty peaking in stage 4. Participants also reported less fluency in stage $4(M=4.5)$ than in stage $5(M=5.3, p=.003, S E=.20)$, perhaps because the very last stage, in which participants complete their animation, is simpler to follow than stage 4 and provides more immediate and rewarding feedback.

No significant effect of stage was found on absorption $\left(\mathrm{F}_{2.8,85}=2.2, \mathrm{p}=.10, \varepsilon=.71\right)$, outcome importance $\left(\mathrm{F}_{1.8,53}=.33, \mathrm{p}=.70, \varepsilon=.44\right)$, desire to continue $\left(\mathrm{F}_{4,120}=1.7, \mathrm{p}=.17\right)$, or any measure of suspense (Fear: $F_{1.7,50}=.48, p=.59, \varepsilon=.42$; Hope: $F_{2.3,70}=.76, p=.49, \varepsilon=.58$; Valence-neutral suspense: $F_{2.0,59}=.32, p=.73, \varepsilon=.49$ ).

\subsubsection{Interaction effects (stage * tutorial type)}

A single significant interaction effect between stage and condition was found for the dependent variable fluency $\left(F_{6.3,95}=2.3, p=.04, \varepsilon=.79\right)$. Post-hoc analysis of the interaction effect on fluency shows that in the story condition, and only in the story condition, there is a significant difference between stage 4 and stages $1(p=.02, S E=.45), 2(p=.01, S E=.47)$, and $5(p=.01, S E=.36)$. No other pairwise comparison was significant $(p>.12)$. This effect is shown below: 


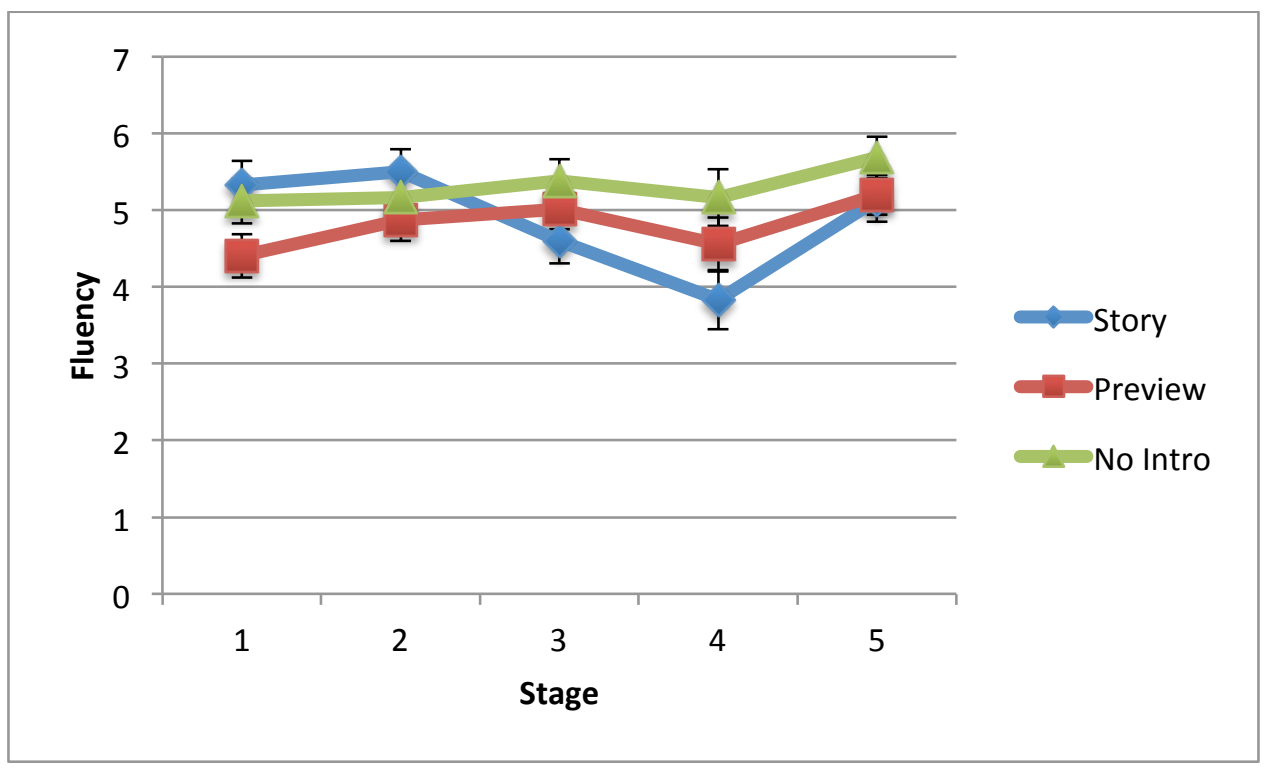

Figure 12. Interaction effect of stage and condition on fluency. Error bars display standard error $(S E)$.

The exact cause of this effect is unclear. Stage 4 of the tutorial is the most difficult stage, requiring participants to perform multiple mode switches and selections, as well as requiring participants to exercise their own subjective judgement about how best to manipulate the 3D sphere to create a "squish" effect. It is presently unclear why participants in the story condition reacted more strongly to this difficulty than those in the other conditions or why they bounced back so completely in stage 5 . It's possible that the addition of story to the tutorial may have increased the total cognitive load of the tutorial, making it more difficult for study participants to simultaneously cope with the difficult late section of the tutorial while also keeping the story in mind. Alternately, it may be that on some level the cartoonish narrative led participants to expect that the tutorial would be an entirely easy and fun experience, leaving them unprepared for the hard work required to successfully complete the later stages of the tutorial. However, this is mere conjecture, and the effect could easily have some other, completely different cause; further study is required to determine the true cause of this interaction effect.

No other significant interaction effects were found. (Fear: $F_{3.3,50}=.62, p=.59, \varepsilon=.62$; Hope: $F_{4.7}$, $70=.74, p=.49, \varepsilon=.59$; Valence-neutral suspense: $F_{4.0,59}=.43, p=.78, \varepsilon=.49$; Absorption: $F_{5.7,85}=1.6$, $p=.15, \varepsilon=.71$; Demand: $F_{3.5,53}=.60, p=.64, \varepsilon=.44 ; F_{4.9,73}=.23, p=.04, \varepsilon=.95$; Desire to continue: $F_{8}$, $120=1.2, p=.31)$ 


\subsubsection{Flow: Perceived Importance of Outcome}

Although it was unexpected, I found a significant main effect of tutorial type on perceived importance of outcome $\left(F_{2,30}=4.6, p=.02\right)$. Post-hoc analysis revealed that participants in the no intro condition $(M=3.2, S E=0.2)$ reported significantly higher $(p=.02)$ perceived outcome importance than those in the preview condition $(M=2.3, S E=0.2)$. No other pairwise difference was significant $(p>.05$, Figure 7).

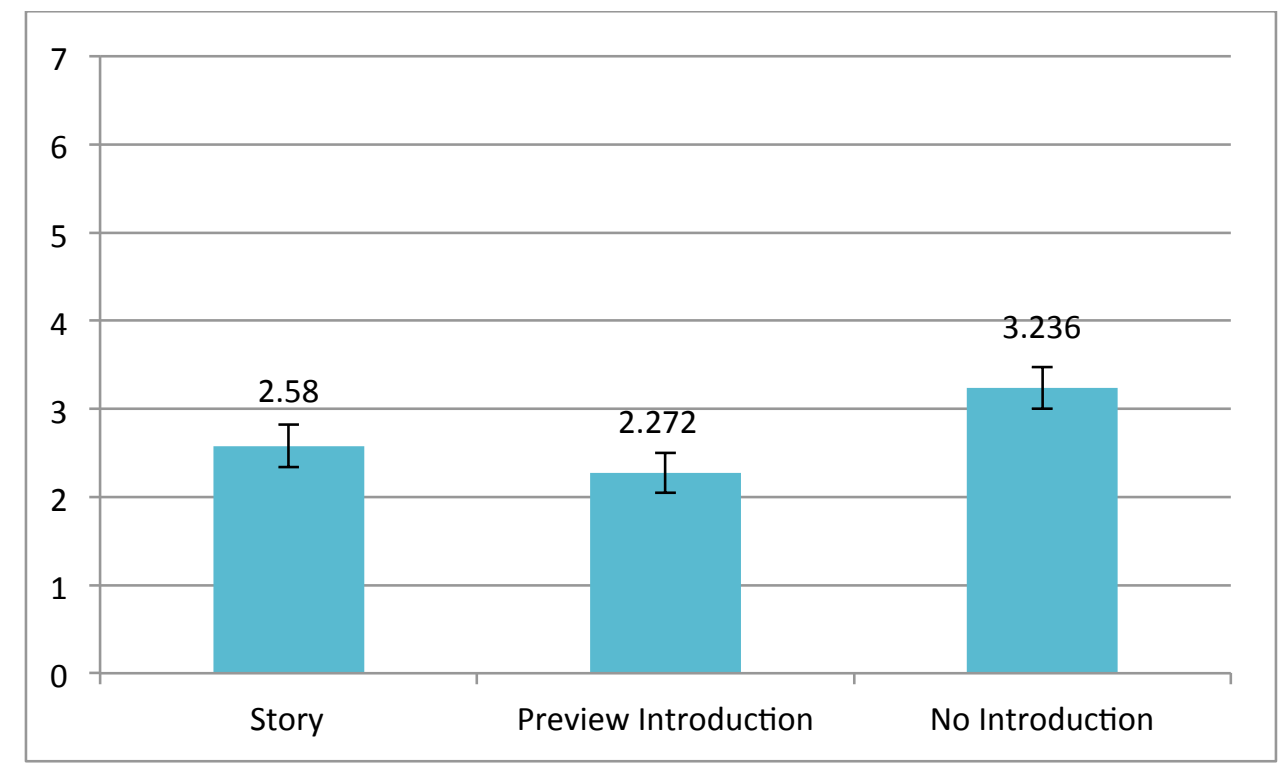

Figure 13. Participants in the no intro condition reported significantly greater perceived importance than those in the preview condition. Error bars display standard error $(S E)$.

This result partially confirms H1a, as participants in the no intro condition did not know what they were supposed to be building, which increased uncertainty. That uncertainty may have caused the participants to worry that any mistake they made might completely derail their attempt to build theknew-not-what, as without a sense of the final goal it would be more difficult for them to evaluate whether they were on track to successfully complete the tutorial. This theory is somewhat confirmed by comments left by participants in the no intro condition: "I think for each step, give the learner an ultimate goal (e.g. what results we will see after finishing this chapter) will help us understand what we are doing", "It is a bit distracting at the beginning of the tutorial since I have no experience with 
the software at all. I went back a bit since I felt I missed some steps, while I actually didn't", and "not enough pics to check if you've done it right."

\subsubsection{Subjective Feedback}

Participants in the story condition demonstrated a wide range of attitudes. Some seemed affected by sympathetic qualities of the ball. Asked what they liked about the tutorial, responses included: "The eyes on the ball's face" and "The purpose of the lesson of saving the poor ball from impending doom". Other participants in the story condition mentioned the aesthetic ("cute") qualities of the animation, perhaps implying a degree of emotional engagement with the ball character. For example: "Cute animation made it more exciting, and the step-by-step instructions were clear" And "It was cute and simple".

One participant in the story condition liked that tutorial task was grounded in a semi-realistic scenario involving recognizable physical objects that might be relevant in other contexts: "I liked the goal driven part that goes over some common things that you would want to do for a simple animation. Like that of a rubber ball bouncing. There were also flying arrows that I feel I could create myself now." In addition, the one participant in the study who requested that their completed animation be emailed to him; this participant worked through the story condition, which may imply a degree of emotional attachment.

Not all participants in the story condition found the story elements notable. One participant did not even wait for the introduction video to finish before skipping ahead to the next step. However, participants that were not interested in the story seemed to appreciate other aspects of the experience, such as the experience of creating (e.g., "the new experience I had in 3D modeling and learned about this Blender software") or the clarity of the instructions (e.g., "The tutorial provided clear step-bystep instructions which I found mostly easy to follow.", "It's pretty clear"). Interestingly, one of the participants who did not mention the story elements as a notable positive element suggested that "a game to begin would have set the tone". The short, narrative movie shown prior to the tutorial may have been insufficient to capture this participant's imagination, while a more interactive, game-like presentation of the narrative may have drawn them in more effectively. 


\subsubsection{Summary of Findings}

Although I was only able to confirm one of my three hypotheses, the results of the study indicate that even a simple narrative can increase people's experience of hopeful suspense, as characterized by agreement with statements such as "I felt eager", "I feel enthusiastic", and "I am looking forward to what happens next". This kind of pleasurable anticipation of a positive event is associated with incentive motivation (Weiner, 2013) and story enjoyment (Brewer \& Ohtsuka, 1988). In addition, the importance of perceived outcome was found to be significantly higher in the no intro condition, as measured by agreement with statements such as "I am worried about failing", which I attribute to increased uncertainty. Finally, in the story condition, and only the story condition, an interaction between tutorial stage and fluency was observed, with participants in the story condition reporting a sharp drop in fluency during the challenging stage 4 and complete recovery in stage 5 .

Although participant responses to the flow short scale and IMI did not indicate a significant difference in intrinsic motivation between conditions, these combined results at least suggest that the story-based prototype was successful at shifting participants from being uncertain about their task, to being emotionally engaged and experiencing suspense. 


\section{Chapter 5 \\ Conclusion and Future Work}

\subsection{Conclusion}

Researchers and practitioners in the field of human-computer interaction can learn a lot from the ancient traditions and techniques of storytellers. Storytelling and interaction design are both fundamentally about crafting experiences, but storytelling is a much older and better-understood area of study, and has already been subjected to many generations of refinement. Like storytellers, interaction designers can use suspense to hold an audience's attention, persuading people to wait or work to reveal a satisfying resolution.

This thesis makes three significant contributions to the field of human-computer interaction. First, it introduced a new theoretical framework for understanding suspense and designing suspenseful applications. This framework, based on prior research on suspense, explains how uncertainty and emotional engagement can be used to create suspenseful interactions, and in what circumstances that might be beneficial. Next I described the design of a 3D animation tutorial that incorporated a suspenseful narrative. This tutorial serves as a case study for how the framework for suspenseful application design might be applied to a real world use case. Finally, I described the results of a study that compared the story based tutorial to two more traditional tutorial designs. This study indicated that participants in the story condition, who learned from the tutorial that incorporated narrative elements, reported greater hopeful suspense than those who used traditional tutorials that included a preview of the tutorial's final product. That is, they were more likely to agree with statements such as "I felt eager", "I feel enthusiastic", and "I am looking forward to what happens next". I also found an interaction effect of tutorial stage and condition on fluency, with participants in the story condition reporting a sharper decline in perceived fluency during the most difficult sections of the tutorial, the cause of which is unclear. Finally, I found that participants who were not given a clear goal or preview of the end result reported greater perceived outcome importance, being more likely to agree with statements such as "I am worried about failing". Though I did not find a clear link between suspenseful design and known measures of intrinsic motivation (specifically, the Flow Short Scale and the Intrinsic Motivation Inventory) my results seem to suggest that including narrative elements to increase suspense may have a positive effect on user interest and engagement. Future work is needed to determine the full effects of narrative and suspense on engagement and motivation. 


\subsection{Limitations}

There are several respects in which both the framework for suspenseful design and the results of the study are quite limited. The framework, while supported by theory, has not truly been experimentally validated as an interaction design tool. The experimental study addressed just one kind of suspense in just one context, and the results of the study were ambiguous; on its own, the study is not a sufficient test of the design framework.

There are several more limitations associated with the experimental study. I was unable to demonstrate a connection between suspenseful, story-based design and either flow or selfdetermination theory's measures of competence, autonomy, or relatedness. It is unclear whether this is because no such connection exists or because the study was insufficiently powered to detect the effect.

Overall, the study results were very noisy, making it easy for results to be obscured by the differences between participants. Participants varied a great deal in tech savvy, language skills, and seeming interest in the tutorial's story, and the between-participants study design made it very difficult to correct for those differences. While this problem was somewhat mitigated by excluding data from participants who were so overwhelmed by the complexity of the tutorial that they were unable to complete it in the allotted 50 minutes, that exclusion is itself an unfortunate distortion in the data.

In addition, the questionnaire used to measure suspense (Moulard et al., 2012) may not have been sensitive enough to measure mild feelings of fearful suspense. A modified version of the questionnaire that measures simple concern, rather than strong fear, might have been more effective. Furthermore, the questionnaire's use of colloquial expressions was also a source of confusion for some non-native English speakers.

The study may also have been hampered by the fact that the creators of the story-based tutorial were not professional storytellers. It is possible that the story, as presented, was too simple or cartoonish to inspire a strong or fearful suspense, coming across as more goofy and unserious.

Finally, any study of motivation is likely to be somewhat effected by the artificial context of a laboratory experiment. Participants' motivation to continue the tutorial could have been affected by the fact that they were being paid to be there, and the self-report surveys may not have accurately captured the participants' true internal state. 


\subsection{Future Work}

There are many ways in which the work described in this thesis could be expanded or improved upon. To begin with, a revised version of the study described in this tutorial could use a withinparticipants study design to eliminate some of the statistical noise that resulted from participants' very different levels of comfort with technology and interest in narrative. Physiological measures of suspense could be used to measure participant reactions perhaps more accurately and less distractingly than was possible with self-report questionnaires. Effects on player motivation might also be measured more accurately if the study could be carried out outside of a laboratory setting or over longer spans of time; for example, if both suspenseful and non-suspenseful tutorial materials were made available online for anybody to use, and user engagement with the material over time was automatically tracked. This would be a more natural setting for tutorial use, and it would avoid the powerful extrinsic motivations inherent to a laboratory-based experimental setup.

Furthermore, while the results of the study do not rule out the possibility that suspense may have motivational effects, perhaps acting as a kind of extrinsic motivation rather than a form of intrinsic motivation, there is much more work that needs to be done to show definitively whether or not this is the case. A follow-up study could ascertain whether suspenseful design induces a state of extrinsic motivation and, if so, the extent to which that extrinsic motivation is internalized (Ryan and Deci, 2011). If adding suspense is shown to result in greater extrinsic motivation, it might also be useful to investigate whether it also causes a resulting decrease in intrinsic motivation, as other forms of extrinsic motivation have been shown to do. Similar experiments could also be run to measure the effect of suspenseful design on participant interest, enjoyment, and desire to continue.

There is much to be learned about the topic of suspenseful tutorial design in general as well. Given the variability of participant response to the Story condition in the study, it seems likely that some participants may have been highly motivated by narrative and suspense while others couldn't care less. This difference may correspond to differences in "player types" observed studies of online video games, where some players are motivated by story and exploration, while others are motivated by social interaction, achievement, or wanton destruction. It is also likely that some people are motivated only by particular genres of story or by particular methods of presentation (e.g., interactive vs. passive). However, further work is required to determine whether this is indeed the case. 
In addition, alternate methods of increasing the emotional engagement and uncertainty, and consequently suspense, could be tried. For example, a tutorial might by enhanced by "raising the stakes" by giving users the opportunity to win or earn real rewards, by finding connections between the task and the user's personal goals, or by employing countdowns and competitions to increase uncertainty.

Suspenseful application design, taken as a whole, is a huge topic. In Chapter 3 I discussed in brief many different types of suspense and how they might be applied in various contexts. For each of these applications and types of suspense, there could be value in quantitatively and experimentally testing the effects of the added suspense. For example, one could test the extent to which it is possible to heighten the excitement of a competition (against others or a goal) by increasing suspense, and perhaps investigate at what point that pleasant excitement turns to stomach churning stress and anxiety. It would also be very interesting to experiment with using suspense as a means of sustaining interest and engagement with an application in the over long periods of time, say with a health tracking or habit building application. Alternately, one could study of the effects of brief moments of micro-suspense: the computer interface equivalent of waiting for the roulette wheel to stop spinning or for the dice to land.

While suspenseful application design is a vast topic, suspense is still just one aspect of storytelling, albeit an important one. While the fictional narrative used in my story-based tutorial was deliberately made very simple, there are many more complex and subtle ways in which a fictional narrative might be used. For example, in video games it is commonplace for players to choose the protagonist of the game's story and to be actively involved in shaping narrative path along which the story proceeds. These kinds of customizable, non-linear storylines would seem to be a natural fit for other interactive interfaces as well, giving users the opportunity to collaborate with the computer in telling unique and personally meaningful story. Furthermore, just as many stories present events out of chronological order, using flashforwards and flashbacks being to shape the audience's reaction to events, so too unconventional approaches to progressive disclosure, onboarding, and information architecture might be used to increase user interest and evoke particular emotional responses. An application might begin in media res - in the middle of things - dropping new users directly into an intermediate or advanced workflow, then gradually revealing the fundamental beginner concepts that underlie that workflow, or it might enable users to "flashback" to a prior experience or activity. An application 
might use a kind of foreshadowing to hint at advanced functionality or to prepare users for future tasks.

By examining interaction design through the lens of storytelling, it is possible to see many ways in which computer interfaces could evoke powerful emotions, from humor to pathos to exaltation. Interactive experiences could be designed build to a dramatic climax or that surprise users with moments of unexpected anticlimax. An interface might be designed to guide users along an archetypal and emotional storyline, such as the "hero's journey" (Campbell, 1972), venturing from the ordinary world into a supernatural realm of the unknown, challenged, transformed, and ultimately triumphant. And all of this is only a small subset of what is possible. 


\section{References}

Alwitt, L. F. (2002). Suspense and advertising responses. Journal of Consumer Psychology, 12(1), $35-49$.

Bederson, B. B. (2004). Interfaces for staying in the flow. Ubiquity, 2004(September), 1-1.

Bergman, L., Castelli, V., Lau, T., \& Oblinger, D. (2005, October). DocWizards: a system for authoring follow-me documentation wizards. In Proceedings of the 18th annual ACM symposium on User interface software and technology (pp. 191-200). ACM..

Blender: easy or hard to learn and use. (2012). Ubuntu Forums. Retrieved from http://ubuntuforums.org/showthread.php?t=747133

Blender 3D: Noob to Pro. (2013). Retrieved from http://en.wikibooks.org/wiki/Blender_3D:_Noob_to_Pro

Bonsignore, E. (2011, May). Sharing stories in the wild: a mobile storytelling case study. In CHI'11 Extended Abstracts on Human Factors in Computing Systems (pp. 917-922). ACM.

Brewer, William F. and Edward H. Lichtenstein (1981), "Event Schemas, Story Schemas, and Story Grammars," in Attention and Performance IX, John Long and Alan Baddeley, eds. Hillsdale, NJ: Lawrence Erlbaum Associates.

Brewer, W. F., \& Lichtenstein, E. H. (1982). Stories are to entertain: A structural-affect theory of stories. Journal of Pragmatics, 6(5), 473-486.

Brewer, W. F., \& Ohtsuka, K. (1988). Story structure, characterization, just world organization, and reader affect in American and Hungarian short stories. Poetics, 17(4), 395-415.

Bruner, J. S. (1990). Acts of meaning. Cambridge/London: Harvard University Press.

Byatt, A., \& Burton, R. (2009). The Arabian nights: Tales from a thousand and one nights. Random House LLC.

Cahill, L., \& McGaugh, J. L. (1998). Mechanisms of emotional arousal and lasting declarative memory. Trends in neurosciences, 21(7), 294-299.

Campbell, J. (1972). The Hero with a Thousand Faces. Mythos Books. 
Caplin, A., \& Leahy, J. (2001). Psychological expected utility theory and anticipatory feelings. Quarterly Journal of economics, 55-79.

Carbonaro, M., Cutumisu, M., Duff, H., Gillis, S., Onuczko, C., Siegel, J., \& Waugh, K. (2008). Interactive story authoring: A viable form of creative expression for the classroom. Computers $\&$ Education, 51(2), 687-707.

Carroll, J.M. (1982). The Adventure of Getting to Know a Computer. IEEE Computer 15 49-58.

Carroll, J. M., \& Rosson, M. B. (1987). Paradox of the active user. The MIT Press.

Carroll, Noël. (1984). The Paradox of Suspense. In Vorderer, P., rgen Wulff, H. J., \& Friedrichsen, M. (Eds.). Suspense: Conceptualizations, theoretical analyses, and empirical explorations. Routledge.

Chen, H. (2006). Flow on the net-detecting Web users' positive affects and their flow states. Computers in human behavior, 22(2), 221-233.

Chen, H., Wigand, R. T., \& Nilan, M. (2000). Exploring web users' optimal flow experiences. Information Technology \& People, 13(4), 263-281.

Chen, J. (2007). Flow in games (and everything else). Communications of the ACM, 50(4), 31-34..

Cheong, Y. G., \& Young, R. M. (2008). Narrative generation for suspense: Modeling and evaluation. In Interactive Storytelling (pp. 144-155). Springer Berlin Heidelberg.

Chi, P. Y., Ahn, S., Ren, A., Dontcheva, M., Li, W., \& Hartmann, B. (2012, October). MixT: automatic generation of step-by-step mixed media tutorials. In Proceedings of the 25th annual ACM symposium on User interface software and technology (pp. 93-102). ACM.

Coller, B. D., \& Scott, M. J. (2009). Effectiveness of using a video game to teach a course in mechanical engineering. Computers \& Education, 53(3), 900-912.

Cowley, B., Charles, D., Black, M., \& Hickey, R. (2008). Toward an understanding of flow in video games. Computers in Entertainment (CIE), 6(2), 20.

Csikszentmihalyi, M. (1988). The flow experience and its significance for human psychology. Cambridge: Cambridge University Press. 
Csiksczentmihalyi, M., Kolo, C., \& Baur, T. (2004). Flow: The psychology of optimal experience. Australian Occupational Therapy Journal, 51(1), 3-12.

Deterding, S., Dixon, D., Khaled, R., \& Nacke, L. (2011, September). From game design elements to gamefulness: defining gamification. In Proceedings of the 15th International Academic MindTrek Conference: Envisioning Future Media Environments (pp. 9-15). ACM.

de Wied, M., Tan, E. S., \& Frijda, N. H. (1992). Duration experience under conditions of suspense in films (pp. 325-336). Springer Netherlands.

Deci, E. L., \& Ryan, R. M. (1985). The general causality orientations scale: Self-determination in personality. Journal of research in personality, 19(2), 109-134.

Dolcos, F., LaBar, K. S., \& Cabeza, R. (2005). Remembering one year later: role of the amygdala and the medial temporal lobe memory system in retrieving emotional memories. Proceedings of the National Academy of Sciences of the United States of America, 102(7), 2626-2631.

Domínguez, A., Saenz-de-Navarrete, J., De-Marcos, L., Fernández-Sanz, L., Pagés, C., \& Martínez-Herráiz, J. J. (2013). Gamifying learning experiences: Practical implications and outcomes. Computers \& Education, 63, 380-392.

Dong, T., Dontcheva, M., Joseph, D., Karahalios, K., Newman, M., \& Ackerman, M. (2012, May). Discovery-based games for learning software. In Proceedings of the SIGCHI Conference on Human Factors in Computing Systems (pp. 2083-2086). ACM.

Dontcheva, M., Morris, R. R., Brandt, J. R., \& Gerber, E. M. (2014, April). Combining crowdsourcing and learning to improve engagement and performance. In Proceedings of the 32nd annual ACM conference on Human factors in computing systems (pp. 3379-3388). ACM.

Dunwell, I., de Freitas, S., Petridis, P., Hendrix, M., Arnab, S., Lameras, P., \& Stewart, C. (2014, April). A game-based learning approach to road safety: the code of everand. In Proceedings of the 32nd annual ACM conference on Human factors in computing systems (pp. 3389-3398). ACM.

Engeser, S. (2012). Advances in flow research. Springer.

Engeser, S., \& Rheinberg, F. (2008). Flow, performance and moderators of challenge-skill balance. Motivation and Emotion, 32(3), 158-172. 
Fernquist, J., Grossman, T., \& Fitzmaurice, G. (2011, October). Sketch-sketch revolution: an engaging tutorial system for guided sketching and application learning. In Proceedings of the 24th annual ACM symposium on User interface software and technology (pp. 373-382). ACM.

Gee, J. P. (2005). Learning by design: Good video games as learning machines. E-learning, 2(1), 516.

Gergen, K. J., \& Gergen, M. M. (1988). Narrative and the self as relationship. Advances in experimental social psychology, 21(1), 17-56.

Gerrig, R. J., \& Bernardo, A. B. (1994). Readers as problem-solvers in the experience of suspense. Poetics, 22(6), 459-472.

Gilroy, S., Porteous, J., Charles, F., \& Cavazza, M. (2012, February). Exploring passive user interaction for adaptive narratives. In Proceedings of the 2012 ACM international conference on Intelligent User Interfaces (pp. 119-128). ACM.

Gottschall, J. (2012). The storytelling animal: How stories make us human. Houghton Mifflin Harcourt.

Grabler, F., Agrawala, M., Li, W., Dontcheva, M., \& Igarashi, T. (2009). Generating photo manipulation tutorials by demonstration. ACM, 28(3), 66.

Gratch, J., \& Marsella, S. (2001, May). Tears and fears: Modeling emotions and emotional behaviors in synthetic agents. In Proceedings of the fifth international conference on Autonomous agents (pp. 278-285). ACM.

Grossman, T., \& Fitzmaurice, G. (2010, April). ToolClips: an investigation of contextual video assistance for functionality understanding. In Proceedings of the SIGCHI Conference on Human Factors in Computing Systems (pp. 1515-1524). ACM.

Gruen, D., Rauch, T., Redpath, S., \& Ruettinger, S. (2002). The use of stories in user experience design. International Journal of Human-Computer Interaction, 14(3-4), 503-534.

Guidry, J. A. (2004). The Experience of... Suspense: Understanding the Construct, its Antecedents, and its Consequences in Consumption and Acquisition Contexts. Texas A\&M University.

Hamari, J., \& Tuunanen, J. (2014). Player types: A meta-synthesis. Transactions of the Digital Games Research Association, 1(2). 
Hancock, M., Ten Cate, T., Carpendale, S., \& Isenberg, T. (2010, April). Supporting sandtray therapy on an interactive tabletop. In Proceedings of the SIGCHI Conference on Human Factors in Computing Systems (pp. 2133-2142). ACM..

Hartmann, T., Stuke, D., \& Daschmann, G. (2008). Positive parasocial relationships with drivers affect suspense in racing sport spectators. Journal of Media Psychology: Theories, Methods, and Applications, 20(1), 24-34.

Hsu, C. L., \& Lu, H. P. (2004). Why do people play on-line games? An extended TAM with social influences and flow experience. Information \& Management, 41(7), 853-868.

Kapp, K. M. (2012). The gamification of learning and instruction: game-based methods and strategies for training and education. John Wiley \& Sons.

Kelleher, C., \& Pausch, R. (2005, April). Stencils-based tutorials: design and evaluation. In Proceedings of the SIGCHI conference on Human factors in computing systems (pp. 541-550). ACM.

Kelleher, C., Pausch, R., \& Kiesler, S. (2007, April). Storytelling Alice motivates middle school girls to learn computer programming. In Proceedings of the SIGCHI conference on Human factors in computing systems (pp. 1455-1464). ACM.

Kensinger, E. A. (2004). Remembering emotional experiences: The contribution of valence and arousal. Reviews in the Neurosciences, 15(4), 241-252.

Klimmt, C., Rizzo, A., Vorderer, P., Koch, J., \& Fischer, T. (2009). Experimental evidence for suspense as determinant of video game enjoyment. CyberPsychology \& Behavior, 12(1), 29-31.

Knabe, K. (1995, May). Apple guide: a case study in user-aided design of online help. In Conference companion on Human factors in computing systems(pp. 286-287). ACM.

Konradt, U., \& Sulz, K. (2001). The experience of flow in interacting with a hypermedia learning environment. Journal of educational multimedia and hypermedia, 10(1), 69-84.

Lafreniere, B., Bunt, A., Lount, M., \& Terry, M. (2013). Understanding the roles and uses of web tutorials. In Proceedings of the International AAAI Conference on Weblogs and Social Media, AAAI, Palo Alto, CA, USA (pp. 303-310). 
Lafreniere, B., Grossman, T., \& Fitzmaurice, G. (2013, April). Community enhanced tutorials: improving tutorials with multiple demonstrations. In Proceedings of the SIGCHI Conference on Human Factors in Computing Systems (pp. 1779-1788). ACM.

Laput, G., Adar, E., Dontcheva, M., \& Li, W. (2012, October). Tutorial-based interfaces for cloudenabled applications. In Proceedings of the 25th annual ACM symposium on User interface software and technology (pp. 113-122). ACM.

Laurillard, D. (1998). Multimedia and the learner's experience of narrative. Computers \& education, 31(2), 229-242.

Limayem, M., \& Cheung, C. M. (2011). Predicting the continued use of Internet-based learning technologies: the role of habit. Behaviour \& Information Technology, 30(1), 91-99.

Li, W., Grossman, T., \& Fitzmaurice, G. (2012, October). Gamicad: a gamified tutorial system for first time autocad users. In Proceedings of the 25th annual ACM symposium on User interface software and technology (pp. 103-112). ACM.

Li, W., Zhang, Y., \& Fitzmaurice, G. (2013, August). TutorialPlan: automated tutorial generation from CAD drawings. In Proceedings of the Twenty-Third international joint conference on Artificial Intelligence (pp. 2020-2027). AAAI Press.

Li, W., Grossman, T., \& Fitzmaurice, G. (2014, April). CADament: a gamified multiplayer software tutorial system. In Proceedings of the 32nd annual ACM conference on Human factors in computing systems (pp. 3369-3378). ACM.

Madrigal, R., \& Bee, C. (2005). Suspense as an experience of mixed emotions: feelings of hope and fear while watching suspenseful commercials. Advances in consumer research, 32, 561.

Malone, T. W. (1982, March). Heuristics for designing enjoyable user interfaces: Lessons from computer games. In Proceedings of the 1982 conference on Human factors in computing systems (pp. 63-68). ACM.

McKee, R. (2001). Story. Dixit.

Marchiori, E. J., Del Blanco, Á., Torrente, J., Martinez-Ortiz, I., \& Fernández-Manjón, B. (2011). A visual language for the creation of narrative educational games. Journal of Visual Languages \& Computing, 22(6), 443-452. 
Mateas, M., \& Sengers, P. (1999, November). Narrative intelligence. In Proceedings AAAI Fall Symposium on Narrative Intelligence (pp. 1-10).

Mateas, M., \& Stern, A. (2003, March). Façade: An experiment in building a fully-realized interactive drama. In Game Developers Conference (pp. 4-8).

Motion Module. (2013). Retrieved from http://www.erimez.com/misc/Softimage/tutorials/si_help/introduction/si_uk_motion_intro.htm

Moulard, J. G., Kroff, M. W., \& Folse, J. A. G. (2012). Unraveling consumer suspense: The role of hope, fear, and probability fluctuations. Journal of Business Research, 65(3), 340-346.

Muntean, C. I. (2011, October). Raising engagement in e-learning through gamification. In Proc. 6th International Conference on Virtual Learning ICVL (pp. 323-329).

Nielsen, J. (1993). Iterative user-interface design. Computer, 26(11), 32-41.

Nomikos, M., Opton, E., Averill, J., \& Lazarus, R. (1968). Surprise versus suspense in the production of stress reaction. Journal of personality and social psychology, 8(2), 204-208.

Orji, R., Vassileva, J., \& Mandryk, R. L. (2014). Modeling the efficacy of persuasive strategies for different gamer types in serious games for health. User Modeling and User-Adapted Interaction, 146.

O'Rourke, E., Haimovitz, K., Ballweber, C., Dweck, C., \& Popović, Z. (2014, April). Brain points: a growth mindset incentive structure boosts persistence in an educational game. In Proceedings of the 32nd annual ACM conference on Human factors in computing systems (pp. 3339-3348). ACM.

Pennebaker, J. W. and Seagal, J. D. (1999). Forming a Story: The Health Benefits of Narrative. In Journal of Clinical Psychology, Vol. 55(10), 1243-1254.

Peterson, E. M., \& Raney, A. A. (2008). Reconceptualizing and reexamining suspense as a predictor of mediated sports enjoyment. Journal of Broadcasting \& Electronic Media, 52(4), 544562.

Pongnumkul, S., Dontcheva, M., Li, W., Wang, J., Bourdev, L., Avidan, S., \& Cohen, M. F. (2011, October). Pause-and-play: automatically linking screencast video tutorials with applications. In Proceedings of the 24th annual ACM symposium on User interface software and technology (pp. 135-144). ACM. 
Przybylski, A. K., Rigby, C. S., \& Ryan, R. M. (2010). A motivational model of video game engagement. Review of General Psychology, 14(2), 154.

Querrec, R., \& Chevaillier, P. (2001). Virtual storytelling for training: an application to fire fighting in industrial environment. In Virtual Storytelling Using Virtual Reality Technologies for Storytelling (pp. 201-204). Springer Berlin Heidelberg.

Quesenbery, W., \& Brooks, K. (2010). Storytelling for user experience: Crafting stories for better design. Rosenfeld Media.

Reeve, J. (2009). Why teachers adopt a controlling motivating style toward students and how they can become more autonomy supportive. Educational Psychologist, 44(3), 159-175.

Rheinberg, F., \& Vollmeyer, R. (2003). Flow experience in a computer game under experimentally controlled conditions. Zeitschrift fur Psychologie, 211(4), 161-170.

Riedl, M., \& Bulitko, V. (2012, July). Interactive Narrative: A Novel Application of Artificial Intelligence for Computer Games. In $A A A I$.

Riedl, M. O., \& Young, R. M. (2010). Narrative planning: balancing plot and character. Journal of Artificial Intelligence Research, 39(1), 217-268.

Roberts, D. L., \& Isbell, C. L. (2008). A survey and qualitative analysis of recent advances in drama management. International Transactions on Systems Science and Applications, Special Issue on Agent Based Systems for Human Learning, 4(2), 61-75.

Robertson, J., \& Good, J. (2005). Story creation in virtual game worlds. Communications of the $A C M, 48(1), 61-65$.

Ryan, R. M. (1982). Control and information in the intrapersonal sphere: An extension of cognitive evaluation theory. Journal of personality and social psychology, 43(3), 450.

Ryan, R. M., \& Deci, E. L. (2000). Self-determination theory and the facilitation of intrinsic motivation, social development, and well-being. American psychologist, 55(1), 68.

Ryan, R. M., Rigby, C. S., \& Przybylski, A. (2006). The motivational pull of video games: A selfdetermination theory approach. Motivation and emotion, 30(4), 344-360.

Shang, R. A., Chen, Y. C., \& Shen, L. (2005). Extrinsic versus intrinsic motivations for consumers to shop on-line. Information \& Management, 42(3), 401-413. 
Swanson, R., \& Gordon, A. S. (2012). Say anything: Using textual case-based reasoning to enable open-domain interactive storytelling. ACM Transactions on Interactive Intelligent Systems (TiiS), 2(3), 16.

Sweetser, P., \& Wyeth, P. (2005). GameFlow: a model for evaluating player enjoyment in games. Computers in Entertainment (CIE), 3(3), 3-3.

Thayer, J. F., \& Levenson, R. W. (1983). Effects of music on psychophysiological responses to a stressful film. Psychomusicology: A Journal of Research in Music Cognition, 3(1), 44.

Vizzari, G., Pizzi, G., \& da Silva, F. S. C. (2007). A Framework for Execution and Visualization of Situated Agents Based Virtual Environments. In WOA (pp. 22-25).

Vorderer, P., rgen Wulff, H. J., \& Friedrichsen, M. (1996). Suspense: Conceptualizations, theoretical analyses, and empirical explorations. Routledge.

Wang, C. Y., Chu, W. C., Chen, H. R., Hsu, C. Y., \& Chen, M. Y. (2014, April). EverTutor: automatically creating interactive guided tutorials on smartphones by user demonstration. In Proceedings of the 32nd annual ACM conference on Human factors in computing systems (pp. 4027-4036). ACM.

Watson, D., Hancock, M., \& Mandryk, R. L. (2013). Gamifying Behaviour that Leads to Learning. Gamification'13, 87-90.

Weiner, B. (2013). Human motivation. Psychology Press.

Wood, G., Vines, J., Balaam, M., Taylor, N., Smith, T., Crivellaro, C., \& Wright, P. C. (2014, April). The dept. of hidden stories: playful digital storytelling for children in a public library. In Proceedings of the 32nd annual ACM conference on Human factors in computing systems (pp. 1885-1894). ACM.

Zillmann, D. (1996). The psychology of suspense in dramatic exposition. Suspense: Conceptualizations, theoretical analyses, and empirical explorations, 199-231.

Zillmann, D., \& Vorderer, P. (2000). Media entertainment: The psychology of its appeal. Routledge. 


\section{Appendix A Questionnaires}

\subsection{Pre-Trial Questionnaire}

1. Age:

2. Sex:

3. Have you ever used the application Blender before?

4. If yes -- What did you use Blender for?

5. Have you ever used 3D modeling software before?

6. If yes -- What 3D modelling software have you used and what did you use it for?

7. Have you ever used animation software before?

8. If yes -- What animation software have you used and what did you do use it for?

\subsection{Mid-Trial Questionnaire (administered 5 times)}

1. I would be upset if the tutorial ended now

2. I feel eager

3. I am afraid

4. This is a nail-biting experience

5. I feel excited

6. This is a tension-filled experience

7. I feel fear

8. I am on the edge of my seat

9. I feel enthusiastic

10. I am petrified

11. This is a gripping experience

12. I am frightened 
13. I am looking forward to what happens next

14. I feel just the right amount of challenge

15. My thoughts/activities run fluidly and smoothly

16. I do not notice time passing

17. I have no difficulty concentrating

18. My mind is completely clear

19. I am totally absorbed in what I am doing

20. The right thoughts/movements occur of their own accord

21. I know what I have to do each step of the way

22. I feel that I have everything under control

23. I am completely lost in thought

24. Something important to me is at stake here

25. I must not make any mistakes here

26. I am worried about failing

27. Compared to all other activities which I partake in, this one is... [Easy - Difficult]

28. I think that my competence in this area is... [Low - High]

29. For me personally, the current demands are... [Too Low - Just Right - Too High]

\subsection{Post-Trial Questionnaire}

1. I enjoyed doing this activity very much

2. This activity was fun to do

3. I thought this was a boring activity

4. This activity did not hold my attention at all

5. I would describe this activity as very interesting

6. I thought this activity was quite enjoyable 
7. While I was doing this activity, I was thinking about how much I enjoyed it

8. I think I am pretty good at this activity

9. I think I did pretty well at this activity, compared to other participants

10. After working at this activity for awhile, I felt pretty competent

11. I am satisfied with my performance at this task

12. I was pretty skilled at this activity

13. This was an activity that I couldn't do very well

14. I put a lot of effort into this

15. I didn't try very hard to do well at this activity

16. I tried very hard on this activity

17. It was important to me to do well at this task

18. I didn't put much energy into this

19. I did not feel nervous at all while doing this

20. I felt very tense while doing this activity

21. I was very relaxed in doing these

22. I was anxious while working on this task

23. I felt pressured while doing these

24. I believe I had some choice about doing this activity

25. I felt like it was not my own choice to do this task

26. I didn't really have a choice about doing this task

27. I felt like I had to do this

28. I did this activity because I had no choice

29. I did this activity because I wanted to

30. I did this activity because I had to 
31. I believe this activity could be of some value to me

32. I think that doing this activity is useful

33. I think this is important to do

34. I would be willing to do this again because it has some value to me

35. I think doing this activity could help me learn how to use Blender

36. I believe doing this activity could be beneficial to me

37. I think this is an important activity

38. I find the relationships I formed in this activity fulfilling

39. I find the relationships I formed in this activity important

40. I don't feel close to others when I am engaged in this activity

41. What did you like about the tutorial?

42. What did you dislike about the tutorial?

43. Do you have any other observations about the tutorial? 


\section{Appendix B}

\section{Tutorial}

\section{Introduction}

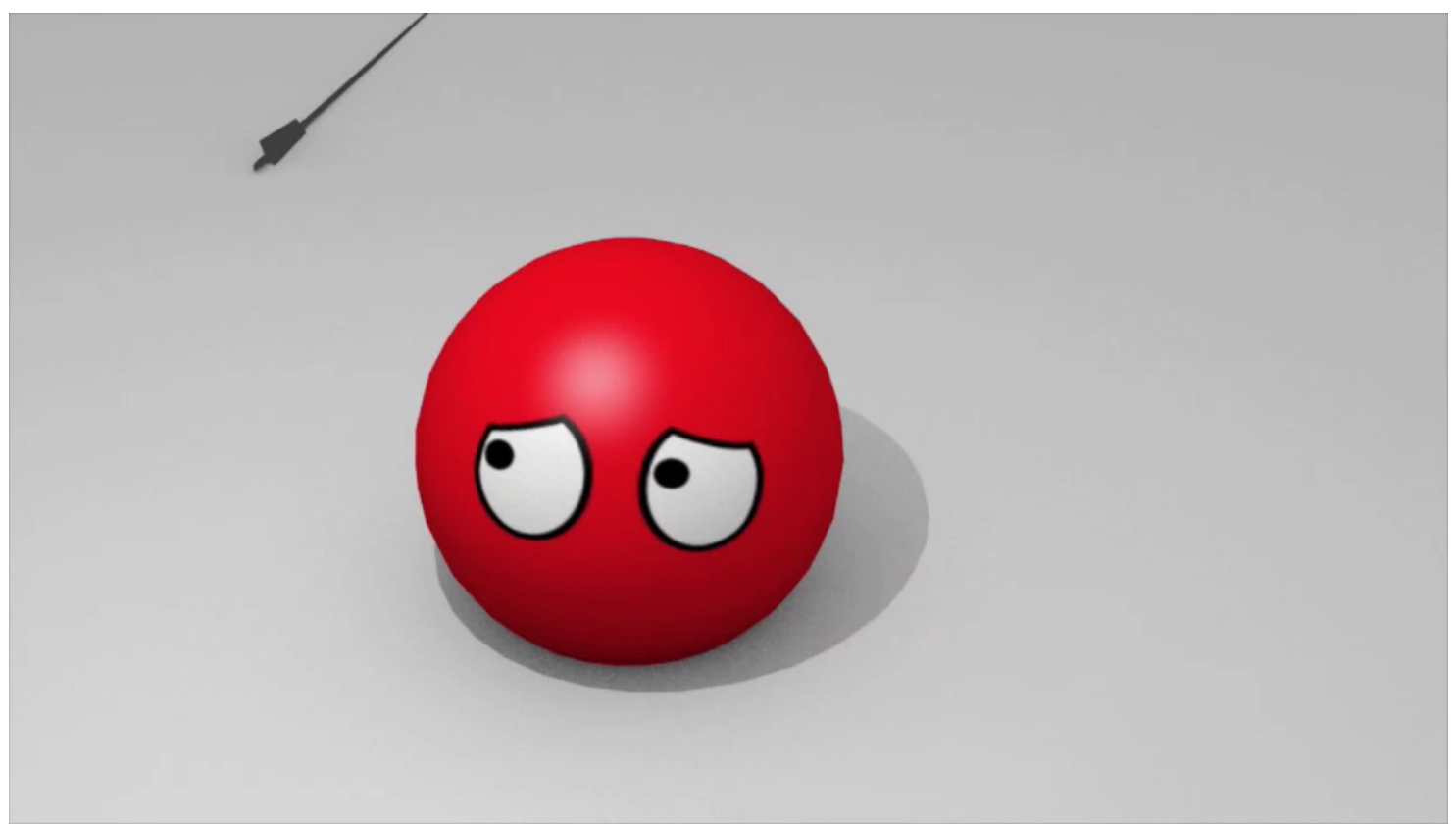

That defenceless red ball is about to be hit by an arrow! But you can help him jump out of the way using the power of Blender.

Begin Tutorial 


\section{Welcome to Blender.}

Blender is a powerful 3D modelling and animation program. It can be used to create visual effects, art, 3D video games, animated films, and more.

In the window you just opened, you should see the red ball.

You can use Blender's animation tools to move the red ball out of the path of the oncoming arrow. However, before you begin animating, you need to learn about how 3D animation works, starting with the concept of frames and keyframes.

\section{Animation Basics}

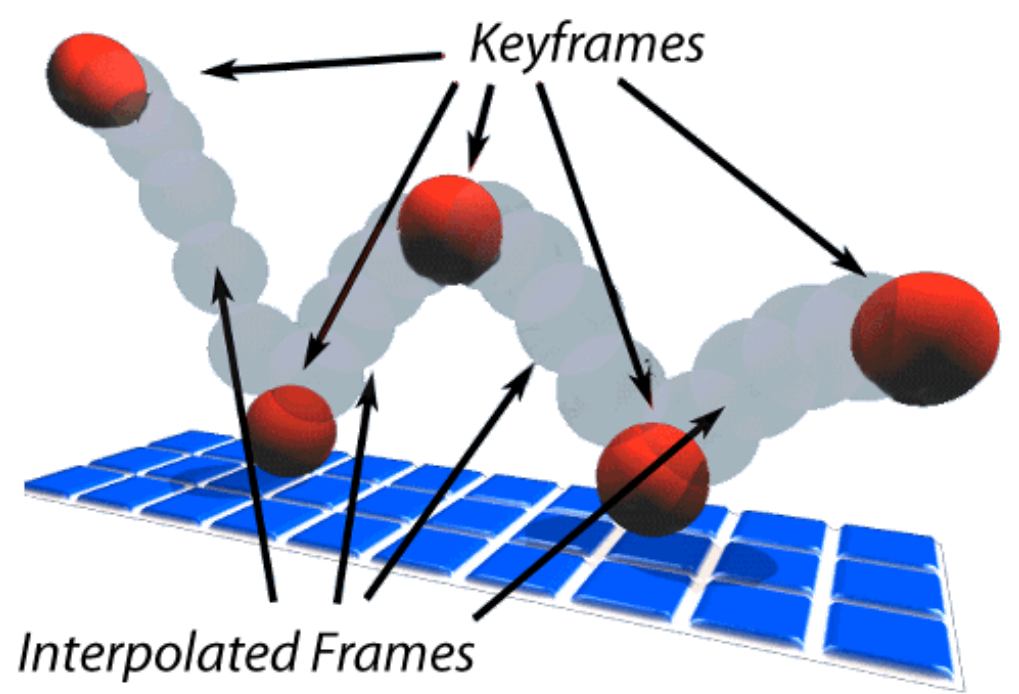

A frame is a snapshot of the scene at one moment in time. An animation consists of displaying a succession of frames representing successive moments in time; if these are shown sufficiently quickly (at least 24 
frames per second), the eye is fooled into seeing smooth movement, instead of a succession of still poses.

In live action video, we can capture the frames simply by letting the camera record as the scene unfolds. In hand-drawn animation (cartoons), each frame had to be drawn by a human animator. The most skilled artists would create keyframes representing pivotal points in the animation (for example, starting and ending poses in a character's movement), and the lower-paid assistants would have the job of filling in all the intermediate frames to produce smooth movement between those endpoints.

Computer animation works in a similar way, except here Blender is your lower-paid assistant. You go to crucial points in the timeline of your animation, position and pose your objects/characters appropriately, and tell Blender that this is a keyframe for the relevant transformations (positioning/rotation/scaling) of those objects/characters. Then when you run the animation, Blender will interpolate the specified transformation parameters between keyframes, giving you smooth motion over those intervals.

Next 


\section{Navigating the Timeline}

At the very bottom of the default Blender screen layout is a window called the timeline. This gives you an overview of your animation.

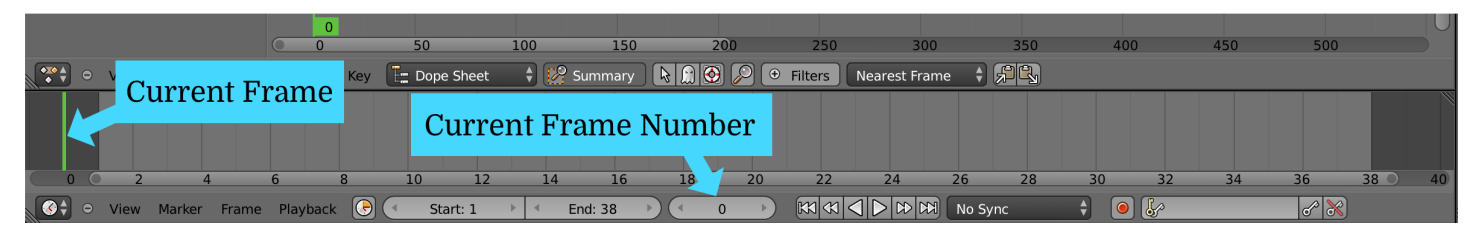

Note: There are two elements that look kind of like timelines on the Blender screen. For now, you only need to pay attention to the one on the bottom

The numbers across the bottom are frame numbers, with your animation starting at frame 1 . The light grey background indicates the total duration of the animation. The vertical green line is positioned at the current frame time, and the current frame number is also displayed in a text field at the bottom of the timeline panel, and at the lower left of the viewport in the $3 \mathrm{D}$ view window.

Try navigating the timeline as follows:

- Jump to any frame in the animation by left-clicking the desired position on the timeline.

- Hop forward and backward a frame at a time with the left- and rightarrow keys.

- Zoom the view in and out with the mouse wheel, or scroll left and right with the middle mouse button.

- "Scrub" by dragging with the left mouse button across the timeline, causing the animation to run backwards or forwards at whatever speed you choose.

Survey 
yellow lines in the timeline, and watch the sphere move smoothly between the two positions you set as keyframes.

8. Press the OPTION + A keys, and Blender will automatically cycle through the timeline for you, animating the cube as it goes. The sphere will hang in the air after it gets to frame 133, because by default the animation will run until frame 179. Press ESC to stop the animation.

\section{Survey}




\section{Inserting Keyframes}

By setting keyframes, you can make the ball jump upwards, out of the path of the oncoming arrow.

1. Right-click on the sphere in the middle of the screen to ensure that it's selected. Selected objects have an orange outline.

2. Using the left mouse button or arrow keys, go frame 123, just before the arrow strikes.

3. With your cursor hovering over the $3 \mathrm{D}$ view panel (where you can see the ball), press I, and choose "Location"; this inserts a keyframe at frame 123, which remembers the current location of the sphere. Move the current frame (green line) away from frame 123, and you will see that there is a yellow line left behind on the timeline. Yellow lines indicate where keyframes for the selected object have been inserted.

4. Go to frame 133, using the left mouse button or arrow keys.

5. With the sphere still selected, pull upwards on the sphere's up (blue) arrow to move it a few sphere-heighths above its starting position.

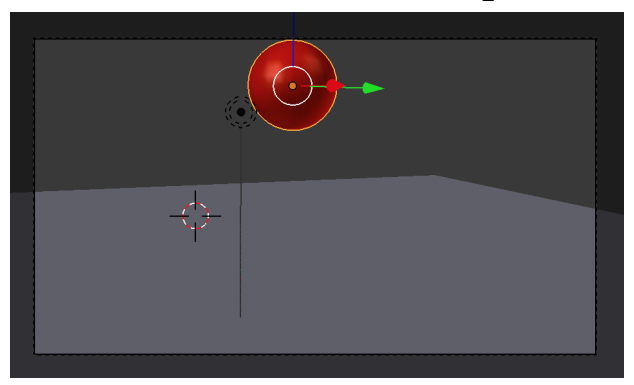

6. With your cursor over the 3D view panel, press I again, and insert another Location keyframe.

7. Now try scrubbing with the left mouse button between the two 
yellow lines in the timeline, and watch the sphere move smoothly between the two positions you set as keyframes.

8. Press the OPTION + A keys, and Blender will automatically cycle through the timeline for you, animating the cube as it goes. The sphere will hang in the air after it gets to frame 133, because by default the animation will run until frame 179. Press ESC to stop the animation.

\section{Survey}

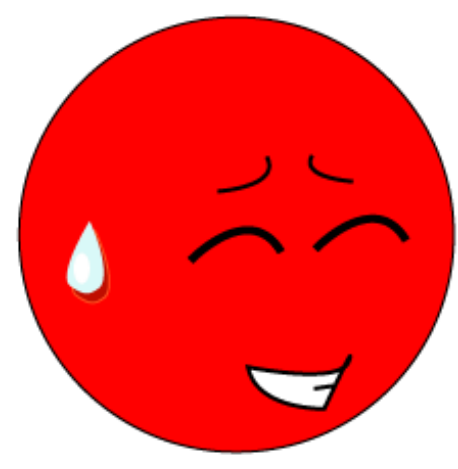

$$
\begin{aligned}
& \text { Whew! That was close. } \\
& \text { Thanks for helping me dodge that arrow! } \\
& \text { There's just one thing... }
\end{aligned}
$$

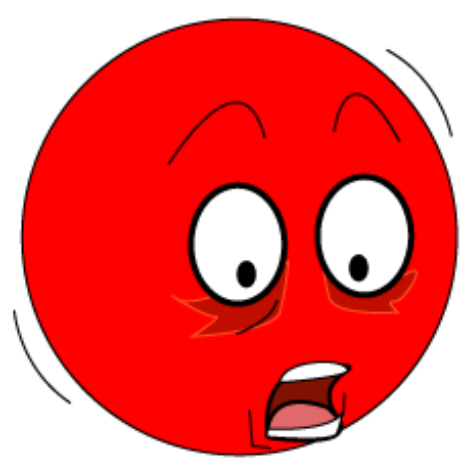

HOW DO I GET DOWN FROM HERE??

Next 


\section{Working With Lattices}

You've dodged the arrow, but now you need to bring the red ball safely back to earth. Use lattices to give the ball a soft, bouncy landing, so he doesn't crack apart like Humpty Dumpty.

A lattice is a simple container that can be used to temporarily deform and manipulate a complex object. Because it is really the lattice that gets deformed, not the underlying object, it remains easy to return the object to its original shape.

To create a lattice, do the following:

1. Set the current frame to 1 .

2. Left click on an empty space just to the left of the ball. Wherever you click, that is where the lattice will be added in the next step.

3. With your cursor over the 3D View Panel (in which the ball is visible) press SHIFT+A, and select "Lattice".

The default Lattice looks like a wireframe cube when first added. The Lattice can be moved, resized and rotated like any other Blender Object. However, when you deselect it, it will lock onto any objects that it currently surrounds, so don't deselect the lattice until it's exactly where you want it to be.

1. Press the 1 key to switch to a side perspective of the ball and lattice. If necessary, use your mouse's scroll wheel to zoom in or out.

2. Resize the lattice by pressing the $\mathbf{S}$ key and then moving the mouse away from the center of the lattice until the lattice appears slightly larger than the ball, then click with your left mouse button to accept 
the change.

3. Center the lattice on the ball. Pull the arrows emininating from the center of the lattice or press $\mathbf{G}$ to move it freely.

4. Switch between perspectives by pressing the 1, 3, 7, and 0 keys, and make sure the lattice is centered over the ball in each perspective.

(If you deselected the lattice prematurely, it will become partially stuck to the ball, and you will need to delete it and start over. To delete the lattice, select the lattice, press the $\mathrm{X}$ key, and select Delete.)

\section{Connecting a Lattice to an Object}

On its own, a Lattice serves no purpose, as it can't be seen in a rendered image. Its only use is to manipulate another object, in this case the ball, and so we need to fully associate that other object with the lattice.

1. Right click on the ball to select it.

2. In the far right panel, click on wrench icon (Object Modifiers).

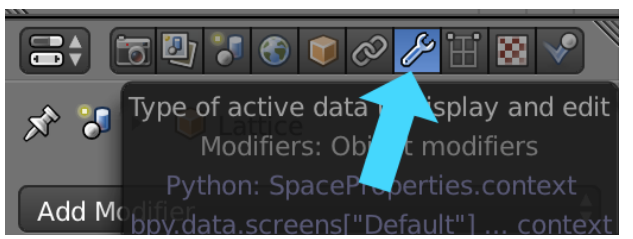

3. From the Add Modifier menu, select Lattice.

4. From the Object menu, select Lattice. 


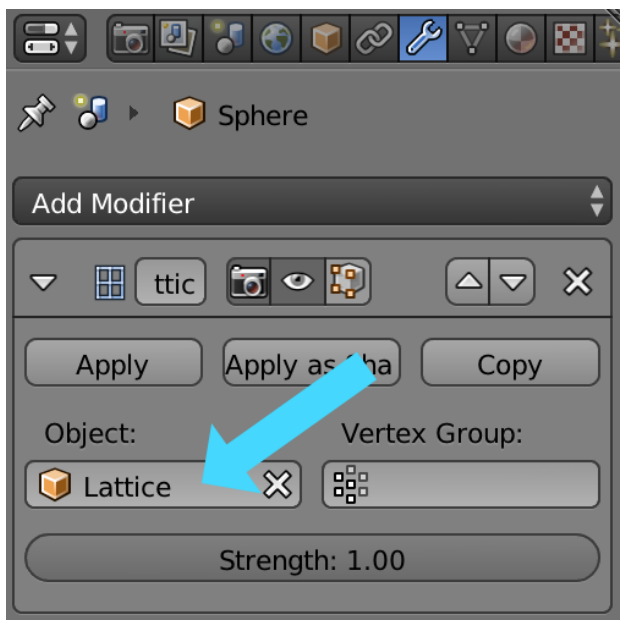

Now the ball is attached to the lattice. When you manipulate the lattice, you will manipulate the ball as well.

Survey 


\section{Creating Lattice Shape Keys}

You can save distorted versions of an object as shape keys. Shape keys make it easier to animate complex objects.

You will be using a shape key to make the ball squash and stretch as it bounces.

To create shape keys for the ball, do the following:

1. Right-click the lattice to select it.

2. In the far right panel, click on the Object Data (grid) icon.

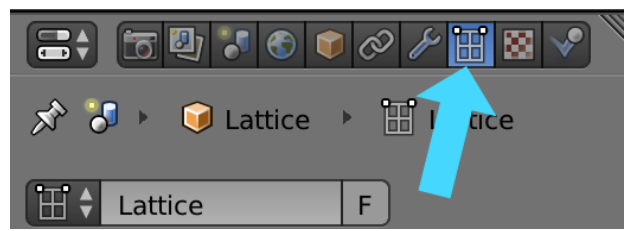

3. Under the Shape Keys header, press the plus button. This adds a "Basis" shape key to the lattice that captures the ball's current, undistorted shape.

4. Press the plus button again to add another shape key, "Key 1".

5. Select "Key 1", and use the text box below to rename it "Squish".

Now, modify the shape key to make a squished shape:

1. With your cursor over the 3D view panel, press TAB to enter Edit mode. In Edit mode you can change objects' shapes.

2. Press the 1 key to change to a side perspective

3. With your left mouse button, click in the middle of the lattice. This moves the 3D cursor to the point where you clicked. Any changes you make to the lattice will be centered on the 3D cursor.

4. Press the 3 key to change to a different side perspective. Again, left- 
click in the middle of the lattice to center the 3D cursor.

5. Press B while clicking and dragging with the left mouse button to box-select the lattice's bottom vertices. Left click to confirm your selection.

6. Press $\mathbf{S}$, then move your cursor away from the ball to scale the bottom vertices, making the bottom of the ball much wider.

7. Left-click just below the sphere, moving the 3D cursor to the bottom of the lattice.

8. Box-select all the lattice's vertices by pressing B while left-clicking and dragging.

9. Press $\mathbf{S}$, then $\mathbf{Z}$, then move your cursor to scale just along the $\mathbf{Z}$ (vertical) axis, squishing the ball to half its original height.

10. Pull down on the lattice's vertical arrow to lower the ball to the ground (horizontal green line).

At this point, your ball should look something like this:

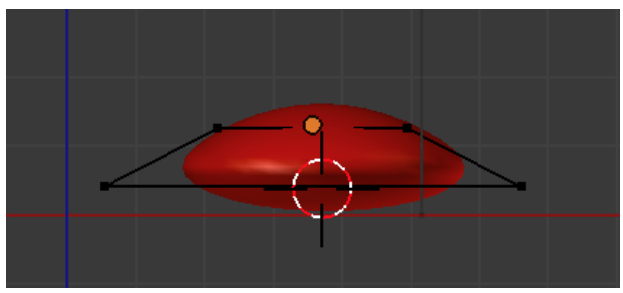

11. With your cursor over the $3 \mathrm{D}$ view panel, press TAB to return to exit Edit mode and return to Object mode.

Note that when you return to Object Mode, the cube snaps back to the basis shape. That's because the value of the Squish shape key is currently set to zero. If you select "Squish" from the panel on the right and crank its value up to 1.000 you can see that the ball deforms into the squished shape you just made.

Survey 


\section{Animating With Shape Keys}

Next, you'll want to use the Shape Key editor to add the squish effect to your animation. The Shape Key editor is the upper timeline in your Blender window. Under the heading "DopeSheet Summary" you should see your "Squish" shape key listed.

First, add some squish to the beginning of the ball's jump:

1. Go to frame 120. Set Squish to 0.000 .

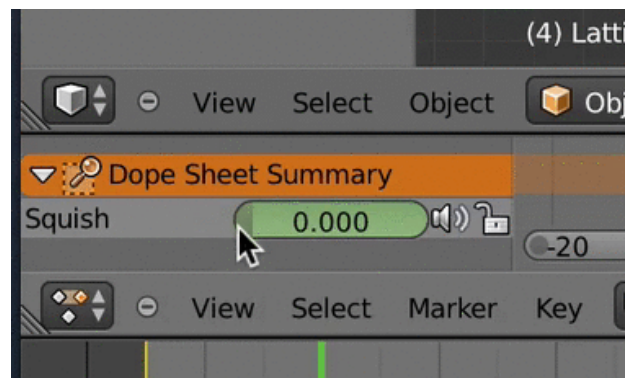

2. Go to frame 123. Set Squish to 1.000 .

3. Go to frame 126. Set Squish to 0.000 .

4. Left-click and drag along the timeline (scrub) to preview.

And now the final landing:

1. Go to frame 135 . Without moving the ball, set the location keyframe. (Press I and select "Location".)

2. Go to frame 145. Move the ball back to its start position, resting on the ground. With your cursor over the 3D view panel, press I and select "Location" to set a location keyframe.

3. Right click the lattice to select it. Set Squish to 0.000.

4. Go to frame 148. Set Squish to 1.000.

5. Go to frame 151. Set Squish to 0.000 .

Press OPTION+A to watch a preview of the animation. Press ESC to stop the preview.

Survey 


\section{Rendering Animations}

1. To speed up the rendering process, change the start frame to 87 . This will cause only frames 87 and later to be rendered.

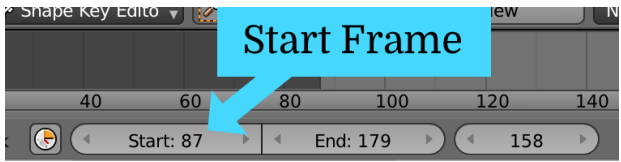

2. To render your animation, click on the Render (camera) icon in the far right panel.

3. Press the "Animation" button, and wait.

Once your animation has finished rendering, click the play button to view it at full speed.

Click here to fill out the final questionnaire: Final Questionnaire 


\section{Appendix C \\ Ethics Approval}

\subsection{Ethics Clearance}

Ethics Clearance (ORE \# 18268)

Dear Researcher:

The recommended revisions/additional information requested in the ethics review of your ORE application:

Title: Tutorial Stories: Introducing New Interaction Techniques Through Narrative ORE \#: 18268

Faculty Supervisor: Mark Hancock (mark.hancock@uwaterloo.ca)

Faculty Supervisor: Nei1 Randa11 (nranda11@uwater1oo.ca)

Student Investigator: Rebecca Langer (k1anger@uwaterloo.ca)

student Investigator: Amber west (awest@uwater1oo.ca)

have been reviewed and are considered acceptable. As a result, your application now has received full ethics clearance.

A signed copy of the Notification of Full Ethics clearance will be sent to the Principal Investigator or Faculty Supervisor in the case of student research.

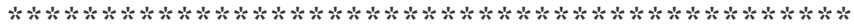

Note 1: This ethics clearance from the office of Research Ethics (ORE) is valid for one year from the date shown on the certificate and is renewable annually, for four consecutive years. Renewal is through completion and ethics clearance of the Annual Progress Report for Continuing Research (ORE Form 105). A new ORE Form 101 application must be submitted for a project continuing beyond five years.

Note 2: This project must be conducted according to the application description and revised materials for which ethics clearance has been granted. Al1 subsequent modifications to the project also must receive prior ethics clearance (i.e. Request for Ethics Clearance of a Modification, ORE Form 104) through the office of Research Ethics and must not begin until notification has been received by the investigators.

Note 3: Researchers must submit a Progress Report on Continuing Human Research Projects (ORE Form 105) annually for all ongoing research projects or on the completion of the project. The office of Research Ethics sends the ORE Form 105 for a project to the Principal Investigator or Faculty Supervisor for completion. If ethics clearance of an ongoing project is not renewed and consequently expires, the office of Research Ethics may be obliged to notify Research Finance for their action in accordance with university and funding agency regulations.

Note 4: Any unanticipated event involving a participant that adversely affected the participant(s) must be reported immediately (i.e., within 1 business day of becoming aware of the event) to the ORE using ORE Form 106.

Best wishes for success with this study.

Susanne Santi, M. Math., Senior Manager

Office of Research Ethics $\mathrm{NH} 1027$

$519.888 .4567 \times 37163$

ssanti@uwater1oo.ca 


\subsection{Ethics Clearance of Modifications, no comments (ORE \# 18268)}

Ethics Clearance of Modifications, no comments (ORE \# 18268)

Dear Researcher:

A Request for ethics review of a modification or amendment (ORE 104) to your ORE application:

Title: Tutorial Stories: Introducing New Interaction Techniques Through

Narrative

ORE \#: 18268

Faculty Supervisor: Mark Hancock (mark.hancock@uwaterloo.ca)

Facu1ty Supervisor: Nei1 Randa11 (nranda11@uwater1oo.ca)

Student Investigator: Rebecca Langer (klanger@uwaterloo.ca)

Student Investigator: Amber west (awest@uwater100.ca)

together with a copy of relevant materials, was received in the office of Research Ethics on:

28 November 2013 -- Using a between-subjects rather than a within-subjects design. Looking at three conditions: a tutorial with a clear goal and story elements, a tutorial with a clear goal but no story elements, and a tutorial with no clear goal. The purpose on the ICL has been revised and tutorials has been changed to tutorial.

The proposed modification request has been reviewed and has received ful1 ethics clearance.

A signed copy of the 'Request for Ethics Clearance of a Modification to an Ongoing Application to Conduct Research with Human Participants' wi11 be provided through regular mail. In the case of student research, the signed copy will be sent to the Faculty Supervisor.

$* * * * * * * * * * * * *$

Note 1: This project must be conducted in accordance with the description in the application and modification for which ethics clearance has been granted. A11 subsequent modifications to the protocol must receive prior ethics clearance through the Office of Research Ethics.

Note 2: Researchers must submit a Progress Report on Continuing Human Research Projects (ORE Form 105) annually for a 11 ongoing research projects. In addition, researchers must submit a Form 105 at the conclusion of the project if it continues for less than a year.

Note 3: Any events related to the procedures used that adversely affect participants must be reported immediately to the ORE using ORE Form 106.

Susanne Santi, M. Math.,

Senior Manager

Office of Research Ethics

$\mathrm{NH} 1027$

$519.888 .4567 \times 37163$

ssanti@uwater7oo.ca 


\section{Appendix D \\ Consent Form}

\section{Waterloo 3}

Project Title:

Tutorial Stories: Incorporating Narrative Techniques Into Tutorials

Student Investigators:

Rebecca Langer, Computer Science department

klanger@uwaterloo.ca

Faculty Advisor:

Dr. Mark Hancock, Management Science department

mark.hancock@uwaterloo.ca

\section{Study Purpose:}

The purpose of our study is to investigate the effects of integrating narrative and suspense into tutorial content.

\section{Study Procedures:}

You will be asked to work through a tutorial and provide feedback about your experience. The session will take less than an hour to complete. With your permission, the session will be audiotaped for coding and analyzing purposes.

\section{Risks and Benefits to the Participant:}

There are no known or anticipated risks from participation in this study. Your participation in the research will contribute to the body of knowledge in human- computer interaction.

Participant's Right to Withdraw from the Study:

You have the right to refuse to participate or to withdraw at any time, without penalty by advising the student investigator.

\section{Remuneration to the Participant:}


You will be given a $\$ 10$ gift card to a local coffee establishment for participation in this study. Please note that the amount received is taxable.

\section{Confidentiality and Privacy:}

All data collected will be regarded as confidential, and every effort will be made to ensure that you will not be identified either directly or indirectly in either verbal or written reports. Your name will not appear in any publication resulting from this study; however, with your permission anonymous quotations may be used. In these cases participants will be referred to as Participant 1 , Participant $2, \ldots$ (or P1, P2, .. ). Data, including video and audio recordings, collected during this study will be retained for 5 years in locked drawers or on password protected computers in a secure location accessible only to researchers associated with this project. Electronic data will be anonymized before being stored.

You will be explicitly asked for consent for the use of video or audio data for the purpose of reporting the study's findings. If consent is granted, these data will be used only for the purposes associated with teaching, scientific presentations, publications, and/or sharing with other researchers and you will not be identified by name.

\section{Report of results}

We appreciate your time and patience in participating in our study. If you want to receive a copy of the report describing the results, please contact me at klanger@uwaterloo.ca.

\section{Contact information and Ethics Clearance for the study}

If you have any questions regarding this study, or would like additional information to assist you in reaching a decision about participation, please contact me at (226) 600-4704 or by e-mail at klanger@uwaterloo.ca.

This study has been reviewed and received ethics clearance through the Office of Research Ethics at the University of Waterloo. However, the final decision about participation is yours. If you have any comments or concerns resulting from your participation in this study, please contact the director of this office at (519) 888-4567 Ext. 36005.

\section{Consent of Participant:}

I have read the information presented in the information letter about a study being conducted by Rebecca Langer and Amber West under the supervision of Mark Hancock in the Management Science Department at the University of Waterloo. I have had the opportunity to ask any questions related to this 
study, to receive satisfactory answers to my questions, and any additional details I wanted. I am aware that I may withdraw from the study without penalty at any time by advising the researchers of this decision.

This project has been reviewed by, and received ethics clearance through, the Office of Research Ethics at the University of Waterloo. I was informed that if I have any comments or concerns resulting from my participation in this study, I may contact the Director, Office of Research Ethics at 519-8884567 ext.36005 or ssykes@uwaterloo.ca.

With full knowledge of all foregoing, I agree, of my own free will, to participate in this study.

Participant's Print Name:

Participant's Signature:

Dated at Waterloo, Ontario:

Witness's Signature:

Dated at Waterloo Ontario:

E-mail address to be sent a copy of results report:

\begin{tabular}{|c|c|c|c|}
\hline & \multicolumn{2}{|c|}{ Please circle one } & $\begin{array}{c}\text { Please initial your } \\
\text { choice }\end{array}$ \\
\hline $\begin{array}{r}\text { I agree to the study being audio recorded } \\
\text { directly quoted, anonymously, in presentation of the } \\
\text { research results }\end{array}$ & YES & NO & \\
\hline $\begin{array}{r}\text { I agree to let audio recordings be used for presentation } \\
\text { of the research results }\end{array}$ & YES & NO & \\
\hline
\end{tabular}




\section{Appendix E SPSS Output}

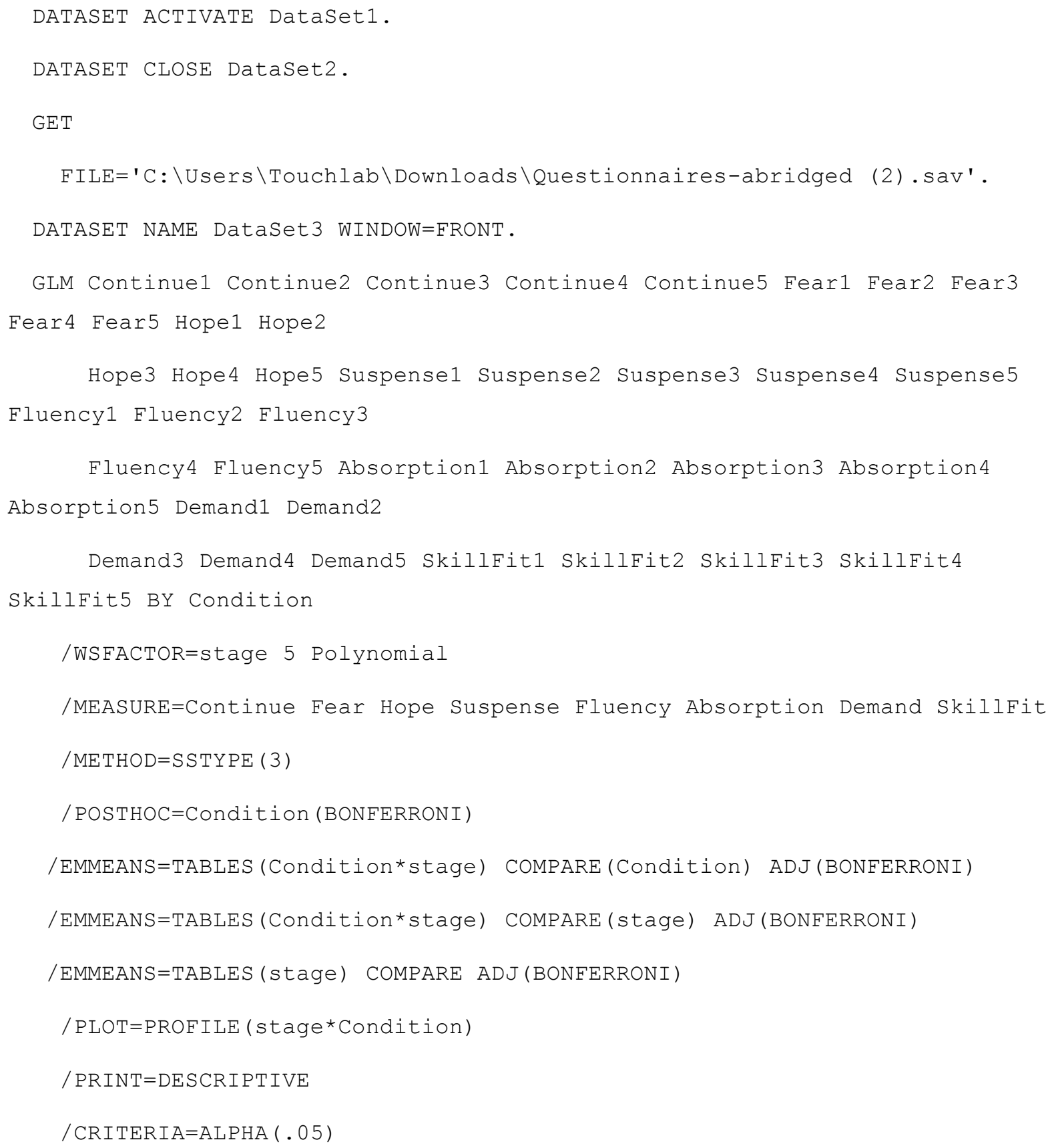


Tests of Between-Subjects Effects

Transformed Variable: Average

\begin{tabular}{|c|c|c|c|c|c|c|c|}
\hline Source & Measure & $\begin{array}{l}\text { Type III Sum } \\
\text { of Squares }\end{array}$ & df & $\begin{array}{l}\text { Mean } \\
\text { Square }\end{array}$ & $F$ & Sig. & $\begin{array}{l}\text { Partial Eta } \\
\text { Squared }\end{array}$ \\
\hline \multirow[t]{8}{*}{ Intercept } & Continue & 3820.640 & 1 & 3820.640 & 687.279 & .000 & .958 \\
\hline & Fear & 502.927 & 1 & 502.927 & 189.167 & .000 & .863 \\
\hline & Hope & 4293.633 & 1 & 4293.633 & 1909.143 & .000 & .985 \\
\hline & Suspense & 1341.767 & 1 & 1341.767 & 544.048 & .000 & .948 \\
\hline & Fluency & 4099.393 & 1 & 4099.393 & 2052.089 & .000 & .986 \\
\hline & Absorption & 3353.241 & 1 & 3353.241 & 2445.174 & .000 & .988 \\
\hline & Demand & 1192.836 & 1 & 1192.836 & 396.853 & .000 & .930 \\
\hline & SkillFit & 2073.851 & 1 & 2073.851 & 1909.371 & .000 & .985 \\
\hline \multirow[t]{8}{*}{ Condition } & Continue & 6.803 & 2 & 3.402 & .612 & .549 & .039 \\
\hline & Fear & .537 & 2 & .269 & .101 & .904 & .007 \\
\hline & Hope & 16.499 & 2 & 8.250 & 3.668 & .038 & .196 \\
\hline & Suspense & 13.581 & 2 & 6.791 & 2.753 & .080 & .155 \\
\hline & Fluency & 7.995 & 2 & 3.997 & 2.001 & .153 & .118 \\
\hline & Absorption & 4.646 & 2 & 2.323 & 1.694 & .201 & .101 \\
\hline & Demand & 27.494 & 2 & 13.747 & 4.574 & .018 & .234 \\
\hline & SkillFit & 2.903 & 2 & 1.451 & 1.336 & .278 & .082 \\
\hline
\end{tabular}




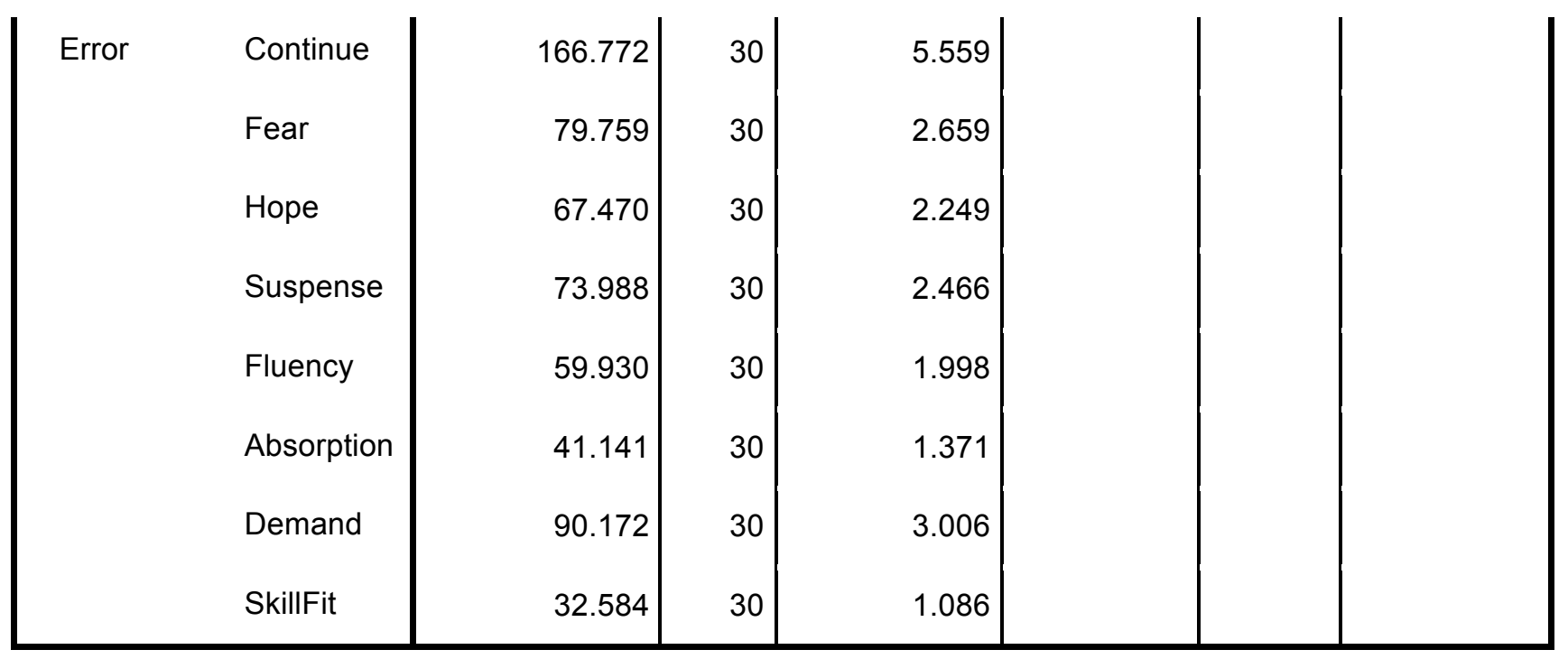

Estimates

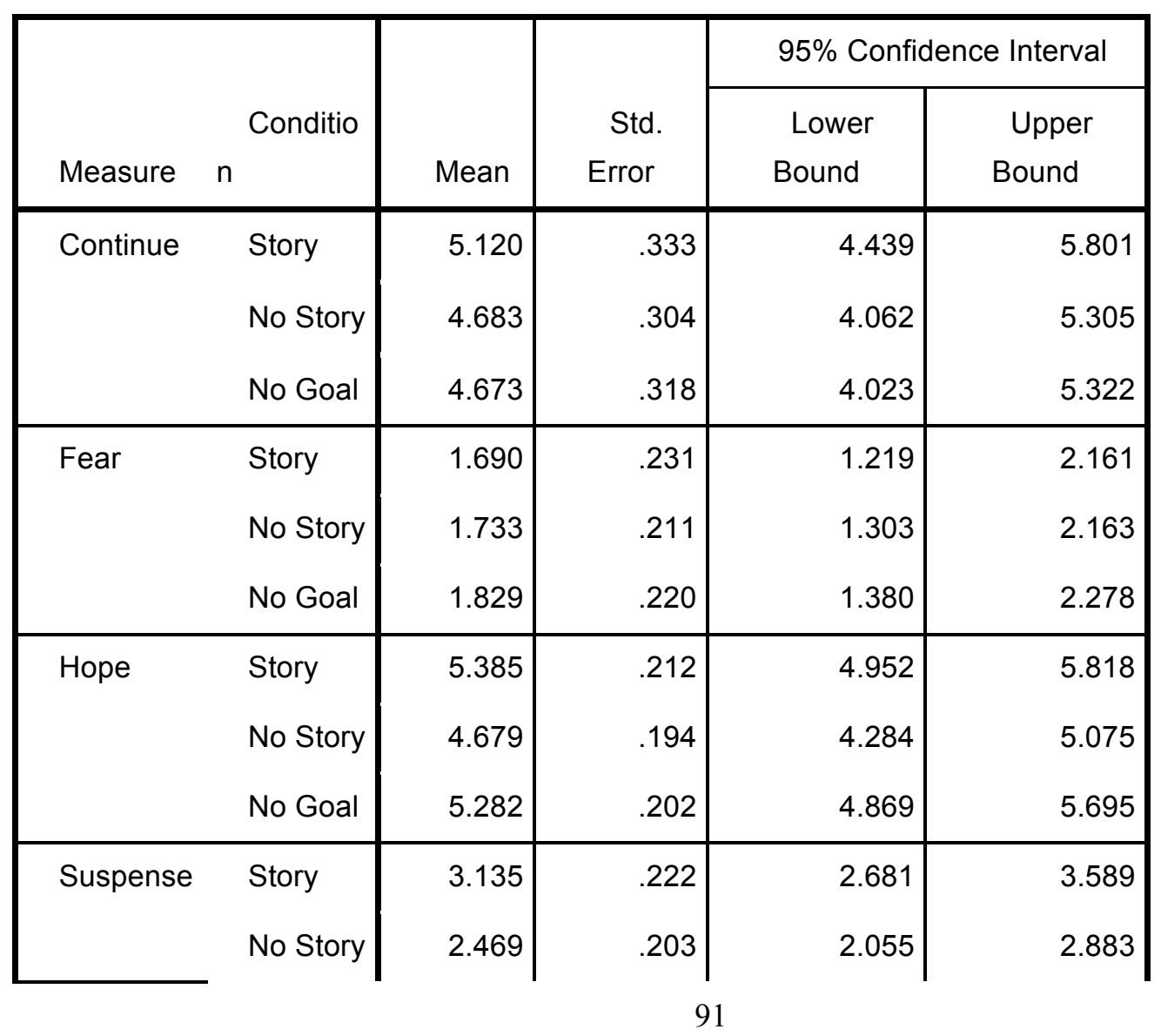




\begin{tabular}{|cl|r|r|r|r|} 
& No Goal & 2.974 & .212 & 2.542 & 3.407 \\
\hline Fluency & Story & 4.880 & .200 & 4.472 & 5.288 \\
& No Story & 4.810 & .182 & 4.437 & 5.183 \\
& No Goal & 5.305 & .191 & 4.916 & 5.694 \\
\hline Absorptio & Story & 4.590 & .166 & 4.252 & 4.928 \\
& No Story & 4.294 & .151 & 3.986 & 4.603 \\
& No Goal & 4.677 & .158 & 4.355 & 5.000 \\
\hline Demand & Story & 2.580 & .245 & 2.079 & 3.081 \\
& No Story & 2.272 & .224 & 1.815 & 2.729 \\
& No Goal & 3.236 & .234 & 2.759 & 3.714 \\
\hline SkillFit & Story & 3.740 & .147 & 3.439 & 4.041 \\
& No Story & 3.422 & .135 & 3.147 & 3.697 \\
& No Goal & 3.503 & .141 & 3.216 & 3.790 \\
\hline
\end{tabular}

Pairwise Comparisons

\begin{tabular}{|c|c|c|c|c|c|c|c|}
\hline \multirow[b]{2}{*}{ Measure } & \multirow[b]{2}{*}{$\begin{array}{c}\text { (I) } \\
\text { Condition }\end{array}$} & \multirow[b]{2}{*}{$\begin{array}{c}(\mathrm{J}) \\
\text { Condition }\end{array}$} & \multirow{2}{*}{$\begin{array}{c}\text { Mean } \\
\text { Difference } \\
(\mathrm{I}-J)\end{array}$} & \multirow[b]{2}{*}{ Std. Error } & \multirow[b]{2}{*}{ Sig. ${ }^{b}$} & \multicolumn{2}{|c|}{$\begin{array}{l}95 \% \text { Confidence } \\
\text { Interval for } \\
\text { Difference }^{b}\end{array}$} \\
\hline & & & & & & $\begin{array}{l}\text { Lower } \\
\text { Bound }\end{array}$ & $\begin{array}{l}\text { Upper } \\
\text { Bound }\end{array}$ \\
\hline \multirow[t]{5}{*}{ Continue } & Story & No Story & .437 & .451 & 1.000 & -.708 & 1.581 \\
\hline & & No Goal & .447 & .461 & 1.000 & -.721 & 1.616 \\
\hline & No Story & Story & -.437 & .451 & 1.000 & -1.581 & .708 \\
\hline & & No Goal & .011 & .440 & 1.000 & -1.105 & 1.127 \\
\hline & No Goal & Story & -.447 & .461 & 1.000 & -1.616 & .721 \\
\hline
\end{tabular}




\begin{tabular}{|c|c|c|c|c|c|c|c|}
\hline & & No Story & -.011 & .440 & 1.000 & -1.127 & 1.105 \\
\hline \multirow[t]{6}{*}{ Fear } & \multirow[t]{2}{*}{ Story } & No Story & -.043 & .312 & 1.000 & -.835 & .748 \\
\hline & & No Goal & -.139 & .319 & 1.000 & -.947 & .669 \\
\hline & \multirow[t]{2}{*}{ No Story } & Story & .043 & .312 & 1.000 & -.748 & .835 \\
\hline & & No Goal & -.095 & .304 & 1.000 & -.867 & .676 \\
\hline & \multirow[t]{2}{*}{ No Goal } & Story & .139 & .319 & 1.000 & -.669 & .947 \\
\hline & & No Story & .095 & .304 & 1.000 & -.676 & .867 \\
\hline \multirow[t]{6}{*}{ Hope } & \multirow[t]{2}{*}{ Story } & No Story & .706 & .287 & .060 & -.022 & 1.434 \\
\hline & & No Goal & .103 & .293 & 1.000 & -.640 & .846 \\
\hline & \multirow[t]{2}{*}{ No Story } & Story & -.706 & .287 & .060 & -1.434 & .022 \\
\hline & & No Goal & -.603 & .280 & .119 & -1.313 & .107 \\
\hline & \multirow[t]{2}{*}{ No Goal } & Story & -.103 & .293 & 1.000 & -.846 & .640 \\
\hline & & No Story & .603 & .280 & .119 & -.107 & 1.313 \\
\hline \multirow{6}{*}{$\mathrm{e}^{\text {Suspens }}$} & \multirow[t]{2}{*}{ Story } & No Story & .666 & .301 & .104 & -.097 & 1.428 \\
\hline & & No Goal & .161 & .307 & 1.000 & -.617 & .939 \\
\hline & \multirow[t]{2}{*}{ No Story } & Story & -.666 & .301 & .104 & -1.428 & .097 \\
\hline & & No Goal & -.505 & .293 & .286 & -1.248 & .239 \\
\hline & \multirow[t]{2}{*}{ No Goal } & Story & -.161 & .307 & 1.000 & -.939 & .617 \\
\hline & & No Story & .505 & .293 & .286 & -.239 & 1.248 \\
\hline \multirow[t]{6}{*}{ Fluency } & \multirow[t]{2}{*}{ Story } & No Story & .070 & .271 & 1.000 & -.616 & .756 \\
\hline & & No Goal & -.425 & .276 & .403 & -1.125 & .275 \\
\hline & \multirow[t]{2}{*}{ No Story } & Story & -.070 & .271 & 1.000 & -.756 & .616 \\
\hline & & No Goal & -.495 & .264 & .211 & -1.164 & .174 \\
\hline & \multirow[t]{2}{*}{ No Goal } & Story & .425 & .276 & .403 & -.275 & 1.125 \\
\hline & & No Story & .495 & .264 & .211 & -.174 & 1.164 \\
\hline
\end{tabular}




\begin{tabular}{|c|c|c|c|c|c|c|c|}
\hline \multirow[t]{5}{*}{$\begin{array}{l}\text { Absorpti } \\
\text { on }\end{array}$} & Story & $\begin{array}{l}\text { No Story } \\
\text { No Goal }\end{array}$ & $\begin{array}{r}.296 \\
-.087\end{array}$ & $\begin{array}{l}.224 \\
.229\end{array}$ & $\begin{array}{r}.592 \\
1.000\end{array}$ & $\begin{array}{l}-.273 \\
-.668\end{array}$ & $\begin{array}{l}.864 \\
.493\end{array}$ \\
\hline & \multirow[t]{2}{*}{ No Story } & Story & -.296 & .224 & .592 & -.864 & .273 \\
\hline & & No Goal & -.383 & .219 & .270 & -.937 & 172 \\
\hline & \multirow[t]{2}{*}{ No Goal } & Story & .087 & .229 & 1.000 & -.493 & .668 \\
\hline & & No Story & .383 & .219 & .270 & -.172 & .937 \\
\hline \multirow[t]{6}{*}{ Demand } & \multirow[t]{2}{*}{ Story } & No Story & .308 & .332 & 1.000 & -.534 & 1.150 \\
\hline & & No Goal & -.656 & .339 & 186 & -1.515 & .203 \\
\hline & \multirow[t]{2}{*}{ No Story } & Story & -.308 & .332 & 1.000 & -1.150 & .534 \\
\hline & & No Goal & -.964 & .324 & .017 & -1.785 & -.143 \\
\hline & \multirow[t]{2}{*}{ No Goal } & Story & .656 & .339 & .186 & -.203 & 1.515 \\
\hline & & No Story & $.964^{*}$ & .324 & .017 & .143 & 1.785 \\
\hline \multirow[t]{6}{*}{ SkillFit } & \multirow[t]{2}{*}{ Story } & No Story & .318 & .200 & .365 & -.188 & .824 \\
\hline & & No Goal & .237 & .204 & .761 & -.279 & .753 \\
\hline & \multirow[t]{2}{*}{ No Story } & Story & -.318 & .200 & .365 & -.824 & 188 \\
\hline & & No Goal & -.081 & 195 & 1.000 & -.574 & .413 \\
\hline & \multirow[t]{2}{*}{ No Goal } & Story & -.237 & .204 & .761 & -.753 & .279 \\
\hline & & No Story & .081 & 195 & 1.000 & -.413 & .574 \\
\hline
\end{tabular}

Based on estimated marginal means

${ }^{*}$. The mean difference is significant at the

b. Adjustment for multiple comparisons: Bonferroni.

\section{General Linear Model}

Descriptive Statistics 


\begin{tabular}{|c|c|c|c|c|}
\hline & Condition & Mean & $\begin{array}{c}\text { Std. } \\
\text { Deviation }\end{array}$ & $\mathrm{N}$ \\
\hline \multirow[t]{4}{*}{ Continue1 } & Story & 6.10 & .738 & 10 \\
\hline & No Story & 4.50 & 2.316 & 12 \\
\hline & No Goal & 4.55 & 2.162 & 11 \\
\hline & Total & 5.00 & 2.000 & 33 \\
\hline \multirow[t]{4}{*}{ Continue2 } & Story & 5.50 & 1.509 & 10 \\
\hline & No Story & 4.67 & 1.371 & 12 \\
\hline & No Goal & 5.18 & 1.471 & 11 \\
\hline & Total & 5.09 & 1.444 & 33 \\
\hline \multirow[t]{4}{*}{ Continue3 } & Story & 5.00 & 1.563 & 10 \\
\hline & No Story & 4.92 & 1.165 & 12 \\
\hline & No Goal & 4.73 & 1.794 & 11 \\
\hline & Total & 4.88 & 1.474 & 33 \\
\hline \multirow[t]{4}{*}{ Continue4 } & Story & 4.80 & 1.932 & 10 \\
\hline & No Story & 5.17 & .937 & 12 \\
\hline & No Goal & 4.36 & 1.963 & 11 \\
\hline & Total & 4.79 & 1.635 & 33 \\
\hline \multirow[t]{4}{*}{ Continue5 } & Story & 4.20 & 1.476 & 10 \\
\hline & No Story & 4.17 & 1.801 & 12 \\
\hline & No Goal & 4.55 & 1.809 & 11 \\
\hline & Total & 4.30 & 1.667 & 33 \\
\hline \multirow[t]{4}{*}{ Fear1 } & Story & 1.7500 & .65617 & 10 \\
\hline & No Story & 2.0000 & 1.11294 & 12 \\
\hline & No Goal & 1.7273 & .80974 & 11 \\
\hline & Total & 1.8333 & .87649 & 33 \\
\hline
\end{tabular}




\begin{tabular}{|c|c|c|c|c|}
\hline \multirow[t]{4}{*}{ Fear2 } & Story & 1.3000 & .49721 & 10 \\
\hline & No Story & 1.6875 & .74715 & 12 \\
\hline & No Goal & 1.8636 & 1.22660 & 11 \\
\hline & Total & 1.6288 & .88636 & 33 \\
\hline \multirow[t]{4}{*}{ Fear3 } & Story & 1.7000 & .65405 & 10 \\
\hline & No Story & 1.6667 & 1.14977 & 12 \\
\hline & No Goal & 1.6894 & .92127 & 11 \\
\hline & Total & 1.6843 & .91661 & 33 \\
\hline \multirow[t]{4}{*}{ Fear4 } & Story & 1.8500 & .90676 & 10 \\
\hline & No Story & 1.7708 & 1.24981 & 12 \\
\hline & No Goal & 1.8636 & 1.16921 & 11 \\
\hline & Total & 1.8258 & 1.09417 & 33 \\
\hline \multirow[t]{4}{*}{ Fear5 } & Story & 1.8500 & 1.00139 & 10 \\
\hline & No Story & 1.5417 & 1.15224 & 12 \\
\hline & No Goal & 2.0000 & 1.31339 & 11 \\
\hline & Total & 1.7879 & 1.14755 & 33 \\
\hline \multirow[t]{4}{*}{ Hope1 } & Story & 5.8000 & .86442 & 10 \\
\hline & No Story & 5.0208 & .80804 & 12 \\
\hline & No Goal & 5.0455 & 1.02359 & 11 \\
\hline & Total & 5.2652 & .94360 & 33 \\
\hline \multirow[t]{4}{*}{ Hope2 } & Story & 5.5750 & .64603 & 10 \\
\hline & No Story & 4.7500 & 1.21075 & 12 \\
\hline & No Goal & 5.2727 & 1.29158 & 11 \\
\hline & Total & 5.1742 & 1.12411 & 33 \\
\hline \multirow[t]{2}{*}{ Hope3 } & Story & 5.2500 & .77280 & 10 \\
\hline & No Story & 4.5000 & 1.13818 & 12 \\
\hline
\end{tabular}




\begin{tabular}{|c|c|c|c|c|}
\hline & No Goal & 5.4318 & .85214 & 11 \\
\hline & Total & 5.0379 & 1.00802 & 33 \\
\hline \multirow[t]{4}{*}{ Hope4 } & Story & 5.0750 & 1.02774 & 10 \\
\hline & No Story & 4.5417 & 1.15224 & 12 \\
\hline & No Goal & 5.1818 & 1.14614 & 11 \\
\hline & Total & 4.9167 & 1.11745 & 33 \\
\hline \multirow[t]{4}{*}{ Hope5 } & Story & 5.2250 & .82031 & 10 \\
\hline & No Story & 4.5833 & 1.27178 & 12 \\
\hline & No Goal & 5.4773 & 1.18033 & 11 \\
\hline & Total & 5.0758 & 1.15496 & 33 \\
\hline \multirow[t]{4}{*}{ Suspense1 } & Story & 3.4000 & 1.13162 & 10 \\
\hline & No Story & 2.5833 & 1.35820 & 12 \\
\hline & No Goal & 2.9318 & 1.22521 & 11 \\
\hline & Total & 2.9470 & 1.25586 & 33 \\
\hline \multirow[t]{4}{*}{ Suspense2 } & Story & 3.0750 & 1.16100 & 10 \\
\hline & No Story & 2.9792 & 1.17965 & 12 \\
\hline & No Goal & 2.8864 & 1.42900 & 11 \\
\hline & Total & 2.9773 & 1.22532 & 33 \\
\hline \multirow[t]{4}{*}{ Suspense3 } & Story & 3.1250 & 1.21478 & 10 \\
\hline & No Story & 2.2500 & 1.23399 & 12 \\
\hline & No Goal & 3.0682 & 1.08450 & 11 \\
\hline & Total & 2.7879 & 1.21533 & 33 \\
\hline \multirow[t]{4}{*}{ Suspense4 } & Story & 3.0000 & 1.06719 & 10 \\
\hline & No Story & 2.2014 & 1.17929 & 12 \\
\hline & No Goal & 3.0000 & 1.17792 & 11 \\
\hline & Total & 2.7096 & 1.17651 & 33 \\
\hline
\end{tabular}




\begin{tabular}{|c|c|c|c|c|}
\hline \multirow[t]{4}{*}{ Suspense5 } & Story & 3.0750 & 1.16100 & 10 \\
\hline & No Story & 2.3333 & 1.36237 & 12 \\
\hline & No Goal & 2.9848 & 1.25267 & 11 \\
\hline & Total & 2.7753 & 1.27433 & 33 \\
\hline \multirow[t]{4}{*}{ Fluency1 } & Story & 5.3333 & 1.01227 & 10 \\
\hline & No Story & 4.4028 & .98591 & 12 \\
\hline & No Goal & 5.1212 & .95479 & 11 \\
\hline & Total & 4.9242 & 1.03673 & 33 \\
\hline \multirow[t]{4}{*}{ Fluency2 } & Story & 5.5000 & .88192 & 10 \\
\hline & No Story & 4.8750 & 1.14840 & 12 \\
\hline & No Goal & 5.1667 & .75645 & 11 \\
\hline & Total & 5.1616 & .95787 & 33 \\
\hline \multirow[t]{4}{*}{ Fluency3 } & Story & 4.6000 & .70798 & 10 \\
\hline & No Story & 5.0139 & 1.03098 & 12 \\
\hline & No Goal & 5.3848 & .96452 & 11 \\
\hline & Total & 5.0121 & .94758 & 33 \\
\hline \multirow[t]{4}{*}{ Fluency4 } & Story & 3.8333 & 1.36536 & 10 \\
\hline & No Story & 4.5556 & 1.22337 & 12 \\
\hline & No Goal & 5.1636 & 1.09295 & 11 \\
\hline & Total & 4.5394 & 1.30457 & 33 \\
\hline \multirow[t]{4}{*}{ Fluency5 } & Story & 5.1333 & .98068 & 10 \\
\hline & No Story & 5.2028 & .85428 & 12 \\
\hline & No Goal & 5.6879 & .88409 & 11 \\
\hline & Total & 5.3434 & .90973 & 33 \\
\hline \multirow[t]{2}{*}{ Absorption1 } & Story & 4.4000 & .71880 & 10 \\
\hline & No Story & 3.9375 & .81272 & 12 \\
\hline
\end{tabular}




\begin{tabular}{|c|c|c|c|c|}
\hline & No Goal & 4.2955 & .63066 & 11 \\
\hline & Total & 4.1970 & .73356 & 33 \\
\hline \multirow[t]{4}{*}{ Absorption2 } & Story & 5.1250 & .62639 & 10 \\
\hline & No Story & 4.2292 & .83570 & 12 \\
\hline & No Goal & 4.3864 & .88997 & 11 \\
\hline & Total & 4.5530 & .86548 & 33 \\
\hline \multirow[t]{4}{*}{ Absorption3 } & Story & 4.6000 & .67905 & 10 \\
\hline & No Story & 4.4931 & .76662 & 12 \\
\hline & No Goal & 4.7955 & 1.00510 & 11 \\
\hline & Total & 4.6263 & .81493 & 33 \\
\hline \multirow[t]{4}{*}{ Absorption4 } & Story & 4.3250 & .95779 & 10 \\
\hline & No Story & 4.3125 & .94222 & 12 \\
\hline & No Goal & 4.9318 & 1.05529 & 11 \\
\hline & Total & 4.5227 & .99876 & 33 \\
\hline \multirow[t]{4}{*}{ Absorption5 } & Story & 4.5000 & .66667 & 10 \\
\hline & No Story & 4.5000 & .79772 & 12 \\
\hline & No Goal & 4.9773 & .67504 & 11 \\
\hline & Total & 4.6591 & .73372 & 33 \\
\hline \multirow[t]{4}{*}{ Demand1 } & Story & 2.7000 & 1.14881 & 10 \\
\hline & No Story & 2.7222 & 1.16197 & 12 \\
\hline & No Goal & 3.1212 & 1.42418 & 11 \\
\hline & Total & 2.8485 & 1.22783 & 33 \\
\hline \multirow[t]{4}{*}{ Demand2 } & Story & 2.5000 & .78959 & 10 \\
\hline & No Story & 2.2500 & 1.18172 & 12 \\
\hline & No Goal & 3.1515 & 1.39335 & 11 \\
\hline & Total & 2.6263 & 1.18953 & 33 \\
\hline
\end{tabular}




\begin{tabular}{|c|c|c|c|c|}
\hline \multirow[t]{4}{*}{ Demand3 } & Story & 2.7667 & 1.07784 & 10 \\
\hline & No Story & 2.0833 & .78012 & 12 \\
\hline & No Goal & 3.3636 & 1.38608 & 11 \\
\hline & Total & 2.7172 & 1.19641 & 33 \\
\hline \multirow[t]{4}{*}{ Demand4 } & Story & 2.6667 & 1.03040 & 10 \\
\hline & No Story & 2.0000 & .86457 & 12 \\
\hline & No Goal & 3.2424 & 1.48392 & 11 \\
\hline & Total & 2.6162 & 1.23356 & 33 \\
\hline \multirow[t]{4}{*}{ Demand5 } & Story & 2.2667 & 1.15256 & 10 \\
\hline & No Story & 2.3056 & 1.02945 & 12 \\
\hline & No Goal & 3.3030 & 1.25126 & 11 \\
\hline & Total & 2.6263 & 1.20979 & 33 \\
\hline \multirow[t]{4}{*}{ SkillFit1 } & Story & 3.5333 & .54885 & 10 \\
\hline & No Story & 3.4167 & .58818 & 12 \\
\hline & No Goal & 3.2727 & .77198 & 11 \\
\hline & Total & 3.4040 & .63332 & 33 \\
\hline \multirow[t]{4}{*}{ SkillFit2 } & Story & 3.7000 & .79271 & 10 \\
\hline & No Story & 3.3611 & .84636 & 12 \\
\hline & No Goal & 3.4242 & .83121 & 11 \\
\hline & Total & 3.4848 & .81262 & 33 \\
\hline \multirow[t]{4}{*}{ SkillFit3 } & Story & 3.8333 & .86424 & 10 \\
\hline & No Story & 3.3889 & .72242 & 12 \\
\hline & No Goal & 3.5455 & .54309 & 11 \\
\hline & Total & 3.5758 & .71818 & 33 \\
\hline \multirow[t]{2}{*}{ SkillFit4 } & Story & 4.0000 & .96864 & 10 \\
\hline & No Story & 3.6667 & .44947 & 12 \\
\hline
\end{tabular}




\begin{tabular}{|ll|r|r|r|} 
& No Goal & 3.9394 & .53371 & 11 \\
\cline { 2 - 5 } & Total & 3.8586 & .66682 & 33 \\
\hline SkillFit5 & Story & 3.6333 & .71059 & 10 \\
\cline { 2 - 5 } & No Story & 3.2778 & .76321 & 12 \\
& No Goal & 3.3333 & .80277 & 11 \\
& Total & 3.4040 & .75350 & 33 \\
\hline
\end{tabular}

Mauchly's Test of Sphericity ${ }^{a}$

\begin{tabular}{|c|c|c|c|c|c|c|c|c|}
\hline \multirow{2}{*}{$\begin{array}{l}\text { Within } \\
\text { Subjects } \\
\text { Effect }\end{array}$} & \multirow[b]{2}{*}{ Measure } & \multirow[b]{2}{*}{$\begin{array}{l}\text { Mauchly's } \\
\text { W }\end{array}$} & \multirow[b]{2}{*}{$\begin{array}{c}\text { Approx. } \\
\text { Chi-Square }\end{array}$} & \multirow[b]{2}{*}{$d f$} & \multirow[b]{2}{*}{ Sig. } & \multicolumn{3}{|c|}{ Epsilon $^{\text {b }}$} \\
\hline & & & & & & $\begin{array}{c}\text { Greenhouse- } \\
\text { Geisser }\end{array}$ & $\begin{array}{l}\text { Huynh } \\
\text {-Feldt }\end{array}$ & $\begin{array}{l}\text { Lower- } \\
\text { bound }\end{array}$ \\
\hline \multirow[t]{8}{*}{ stage } & Continue & .609 & 14.110 & 9 & .119 & .811 & .982 & .250 \\
\hline & Fear & .017 & 116.015 & 9 & .000 & .416 & .467 & .250 \\
\hline & Hope & .223 & 42.580 & 9 & .000 & .584 & .679 & .250 \\
\hline & Suspense & .028 & 101.685 & 9 & .000 & .494 & .564 & .250 \\
\hline & Fluency & .479 & 20.891 & 9 & .013 & .788 & .949 & .250 \\
\hline & Absorption & .294 & 34.760 & 9 & .000 & .711 & .846 & .250 \\
\hline & Demand & .063 & 78.564 & 9 & .000 & .443 & .500 & .250 \\
\hline & SkillFit & .242 & 40.316 & 9 & .000 & .611 & .714 & .250 \\
\hline
\end{tabular}

Tests the null hypothesis that the error covariance matrix of the orthonormalized transformed dependent variables is proportional to an identity matrix.

a. Design: Intercept + Condition

Within Subjects Design: stage

b. May be used to adjust the degrees of freedom for the averaged tests of significance. Corrected tests are displayed in the Tests of Within-Subjects Effects table. 
Univariate Tests

\begin{tabular}{|c|c|c|c|c|c|c|c|}
\hline Source & Measure & & $\begin{array}{l}\text { Type III } \\
\text { Sum of } \\
\text { Squares }\end{array}$ & df & $\begin{array}{l}\text { Mean } \\
\text { Square }\end{array}$ & $\mathrm{F}$ & Sig. \\
\hline \multirow[t]{15}{*}{ stage } & \multirow[t]{4}{*}{ Continue } & Sphericity Assumed & 13.508 & 4 & 3.377 & 1.650 & .166 \\
\hline & & $\begin{array}{l}\text { Greenhouse- } \\
\text { Geisser }\end{array}$ & 13.508 & 3.245 & 4.163 & 1.650 & .179 \\
\hline & & Huynh-Feldt & 13.508 & 3.927 & 3.439 & 1.650 & .167 \\
\hline & & Lower-bound & 13.508 & 1.000 & 13.508 & 1.650 & .209 \\
\hline & \multirow[t]{4}{*}{ Fear } & Sphericity Assumed & 1.179 & 4 & .295 & .480 & .750 \\
\hline & & $\begin{array}{l}\text { Greenhouse- } \\
\text { Geisser }\end{array}$ & 1.179 & 1.664 & .709 & .480 & .587 \\
\hline & & Huynh-Feldt & 1.179 & 1.867 & .632 & .480 & .608 \\
\hline & & Lower-bound & 1.179 & 1.000 & 1.179 & .480 & .494 \\
\hline & \multirow[t]{4}{*}{ Hope } & Sphericity Assumed & 2.423 & 4 & .606 & .762 & .552 \\
\hline & & $\begin{array}{l}\text { Greenhouse- } \\
\text { Geisser }\end{array}$ & 2.423 & 2.337 & 1.037 & .762 & .489 \\
\hline & & Huynh-Feldt & 2.423 & 2.715 & .892 & .762 & .507 \\
\hline & & Lower-bound & 2.423 & 1.000 & 2.423 & .762 & .390 \\
\hline & \multirow[t]{3}{*}{ Suspense } & Sphericity Assumed & 1.602 & 4 & .400 & .320 & .864 \\
\hline & & $\begin{array}{l}\text { Greenhouse- } \\
\text { Geisser }\end{array}$ & 1.602 & 1.976 & .811 & .320 & .725 \\
\hline & & Huynh-Feldt & 1.602 & 2.256 & .710 & .320 & .753 \\
\hline
\end{tabular}




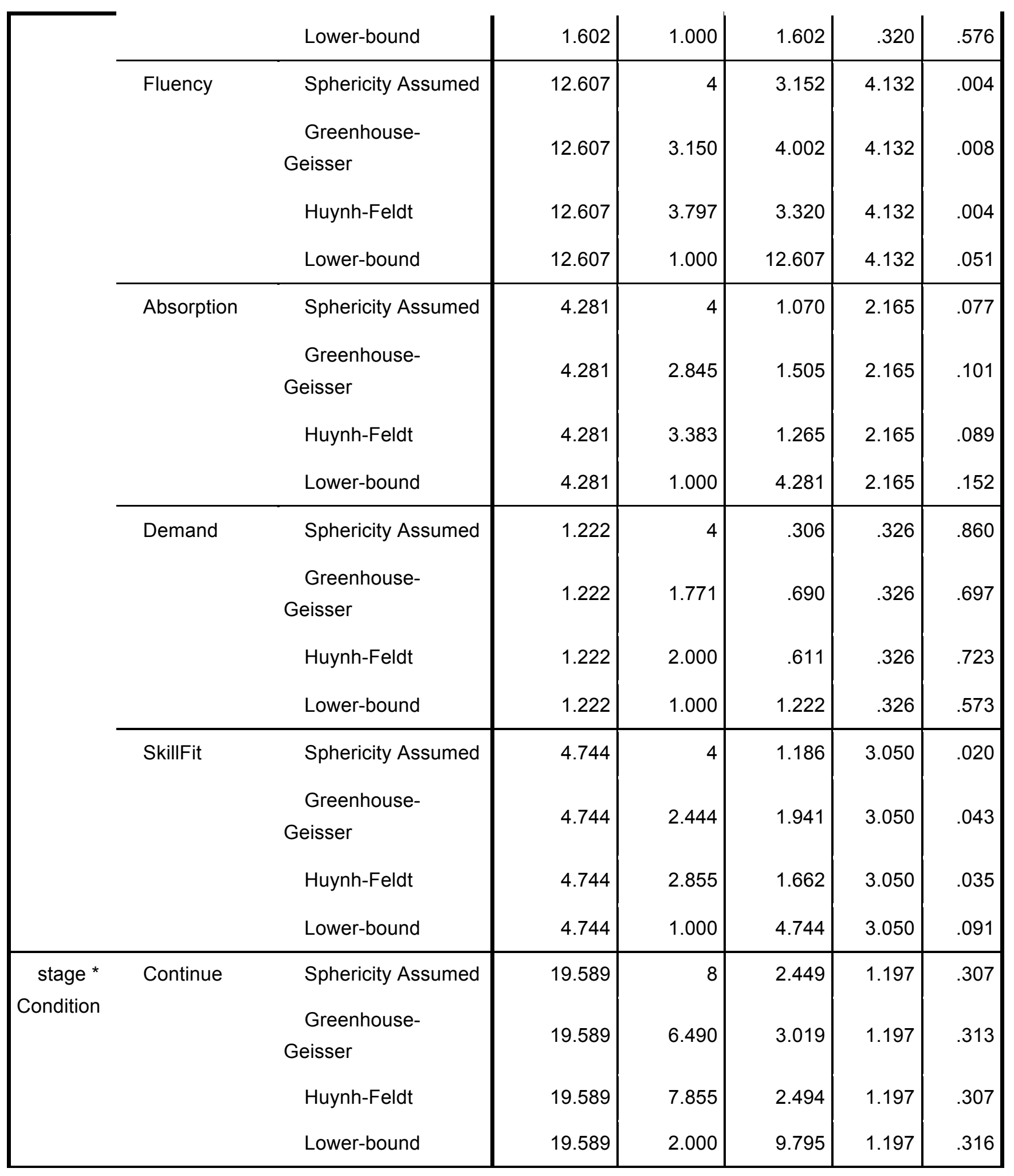




\begin{tabular}{|c|c|c|c|c|c|c|}
\hline Fear & $\begin{array}{l}\text { Sphericity Assumed } \\
\text { Greenhouse- } \\
\text { Geisser } \\
\text { Huynh-Feldt } \\
\text { Lower-bound }\end{array}$ & $\begin{array}{l}3.044 \\
3.044 \\
3.044 \\
3.044\end{array}$ & $\begin{array}{r}8 \\
3.327 \\
3.734 \\
2.000\end{array}$ & $\begin{array}{c}.380 \\
.915 \\
.815 \\
1.522\end{array}$ & $\begin{array}{l}.619 \\
.619 \\
.619 \\
.619\end{array}$ & $\begin{array}{r}.760 \\
.622 \\
.640 \\
.545\end{array}$ \\
\hline Hope & $\begin{array}{l}\text { Sphericity Assumed } \\
\text { Greenhouse- } \\
\text { Geisser } \\
\text { Huynh-Feldt } \\
\text { Lower-bound }\end{array}$ & $\begin{array}{l}4.727 \\
4.727 \\
4.727 \\
4.727\end{array}$ & $\begin{array}{r}8 \\
4.673 \\
5.430 \\
2.000\end{array}$ & $\begin{array}{c}.591 \\
1.012 \\
.871 \\
2.364\end{array}$ & $\begin{array}{l}.743 \\
.743 \\
.743 \\
.743\end{array}$ & $\begin{array}{l}.653 \\
.585 \\
.604 \\
.484\end{array}$ \\
\hline Suspense & $\begin{array}{l}\text { Sphericity Assumed } \\
\text { Greenhouse- } \\
\text { Geisser } \\
\text { Huynh-Feldt } \\
\text { Lower-bound }\end{array}$ & $\begin{array}{l}4.315 \\
4.315 \\
4.315 \\
4.315\end{array}$ & $\begin{array}{r}8 \\
3.952 \\
4.511 \\
2.000\end{array}$ & $\begin{array}{c}.539 \\
1.092 \\
.957 \\
2.158\end{array}$ & $\begin{array}{l}.431 \\
.431 \\
.431 \\
.431\end{array}$ & $\begin{array}{l}.900 \\
.783 \\
.807 \\
.654\end{array}$ \\
\hline Fluency & $\begin{array}{l}\text { Sphericity Assumed } \\
\text { Greenhouse- } \\
\text { Geisser } \\
\text { Huynh-Feldt } \\
\text { Lower-bound }\end{array}$ & $\begin{array}{l}13.985 \\
13.985 \\
13.985 \\
13.985\end{array}$ & $\begin{array}{r}8 \\
6.300 \\
7.594 \\
2.000\end{array}$ & $\begin{array}{l}1.748 \\
2.220 \\
1.842 \\
6.993\end{array}$ & $\begin{array}{l}2.292 \\
2.292 \\
2.292 \\
2.292\end{array}$ & $\begin{array}{l}.025 \\
.039 \\
.028 \\
.118\end{array}$ \\
\hline Absorption & $\begin{array}{l}\text { Sphericity Assumed } \\
\text { Greenhouse- } \\
\text { Geisser } \\
\text { Huynh-Feldt } \\
\text { Lower-bound }\end{array}$ & $\begin{array}{l}6.484 \\
6.484 \\
6.484 \\
6.484\end{array}$ & $\begin{array}{r}8 \\
5.689 \\
6.767 \\
2.000\end{array}$ & $\begin{array}{c}.810 \\
1.140 \\
.958 \\
3.242\end{array}$ & $\begin{array}{l}1.640 \\
1.640 \\
1.640 \\
1.640\end{array}$ & $\begin{array}{l}.150 \\
.135 \\
.211\end{array}$ \\
\hline Demand & Sphericity Assumed & 4.533 & 8 & .567 & .604 & .773 \\
\hline
\end{tabular}




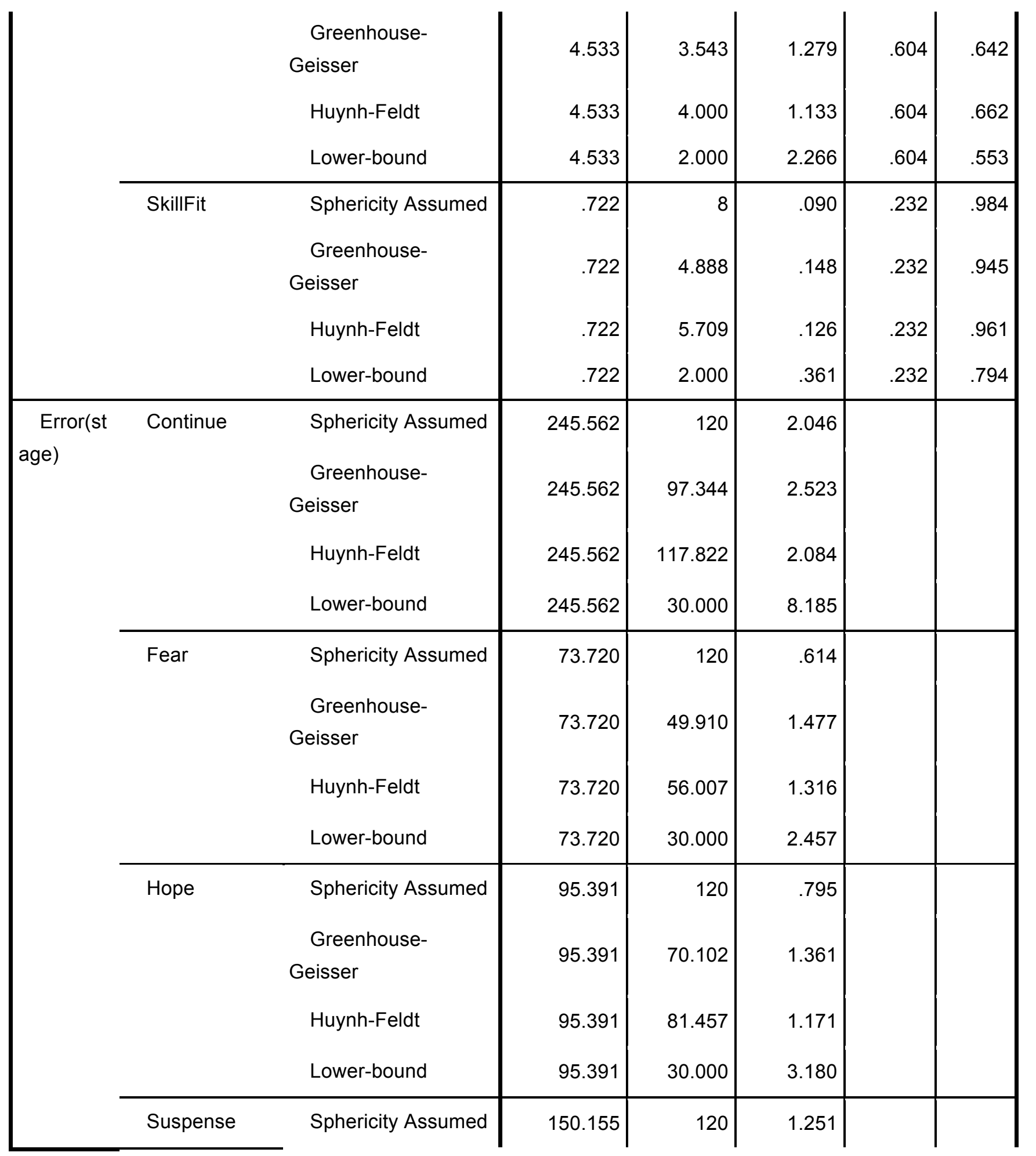




\begin{tabular}{|c|c|c|c|c|c|}
\hline & $\begin{array}{l}\text { Greenhouse- } \\
\text { Geisser } \\
\text { Huynh-Feldt } \\
\text { Lower-bound }\end{array}$ & $\begin{array}{l}150.155 \\
150.155 \\
150.155\end{array}$ & $\begin{array}{l}67.667 \\
30.000\end{array}$ & $\begin{array}{l}2.533 \\
2.219 \\
5.005\end{array}$ & \\
\hline Fluency & $\begin{array}{l}\text { Sphericity Assumed } \\
\text { Greenhouse- } \\
\text { Geisser } \\
\text { Huynh-Feldt } \\
\text { Lower-bound }\end{array}$ & $\begin{array}{l}91.522 \\
91.522 \\
91.522 \\
91.522\end{array}$ & $\begin{array}{r}120 \\
94.501 \\
113.912 \\
30.000\end{array}$ & $\begin{array}{l}.763 \\
.968 \\
.803 \\
3.051\end{array}$ & \\
\hline Absorption & $\begin{array}{l}\text { Sphericity Assumed } \\
\text { Greenhouse- } \\
\text { Geisser } \\
\text { Huynh-Feldt } \\
\text { Lower-bound }\end{array}$ & $\begin{array}{r}59.318 \\
59.318 \\
59.318 \\
59.318\end{array}$ & $\begin{array}{r}120 \\
85.341 \\
101.500 \\
30.000\end{array}$ & $\begin{array}{l}.494 \\
.695 \\
.584 \\
1.977\end{array}$ & \\
\hline Demand & $\begin{array}{l}\text { Sphericity Assumed } \\
\text { Greenhouse- } \\
\text { Geisser } \\
\text { Huynh-Feldt } \\
\text { Lower-bound }\end{array}$ & $\begin{array}{r}112.656 \\
112.656 \\
112.656 \\
112.656\end{array}$ & $\begin{array}{r}120 \\
53.144 \\
60.002 \\
30.000\end{array}$ & $\begin{array}{r}.939 \\
2.120 \\
1.878 \\
3.755\end{array}$ & \\
\hline SkillFit & $\begin{array}{l}\text { Sphericity Assumed } \\
\text { Greenhouse- } \\
\text { Geisser } \\
\text { Huynh-Feldt } \\
\text { Lower-bound }\end{array}$ & $\begin{array}{r}46.660 \\
46.660 \\
46.660\end{array}$ & $\begin{array}{r}120 \\
73.327 \\
85.637\end{array}$ & $\begin{array}{r}.636 \\
.545 \\
1.555\end{array}$ & \\
\hline
\end{tabular}




\section{Estimates}

\begin{tabular}{|c|c|c|c|c|c|}
\hline \multirow[b]{2}{*}{ Measure } & \multirow[b]{2}{*}{ stage } & \multirow[b]{2}{*}{ Mean } & \multirow[b]{2}{*}{ Std. Error } & \multicolumn{2}{|c|}{$95 \%$ Confidence Interval } \\
\hline & & & & $\begin{array}{l}\text { Lower } \\
\text { Bound }\end{array}$ & $\begin{array}{l}\text { Upper } \\
\text { Bound }\end{array}$ \\
\hline \multirow[t]{5}{*}{ Continue } & 1 & 5.048 & .335 & 4.364 & 5.733 \\
\hline & 2 & 5.116 & .253 & 4.600 & 5.632 \\
\hline & 3 & 4.881 & .265 & 4.340 & 5.422 \\
\hline & 4 & 4.777 & .288 & 4.188 & 5.365 \\
\hline & 5 & 4.304 & .299 & 3.693 & 4.915 \\
\hline \multirow[t]{5}{*}{ Fear } & 1 & 1.826 & .156 & 1.507 & 2.145 \\
\hline & 2 & 1.617 & .154 & 1.302 & 1.932 \\
\hline & 3 & 1.685 & .165 & 1.348 & 2.023 \\
\hline & 4 & 1.828 & .197 & 1.426 & 2.231 \\
\hline & 5 & 1.797 & .204 & 1.381 & 2.213 \\
\hline \multirow[t]{4}{*}{ Hope } & 1 & 5.289 & .157 & 4.967 & 5.610 \\
\hline & 2 & 5.199 & .193 & 4.806 & 5.593 \\
\hline & 3 & 5.061 & .165 & 4.723 & 5.398 \\
\hline & 4 & 4.933 & .195 & 4.536 & 5.330 \\
\hline
\end{tabular}




\begin{tabular}{|c|c|c|c|c|c|}
\hline & 5 & 5.095 & .196 & 4.695 & 5.495 \\
\hline \multirow[t]{5}{*}{ Suspense } & 1 & 2.972 & .218 & 2.526 & 3.417 \\
\hline & 2 & 2.980 & .220 & 2.530 & 3.430 \\
\hline & 3 & 2.814 & .206 & 2.394 & 3.235 \\
\hline & 4 & 2.734 & .200 & 2.325 & 3.142 \\
\hline & 5 & 2.798 & .221 & 2.346 & 3.250 \\
\hline \multirow[t]{5}{*}{ Fluency } & 1 & 4.952 & .172 & 4.602 & 5.303 \\
\hline & 2 & 5.181 & .166 & 4.841 & 5.520 \\
\hline & 3 & 5.000 & .161 & 4.671 & 5.328 \\
\hline & 4 & 4.518 & .214 & 4.080 & 4.955 \\
\hline & 5 & 5.341 & .158 & 5.019 & 5.663 \\
\hline \multirow[t]{5}{*}{ Absorption } & 1 & 4.211 & .127 & 3.952 & 4.470 \\
\hline & 2 & 4.580 & .139 & 4.295 & 4.865 \\
\hline & 3 & 4.630 & .145 & 4.333 & 4.926 \\
\hline & 4 & 4.523 & .172 & 4.172 & 4.875 \\
\hline & 5 & 4.659 & .126 & 4.402 & 4.916 \\
\hline \multirow[t]{5}{*}{ Demand } & 1 & 2.848 & .219 & 2.402 & 3.294 \\
\hline & 2 & 2.634 & .203 & 2.220 & 3.047 \\
\hline & 3 & 2.738 & .192 & 2.345 & 3.130 \\
\hline & 4 & 2.636 & .201 & 2.226 & 3.047 \\
\hline & 5 & 2.625 & .200 & 2.217 & 3.033 \\
\hline \multirow[t]{4}{*}{ SkillFit } & 1 & 3.408 & .113 & 3.178 & 3.637 \\
\hline & 2 & 3.495 & .144 & 3.201 & 3.789 \\
\hline & 3 & 3.589 & .125 & 3.334 & 3.845 \\
\hline & 4 & 3.869 & .117 & 3.629 & 4.108 \\
\hline
\end{tabular}




\begin{tabular}{|l|l|l|l|l|}
5 & 3.415 & .133 & 3.143 & 3.686 \\
\hline
\end{tabular}

Pairwise Comparisons

\begin{tabular}{|c|c|c|c|c|c|c|c|}
\hline \multirow[b]{2}{*}{ Measure } & \multirow[b]{2}{*}{$\begin{array}{c}(\mathrm{I}) \\
\text { stage }\end{array}$} & \multirow[b]{2}{*}{$\begin{array}{r}(\mathrm{J}) \\
\text { stage }\end{array}$} & \multirow{2}{*}{$\begin{array}{c}\text { Mean } \\
\text { Difference (I- } \\
\text { J) }\end{array}$} & \multirow[b]{2}{*}{ Std. Error } & \multirow[b]{2}{*}{ Sig. ${ }^{b}$} & \multicolumn{2}{|c|}{$\begin{array}{l}\text { 95\% Confidence Interval } \\
\quad \text { for Difference }\end{array}$} \\
\hline & & & & & & $\begin{array}{l}\text { Lower } \\
\text { Bound }\end{array}$ & $\begin{array}{l}\text { Upper } \\
\text { Bound }\end{array}$ \\
\hline \multirow[t]{17}{*}{ Continue } & 1 & 2 & -.068 & .414 & 1.000 & -1.322 & 1.186 \\
\hline & & 3 & .167 & .321 & 1.000 & -.805 & 1.140 \\
\hline & & 4 & .272 & .358 & 1.000 & -.814 & 1.357 \\
\hline & & 5 & .744 & .351 & .425 & -.320 & 1.809 \\
\hline & 2 & 1 & .068 & .414 & 1.000 & -1.186 & 1.322 \\
\hline & & 3 & .235 & .384 & 1.000 & -.930 & 1.400 \\
\hline & & 4 & .339 & .421 & 1.000 & -.937 & 1.616 \\
\hline & & 5 & .812 & .415 & .598 & -.446 & 2.070 \\
\hline & 3 & 1 & -.167 & .321 & 1.000 & -1.140 & .805 \\
\hline & & 2 & -.235 & .384 & 1.000 & -1.400 & .930 \\
\hline & & 4 & .105 & .248 & 1.000 & -.646 & .855 \\
\hline & & 5 & .577 & .295 & .595 & -.316 & 1.470 \\
\hline & 4 & 1 & -.272 & .358 & 1.000 & -1.357 & .814 \\
\hline & & 2 & -.339 & .421 & 1.000 & -1.616 & .937 \\
\hline & & 3 & -.105 & .248 & 1.000 & -.855 & .646 \\
\hline & & 5 & .473 & .274 & .950 & -.358 & 1.304 \\
\hline & 5 & 1 & -.744 & .351 & .425 & -1.809 & .320 \\
\hline
\end{tabular}




\begin{tabular}{|c|c|c|c|c|c|c|c|}
\hline & & 2 & -.812 & .415 & .598 & -2.070 & .446 \\
\hline & & 3 & -.577 & .295 & .595 & -1.470 & .316 \\
\hline & & 4 & -.473 & .274 & .950 & -1.304 & .358 \\
\hline \multirow[t]{20}{*}{ Fear } & \multirow[t]{4}{*}{1} & 2 & .209 & .246 & 1.000 & -.537 & .955 \\
\hline & & 3 & .140 & .130 & 1.000 & -.254 & .535 \\
\hline & & 4 & -.002 & .155 & 1.000 & -.472 & .467 \\
\hline & & 5 & .029 & .179 & 1.000 & -.515 & .572 \\
\hline & \multirow[t]{4}{*}{2} & 1 & -.209 & .246 & 1.000 & -.955 & .537 \\
\hline & & 3 & -.068 & .251 & 1.000 & -.828 & .691 \\
\hline & & 4 & -.211 & .284 & 1.000 & -1.071 & .649 \\
\hline & & 5 & -.180 & .286 & 1.000 & -1.048 & .687 \\
\hline & \multirow[t]{4}{*}{3} & 1 & -.140 & .130 & 1.000 & -.535 & .254 \\
\hline & & 2 & .068 & .251 & 1.000 & -.691 & .828 \\
\hline & & 4 & -.143 & .058 & .195 & -.318 & .033 \\
\hline & & 5 & -.112 & .079 & 1.000 & -.350 & .126 \\
\hline & \multirow[t]{4}{*}{4} & 1 & .002 & .155 & 1.000 & -.467 & .472 \\
\hline & & 2 & .211 & .284 & 1.000 & -.649 & 1.071 \\
\hline & & 3 & .143 & .058 & .195 & -.033 & .318 \\
\hline & & 5 & .031 & .075 & 1.000 & -.198 & .259 \\
\hline & \multirow[t]{4}{*}{5} & 1 & -.029 & .179 & 1.000 & -.572 & .515 \\
\hline & & 2 & .180 & .286 & 1.000 & -.687 & 1.048 \\
\hline & & 3 & .112 & .079 & 1.000 & -.126 & .350 \\
\hline & & 4 & -.031 & .075 & 1.000 & -.259 & .198 \\
\hline \multirow[t]{2}{*}{ Hope } & \multirow[t]{2}{*}{1} & 2 & .090 & .235 & 1.000 & -.622 & .801 \\
\hline & & 3 & .228 & .217 & 1.000 & -.430 & .886 \\
\hline
\end{tabular}




\begin{tabular}{|c|c|c|c|c|c|c|c|}
\hline & & 4 & .356 & .222 & 1.000 & -.317 & 1.029 \\
\hline & & 5 & .194 & .236 & 1.000 & -.521 & .908 \\
\hline & 2 & 1 & -.090 & .235 & 1.000 & -.801 & .622 \\
\hline & & 3 & .139 & .251 & 1.000 & -.622 & .899 \\
\hline & & 4 & 266 & .283 & 1.000 & -.590 & 1.123 \\
\hline & & 5 & .104 & .293 & 1.000 & -.783 & .991 \\
\hline & 3 & 1 & -.228 & .217 & 1.000 & -.886 & .430 \\
\hline & & 2 & -.139 & .251 & 1.000 & -.899 & .622 \\
\hline & & 4 & 128 & .120 & 1.000 & -.237 & .492 \\
\hline & & 5 & -.035 & .134 & 1.000 & -.441 & .372 \\
\hline & 4 & 1 & -.356 & .222 & 1.000 & -1.029 & .317 \\
\hline & & 2 & -.266 & .283 & 1.000 & -1.123 & .590 \\
\hline & & 3 & -.128 & .120 & 1.000 & -.492 & .237 \\
\hline & & 5 & -.162 & 127 & 1.000 & -.547 & .222 \\
\hline & 5 & 1 & -.194 & .236 & 1.000 & -.908 & .521 \\
\hline & & 2 & -.104 & .293 & 1.000 & -.991 & .783 \\
\hline & & 3 & .035 & .134 & 1.000 & -.372 & .441 \\
\hline & & 4 & .162 & .127 & 1.000 & -.222 & .547 \\
\hline Suspense & 1 & 2 & -.008 & .328 & 1.000 & -1.002 & .985 \\
\hline & & 3 & .157 & .293 & 1.000 & -.732 & 1.046 \\
\hline & & 4 & .238 & .273 & 1.000 & -.588 & 1.064 \\
\hline & & 5 & .174 & .303 & 1.000 & -.744 & 1.092 \\
\hline & 2 & 1 & .008 & .328 & 1.000 & -.985 & 1.002 \\
\hline & & 3 & .166 & .347 & 1.000 & -.887 & 1.218 \\
\hline & & 4 & .246 & .356 & 1.000 & -.833 & 1.326 \\
\hline & & 5 & .182 & .362 & 1.000 & -.915 & 1.280 \\
\hline
\end{tabular}




\begin{tabular}{|c|c|c|c|c|c|c|c|}
\hline & \multirow[t]{4}{*}{3} & 1 & -.157 & .293 & 1.000 & -1.046 & .732 \\
\hline & & 2 & -.166 & .347 & 1.000 & -1.218 & .887 \\
\hline & & 4 & .081 & .083 & 1.000 & -.171 & .332 \\
\hline & & 5 & .017 & .088 & 1.000 & -.251 & .284 \\
\hline & \multirow[t]{4}{*}{4} & 1 & -.238 & .273 & 1.000 & -1.064 & .588 \\
\hline & & 2 & -.246 & .356 & 1.000 & -1.326 & .833 \\
\hline & & 3 & -.081 & .083 & 1.000 & -.332 & .171 \\
\hline & & 5 & -.064 & .096 & 1.000 & -.356 & .228 \\
\hline & \multirow[t]{4}{*}{5} & 1 & -.174 & .303 & 1.000 & -1.092 & .744 \\
\hline & & 2 & -.182 & .362 & 1.000 & -1.280 & .915 \\
\hline & & 3 & -.017 & .088 & 1.000 & -.284 & .251 \\
\hline & & 4 & .064 & .096 & 1.000 & -.228 & .356 \\
\hline \multirow[t]{14}{*}{ Fluency } & \multirow[t]{4}{*}{1} & 2 & -.228 & .250 & 1.000 & -.986 & .530 \\
\hline & & 3 & -.047 & .190 & 1.000 & -.624 & .530 \\
\hline & & 4 & .435 & .249 & .912 & -.320 & 1.190 \\
\hline & & 5 & -.389 & .206 & .686 & -1.013 & .235 \\
\hline & \multirow[t]{4}{*}{2} & 1 & .228 & .250 & 1.000 & -.530 & .986 \\
\hline & & 3 & 181 & .242 & 1.000 & -.553 & .915 \\
\hline & & 4 & .663 & .259 & .157 & -.121 & 1.447 \\
\hline & & 5 & -.161 & .229 & 1.000 & -.853 & .532 \\
\hline & \multirow[t]{4}{*}{3} & 1 & .047 & .190 & 1.000 & -.530 & .624 \\
\hline & & 2 & -.181 & .242 & 1.000 & -.915 & .553 \\
\hline & & 4 & .482 & .160 & .052 & -.003 & .967 \\
\hline & & 5 & -.342 & .136 & .173 & -.753 & .069 \\
\hline & \multirow[t]{2}{*}{4} & 1 & -.435 & .249 & .912 & -1.190 & .320 \\
\hline & & 2 & -.663 & .259 & .157 & -1.447 & .121 \\
\hline
\end{tabular}




\begin{tabular}{|c|c|c|c|c|c|c|c|}
\hline & & 3 & -.482 & .160 & .052 & -.967 & .003 \\
\hline & & 5 & $-.824^{*}$ & .199 & .003 & -1.426 & -.221 \\
\hline & 5 & 1 & .389 & .206 & .686 & -.235 & 1.013 \\
\hline & & 2 & .161 & .229 & 1.000 & -.532 & .853 \\
\hline & & 3 & .342 & .136 & .173 & -.069 & .753 \\
\hline & & 4 & $.824^{*}$ & .199 & .003 & .221 & 1.426 \\
\hline \multirow[t]{20}{*}{ Absorption } & 1 & 2 & -.369 & .213 & .938 & -1.016 & .277 \\
\hline & & 3 & -.419 & .174 & .227 & -.946 & .109 \\
\hline & & 4 & -.312 & .215 & 1.000 & -.963 & .339 \\
\hline & & 5 & -.448 & .156 & .075 & -.922 & .025 \\
\hline & 2 & 1 & .369 & .213 & .938 & -.277 & 1.016 \\
\hline & & 3 & -.049 & .187 & 1.000 & -.615 & .516 \\
\hline & & 4 & .057 & .203 & 1.000 & -.558 & .672 \\
\hline & & 5 & -.079 & .192 & 1.000 & -.659 & .501 \\
\hline & 3 & 1 & .419 & .174 & .227 & -.109 & .946 \\
\hline & & 2 & .049 & .187 & 1.000 & -.516 & .615 \\
\hline & & 4 & .106 & .118 & 1.000 & -.253 & .465 \\
\hline & & 5 & -.030 & .086 & 1.000 & -.289 & .230 \\
\hline & 4 & 1 & .312 & .215 & 1.000 & -.339 & .963 \\
\hline & & 2 & -.057 & .203 & 1.000 & -.672 & .558 \\
\hline & & 3 & -.106 & .118 & 1.000 & -.465 & .253 \\
\hline & & 5 & -.136 & .143 & 1.000 & -.570 & .299 \\
\hline & 5 & 1 & .448 & .156 & .075 & -.025 & .922 \\
\hline & & 2 & .079 & .192 & 1.000 & -.501 & .659 \\
\hline & & 3 & .030 & .086 & 1.000 & -.230 & .289 \\
\hline & & 4 & .136 & .143 & 1.000 & -.299 & .570 \\
\hline
\end{tabular}




\begin{tabular}{|c|c|c|c|c|c|c|c|}
\hline \multirow[t]{19}{*}{ Demand } & \multirow[t]{3}{*}{1} & 3 & $\begin{array}{l}.214 \\
.110\end{array}$ & $\begin{array}{l}.365 \\
.181\end{array}$ & $\begin{array}{l}1.000 \\
1.000\end{array}$ & $\begin{array}{l}-.891 \\
-.439\end{array}$ & $\begin{array}{r}1.319 \\
.659\end{array}$ \\
\hline & & 4 & .211 & .188 & 1.000 & -.358 & .781 \\
\hline & & 5 & .223 & .154 & 1.000 & -.245 & .690 \\
\hline & \multirow[t]{4}{*}{2} & 1 & -.214 & .365 & 1.000 & -1.319 & .891 \\
\hline & & 3 & -.104 & .311 & 1.000 & -1.046 & .838 \\
\hline & & 4 & -.003 & .319 & 1.000 & -.970 & .965 \\
\hline & & 5 & .009 & .331 & 1.000 & -.995 & 1.012 \\
\hline & \multirow[t]{4}{*}{3} & 1 & -.110 & .181 & 1.000 & -.659 & .439 \\
\hline & & 2 & .104 & .311 & 1.000 & -.838 & 1.046 \\
\hline & & 4 & .102 & .082 & 1.000 & -.145 & .349 \\
\hline & & 5 & .113 & .128 & 1.000 & -.275 & .500 \\
\hline & \multirow[t]{4}{*}{4} & 1 & -.211 & .188 & 1.000 & -.781 & .358 \\
\hline & & 2 & .003 & .319 & 1.000 & -.965 & .970 \\
\hline & & 3 & -.102 & .082 & 1.000 & -.349 & .145 \\
\hline & & 5 & .011 & .126 & 1.000 & -.370 & .392 \\
\hline & \multirow[t]{4}{*}{5} & 1 & -.223 & .154 & 1.000 & -.690 & .245 \\
\hline & & 2 & -.009 & .331 & 1.000 & -1.012 & .995 \\
\hline & & 3 & -.113 & .128 & 1.000 & -.500 & .275 \\
\hline & & 4 & -.011 & .126 & 1.000 & -.392 & .370 \\
\hline \multirow[t]{5}{*}{ SkillFit } & \multirow[t]{4}{*}{1} & 2 & -.088 & .212 & 1.000 & -.729 & .554 \\
\hline & & 3 & -.182 & .133 & 1.000 & -.586 & .222 \\
\hline & & 4 & $-.461^{*}$ & .140 & .026 & -.886 & -.036 \\
\hline & & 5 & -.007 & . 127 & 1.000 & -.392 & .377 \\
\hline & 2 & 1 & .088 & .212 & 1.000 & -.554 & .729 \\
\hline
\end{tabular}




\begin{tabular}{|c|c|c|c|c|c|c|}
\hline & 3 & -.094 & .198 & 1.000 & -.693 & .504 \\
\hline & 4 & -.374 & .188 & .559 & -.943 & .195 \\
\hline & 5 & .080 & .191 & 1.000 & -.497 & .658 \\
\hline 3 & 1 & .182 & .133 & 1.000 & -.222 & .586 \\
\hline & 2 & .094 & .198 & 1.000 & -.504 & .693 \\
\hline & 4 & $-.279^{*}$ & .072 & .005 & -.497 & -.062 \\
\hline & 5 & .174 & .105 & 1.000 & -.144 & .492 \\
\hline 4 & 1 & $.461^{*}$ & .140 & .026 & .036 & .886 \\
\hline & 2 & .374 & .188 & .559 & -.195 & .943 \\
\hline & 3 & $.279^{*}$ & .072 & .005 & .062 & .497 \\
\hline & 5 & $.454^{*}$ & .108 & .002 & .125 & .782 \\
\hline 5 & 1 & .007 & .127 & 1.000 & -.377 & .392 \\
\hline & 2 & -.080 & .191 & 1.000 & -.658 & .497 \\
\hline & 3 & -.174 & .105 & 1.000 & -.492 & .144 \\
\hline & 4 & $-.454^{*}$ & .108 & .002 & -.782 & -.125 \\
\hline
\end{tabular}

Based on estimated marginal means

*. The mean difference is significant at the .05 level.

b. Adjustment for multiple comparisons: Bonferroni. 